\title{
Articulated bone sets of manus and pedes of Camarasaurus (Sauropoda, Dinosauria)
}

\author{
Emanuel Tschopp, Oliver Wings, Thomas Frauenfelder, and Winand Brinkmann
}

\begin{abstract}
Skeletons of sauropods are rarely found with fore and hind feet, and until now, only one specimen of this clade has been reported with all four autopodia preserved complete and articulated. This makes interpretations on their locomotion difficult and proper assignments of footprints to genus- or even species-level taxa are generally impossible. Camarasaurus SMA 0002 from the Upper Jurassic Morrison Formation at Howe Ranch in the vicinity of Shell (Wyoming, USA) is the first sauropod with completely preserved and articulated osteological remains of all feet in addition to autopodial skin impressions. We describe in detail the morphology of the SMA 0002 autopodial bones and integumentary impressions, and draw comparisons with the published data on Camarasaurus and other sauropod manus and pedes. Our reconstruction orients the lateral side of the manus claw such that it faces the ground and possibly even contacts it distally. A 3D reconstruction of the autopodia of SMA 0002 yields new insights into the still debated relationship of footprint lengths to hip height in sauropods, and indicates that it might be variable among genera. Furthermore, manual and pedal morphology and the 3D model yield crucial information about the expected footprint shape of Camarasaurus. The recovered characteristics of the footprint do not possess a set of features to be confidently referred to a known ichnospecies.
\end{abstract}

Emanuel Tschopp, Dipartimento di Scienze della Terra, Università di Torino, Italy; GeoBioTec, Faculdade de Ciências e Tecnologia da Universidade Nova de Lisboa, Quinta da Torre, 2825-114 Caparica, Portugal Museu da Lourinhã, Rua João Luís de Moura, 2530-157 Lourinhã, Portugal: etschopp@unito.it Oliver Wings, Landesmuseum Hannover, Willy-Brandt-Allee 5, 30169 Hannover, Germany dr.wings@gmail.com

Thomas Frauenfelder, Institute of Diagnostic and Interventional Radiology, University Hospital Zurich, Rämistr. 100, 8091 Zürich, Switzerland thomas.frauenfelder@usz.ch Winand Brinkmann, Paläontologisches Institut und Museum der Universität Zürich, Karl-Schmid-Str. 4, CH-8006 Zürich, Switzerlandwinand.brinkmann@pim.uzh.ch

Keywords: Sauropoda; Camarasaurus; autopodia; footprint; skin impressions 


\section{INTRODUCTION}

The history of finds of the Late Jurassic sauropod dinosaur Camarasaurus is long, and several descriptions of partial or nearly complete skeletons were published since Cope (1877) erected this genus. Hundreds of bones of the four established species C. supremus Cope, 1877 (the type species), C. grandis (Marsh, 1877), C. lentus (Marsh, 1889), and C. lewisi (Jensen, 1988) were collected in the North American, Upper Jurassic Morrison Formation, covering a large part of its spatial and temporal range (see Ikejiri, 2005, figure 6). Other specimens found in Europe, Asia, and Africa have also been previously assigned to Camarasaurus, but these identifications are currently regarded as dubious or have been rejected or renamed (e.g., Dantas et al., 1998; Averianov et al., 2002). Accepted Camarasaurus findings are limited to North America and include at least five almost complete specimens (CM 11338, KUVP 129716, USNM 13786, GMNH-PV 101, SMA 0002). Besides two monographs by Gilmore (1925) and Mclntosh et al. (1996a) on CM 11338 and GMNHPV 101, respectively, three other important publications provided accurate descriptions of less complete Camarasaurus specimens (Osborn and Mook, 1921 on AMNH 5760 and AMNH 5761: holotype of C. supremus; Mclntosh et al., 1996b on BYU 9047: holotype of C. lewisi; Ikejiri, 2004 on WDC A and WDC B). Due to the amount of preserved bones, complete skeletons, and published descriptions, Camarasaurus is one of the best known sauropod genera worldwide (Harris, 2006; Foster, 2007). However, manual and pedal elements have rarely been found, and if so, they were mostly disarticulated (Wilson, 2005a, 2005b; González Riga et al., 2008). Studies on these bones are therefore scarce; even the previously mentioned monographs lack detailed descriptions of individual bones of the autopodia.

The same is the case in the majority of publications on other sauropod dinosaurs. Some of the exceptions are the works of Hatcher (1902) on Brontosaurus parvus UW 15556, Osborn (1904) on Camarasaurus sp. AMNH 965, and Janensch $(1922,1961)$ on several flagellicaudatan and brachiosaurid specimens. Additionally, Gilmore's (1936) monograph on Apatosaurus and BorsukBialynicka's (1977) paper on Opisthocoelicaudia include adequate descriptions of manus and pes elements. Recently, several publications yielded additional important information on manual and pedal shape in sauropods (Mclntosh et al., 1992, 1996a; Averianov et al., 2002; Bonnan, 2003,
2005; Martínez et al., 2004; Apesteguía, 2005; Bedell and Trexler, 2005; Bonaparte et al., 2006; Harris, 2007; Läng and Goussard, 2007; González Riga et al., 2008; Curry Rogers, 2009; Hocknull et al., 2009; D'Emic et al., 2011; Nair and Salisbury, 2012; Poropat et al., 2015a, 2015b).

Since the renaissance of dinosaur ichnology in the 1980s, more researchers began to pay attention to foot bones, in order to correlate them with their appropriate footprints (e.g., de Beaumont and Demathieu, 1980; Farlow, 1992; Carrano and Wilson, 2001; Wright, 2005). Other recent publications deal with the functional morphology of the feet (e.g., Gallup, 1989; Christiansen, 1997c; Bonnan, 2005; Fowler and Hall, 2011), or study the evolution of manual and pedal shape (e.g., Bonnan, 2003, 2005; Apesteguía, 2005; Bonnan and Yates, 2007; Läng and Goussard, 2007; González Riga et al., 2008; Nair and Salisbury, 2012). However, none of these studies was based on a complete set of articulated fore and hind feet of the same individual. The exact articulation of the single elements of one autopodium is only known in a few taxa, and the relationship between manus and pes of the same individual is still very poorly understood in sauropods.

The present study provides a description of the complete set of manual and pedal elements of the Camarasaurus sp. SMA 0002 from the Upper Jurassic Morrison Formation of north central Wyoming. Due to the fact that the fully articulated pes and manus of the same individual are present, this study helps in distinguishing manual from pedal elements and reveals insights in: 1) the proper reconstruction of sauropod fore and hind feet; 2) their evolution; and 3) the appropriate footprint shape of Camarasaurus. The manus and pedes of this specimen furthermore show morphological anomalies in various elements, which were described in detail and interpreted as various bone pathologies by Tschopp et al. (in press).

\section{Institutional Abbreviations}

AMNH, American Museum of Natural History, New York City, New York, USA; BP, Evolutionary Studies Institute (formerly Bernard Price Institute for Palaeontological Research), University of the Witwatersrand, Johannesburg, South Africa; BYU, Earth Science Museum, Brigham Young University, Provo, Utah, USA; CM, Carnegie Museum, Pittsburgh, Pennsylvania, USA; GMNH-PV, Gunma Museum of Natural History, Gunma, Japan; KUVP, University of Kansas Museum of Natural History, Lawrence, Kansas, USA; MB.R., Museum für 
Naturkunde, Berlin, Germany; MNHN, Muséum National d'Histoire Naturelle, Paris, France; PIMUZ, Paleontological Institute and Museum of the University of Zurich, Switzerland; SMA, Sauriermuseum Aathal, Aathal, Switzerland; UMNH, Natural History Museum of Utah (formerly Utah Museum of Natural History), Salt Lake City, Utah, USA; USNM, National Museum of Natural History (formerly United States National Museum), Washington DC, USA; USZ, University Hospital Zurich, Zurich, Switzerland; WDC, Wyoming Dinosaur Center, Thermopolis, Wyoming, USA; YPM, Yale Peabody Museum of Natural History, New Haven, Connecticut, USA; ZPAL, Institute of Paleobiology, Polish Academy of Sciences, Warsaw, Poland.

\section{Anatomical Abbreviations}

ast, astragalus; calc, calcaneum; f, fibula; $h$, humerus; lat carp, lateral carpal; med carp, medial carpal; mc, metacarpal; mt, metatarsal; phm, manual phalanx; php, pedal phalanx; r, radius; t, tibia; u, ulna

The metapodials are indicated by Roman numerals; the phalanges are indicated by a combination of Roman and Arabic numerals (e.g., III-2 = the second phalanx of the third digit of the manus or pes).

\section{GEOLOGICAL AND GEOGRAPHICAL CONTEXT}

\section{Locality}

The Camarasaurus SMA 0002 was found at the Howe-Stephens Quarry in 1992 (Waskow and Sander, 2014; Tschopp et al., in press). This site lies within Howe Ranch, as does the well-known Howe Quarry, where Barnum Brown organized and led the famous Sinclair Expedition of the AMNH in 1934 (Brown, 1935). The Ranch is located north of Shell, Wyoming, at the western slopes of the Bighorn Mountains (Figure 1). In 1990 Hans-Jakob Siber, director of the SMA, reopened the Howe Quarry with a team of volunteers, but there was not enough to find at this site to assemble a complete sauropod skeleton for display at the Sauriermuseum Aathal (H.-J. Siber, personal commun., 2015). Two years later, after prospecting other parts of the Ranch, he discovered a new locality, the Howe-Stephens Quarry, $450 \mathrm{~m}$ to the southwest of the traditional site (Ayer, 2000; Christiansen and Tschopp, 2010).

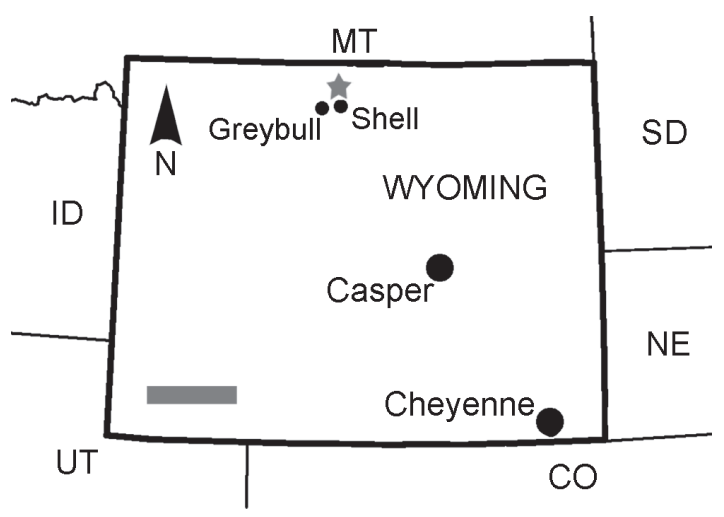

FIGURE 1. Location of the Howe Ranch quarries in the Bighorn Basin, North-Central Wyoming, USA (grey star). Abbreviations: CO, Colorado; ID, Idaho, MT, Montana, N, north; NE, Nebraska; SD, South Dakota; UT, Utah. Scale bar equals $100 \mathrm{~km}$. Modified from Christiansen and Tschopp (2010).

\section{Stratigraphy and Age}

Although many geological studies on the Morrison Formation have been undertaken (e.g., Darton, 1906; Mook, 1918; Moberly, 1960; Mirsky, 1962; Carpenter et al., 1998; Ayer, 2000; Michelis, 2004; Turner et al., 2004), long distance correlation between the various sites of the Morrison Formation is still unclear (Trujillo, 2006). Some studies on Morrison Formation stratigraphy included the Howe-Stephens Quarry (e.g., Turner and Peterson, 1999; Ikejiri, 2005), but the relative position reported there was based on a change in clay mineralogy, which was interpreted to be continuous throughout the entire formation. This interpretation was shown to be doubtful because several clay changes appear to occur in certain sites (Trujillo, 2006). The stratigraphic position of the Howe-Stephens Quarry can thus only be established with certainty in relation to the other quarries located on the Howe Ranch. The Howe-Stephens Quarry lies approximately $35 \mathrm{~m}$ above the marine Middle to Upper Jurassic Sundance Formation, and $30 \mathrm{~m}$ below the terrestrial Lower Cretaceous Cloverly Formation (Schwarz et al., 2007a; Christiansen and Tschopp, 2010). It is stratigraphically slightly higher than the Howe Quarry, but like all the excavation sites on Howe Ranch, it is located beneath the so-called clay change (see Schwarz et al., 2007 a, figure 3 ), which was used for long-distance correlation by Turner and Peterson (1999) and lkejiri $(2004,2005)$. The site was dated to $147 \mathrm{Ma}$ by Kvale et al. (2001, figure 5), based on its position somewhat above a bentonite layer dated to 151.5 +/- 4.0 Ma (Kvale et al., 2001, table 1). 


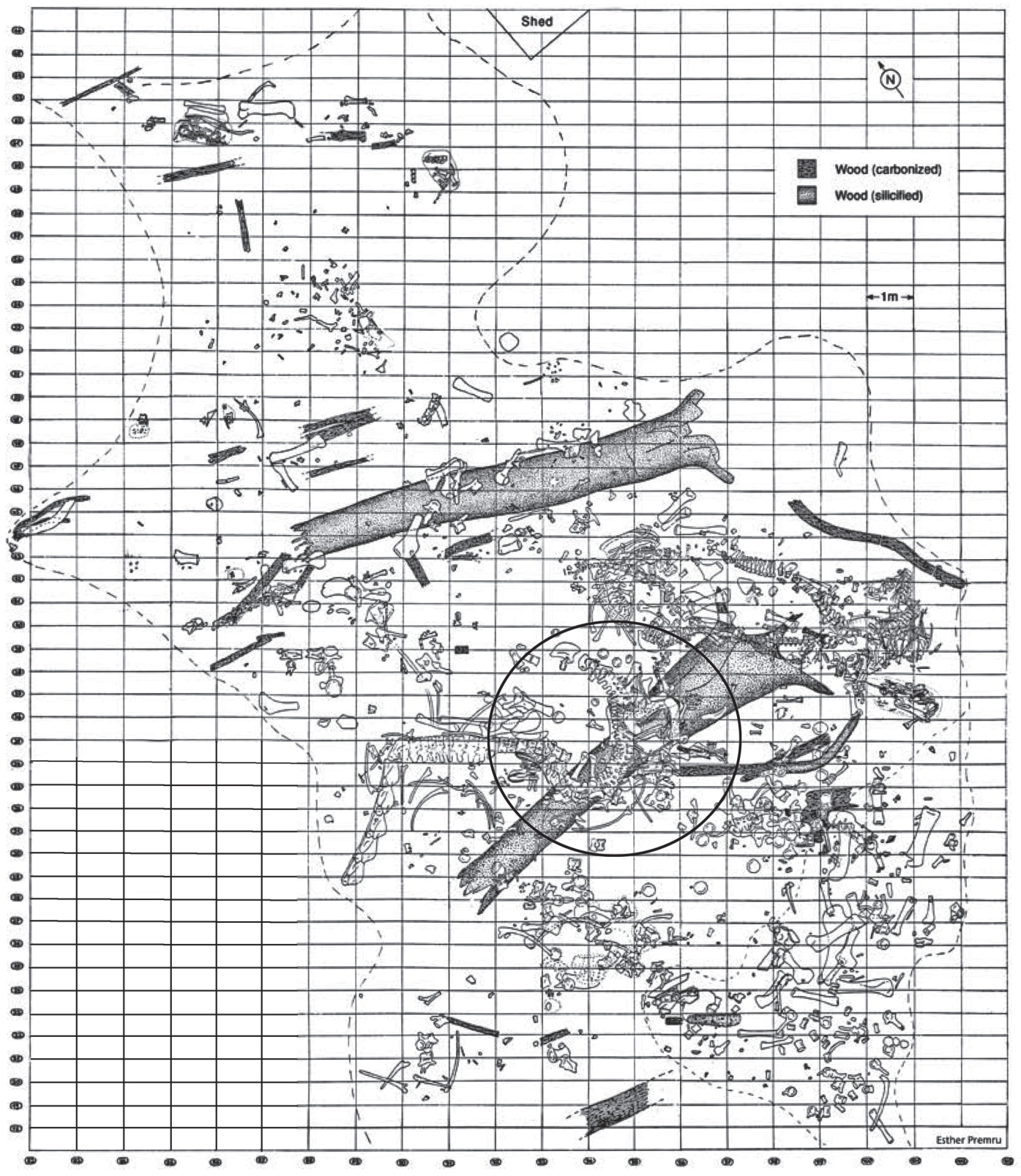

FIGURE 2. General quarry map of the Howe-Stephens Quarry north of Shell, Wyoming. Circle indicates Camarasaurus SMA 0002. Prepared by E. Premru, (c) by SMA.

\section{Paleogeography}

The depositional environment of the Morrison Formation has been described as a vast alluvial plain (e.g., Dodson et al., 1980; Foster, 2003; Turner and Peterson, in Turner et al., 2004). Most of the Morrison Formation quarries exhibit lacustrine, fluviatile, or swamp sediments. The sites at Howe Ranch also comply with this trend, being of fluviatile origin (Ayer, 2000; Michelis, 2004; Schwarz et al., 2007a).
According to the annual quarry maps, the riverbed visible in the Howe-Stephens Quarry was estimated to be 15 to $20 \mathrm{~m}$ wide (Figure 2). The site likely represents an oxbow lake, with a flow direction from the southeast to the northwest (Ayer, 2000). Most of the dinosaur skeletons are rather complete and articulated, and concentrated in an area of $10 \times 12 \mathrm{~m}$ and in a layer of $1 \mathrm{~m}$ in thickness. Ayer (2000) therefore proposed a single flood event washed most of the carcasses into this oxbow lake, where they became embedded around a very large, stuck tree log (Figure 2). 


\section{Fossil Content}

According to Ayer (2000), the sediments of the Howe-Stephens Quarry consist of a finegrained, white sandstone, which is very rich in fossilized plants. Besides Camarasaurus sp. SMA 0002 , remains of at least 13 other dinosaur skeletons were recovered until 2001. These include a Hesperosaurus mjosi (Christiansen and Tschopp, 2010), a juvenile neosauropod (Schwarz et al., 2007a; Carballido et al., 2012a), a second Camarasaurus sp., seven diplodocids, one Allosaurus sp., and two Othnielosaurus sp. (Ayer, 2000). Between the dinosaur remains, two large petrified logs, many smaller pieces of silicified and carbonized wood, and other abundant plant remains (including araucarian cones) were found.

\section{MATERIAL}

Specimen SMA 0002 is one of the most complete Camarasaurus skeletons ever found. It lacks only the vomers, the splenial bones, the distal end of the tail, and one terminal phalanx of the right pes. The bones are preserved in three dimensions and in almost perfect articulation. As commonly observed among amniote skeletons, SMA 0002 is preserved in an opisthotonic body position (head bent backwards, tail bowed forward; see Faux and Padian, 2007; Reisdorf and Wuttke, 2012). Furthermore, small patches with skin impressions are preserved in the region of the lower jaw, the abdominal region, the right hind leg, and the right manus (Figure 3 ).

The assignment of SMA 0002 to Camarasaurus is based on several diagnostic features mentioned by Upchurch et al. (2004a), Ikejiri (2004), and Mclntosh (2005), including: the short and robust skull, the large anteriorly positioned nares, the quadratojugal that contacts the squamosal, the broad spatulate teeth, the U-shaped clefts in the spines of the posterior cervical and the anterior dorsal vertebrae, the chevrons that are not expanded at their distal ends, long cervical ribs, the expanded ends of the scapula, the distally unexpanded ischium, the moderate fore to hind limb length ratio, and the long and slender metacarpals. Even solely based on the preserved foot bones, SMA 0002 can be assigned to Camarasaurus. Manus and pedes are clearly eusauropod due to the following shared synapomorphies mentioned in Wilson (2002): the block-like carpal elements; the reduced manual phalangeal formula, with the single bones being broader than long; the spreading metatarsus; $\mathrm{mt} \mathrm{I}$ that is stouter than any other metatarsal; mt III that is shorter than one fourth tibial length; the pedal phalanges being shorter than wide; the rudimentary penultimate pedal elements in digit II-IV; as well as the enlarged first, sickleshaped second and third, and vestigial to absent fourth ungual. The presence of two carpal bones in SMA 0002 results in an inclusion in Neosauropoda, where it is nested within Macronaria due to the high ratio of longest metacarpal length/radius length. Within Macronaria, SMA 0002 can be excluded from Titanosauriformes based on the distal articular surface of $\mathrm{mc} \mathrm{II}$, which is divided into two condyles that stand in an oblique angle relative to the long axis of the element, instead of being flat and perpendicular to the shaft axis (Wilson, 2002). Since Camarasaurus is the only widely accepted non-titanosauriform macronarian genus in the Late Jurassic of North America (according to the latest phylogenetic analyses; Rauhut et al., 2005; Harris, 2006; Whitlock, 2011; D'Emic, 2012; Mannion et al., 2013), the assignment of the specimen to this taxon based on its autopodia is plausible.

Due to its completeness, SMA 0002 has been used in several studies: Ikejiri (2005) included SMA 0002 in his paper on the distribution and biochronology of Camarasaurus; Witzel (2007) used the skull dimensions for a reconstruction with finite-element structure synthesis and demonstrated that function and structure are directly related to each other; Klein and Sander (2008) and Waskow and Sander (2014) studied the histology of several long bones and dorsal ribs of SMA 0002, and established a very mature individual age of the specimen. Thus, even though SMA 0002 has a relatively small body size (the estimated length is approximately $10 \mathrm{~m}$ ), both long bone and dorsal rib histology indicate a senescent age (Klein and Sander, 2008; Waskow and Sander, 2014), which is independently supported by the accumulation of various pathologies in the autopodia (Tschopp et al., in press). On the basis of small body size, Klein and Sander (2008) and Waskow and Sander (2014) argued that there might be a previously unrecognized small species in Camarasaurus.

The present study concentrates on the autopodia of SMA 0002. All of them were found in nearly perfect articulation with their adjoining epipodia, and apart from some slight scattering within the right pes, all the elements are still arranged as they were in vivo. The only undoubtedly missing bone is the right php IV-2, and the mounted right php IV-2 is therefore a cast.

During excavation, each autopodium was removed as a separate block, retaining their origi- 


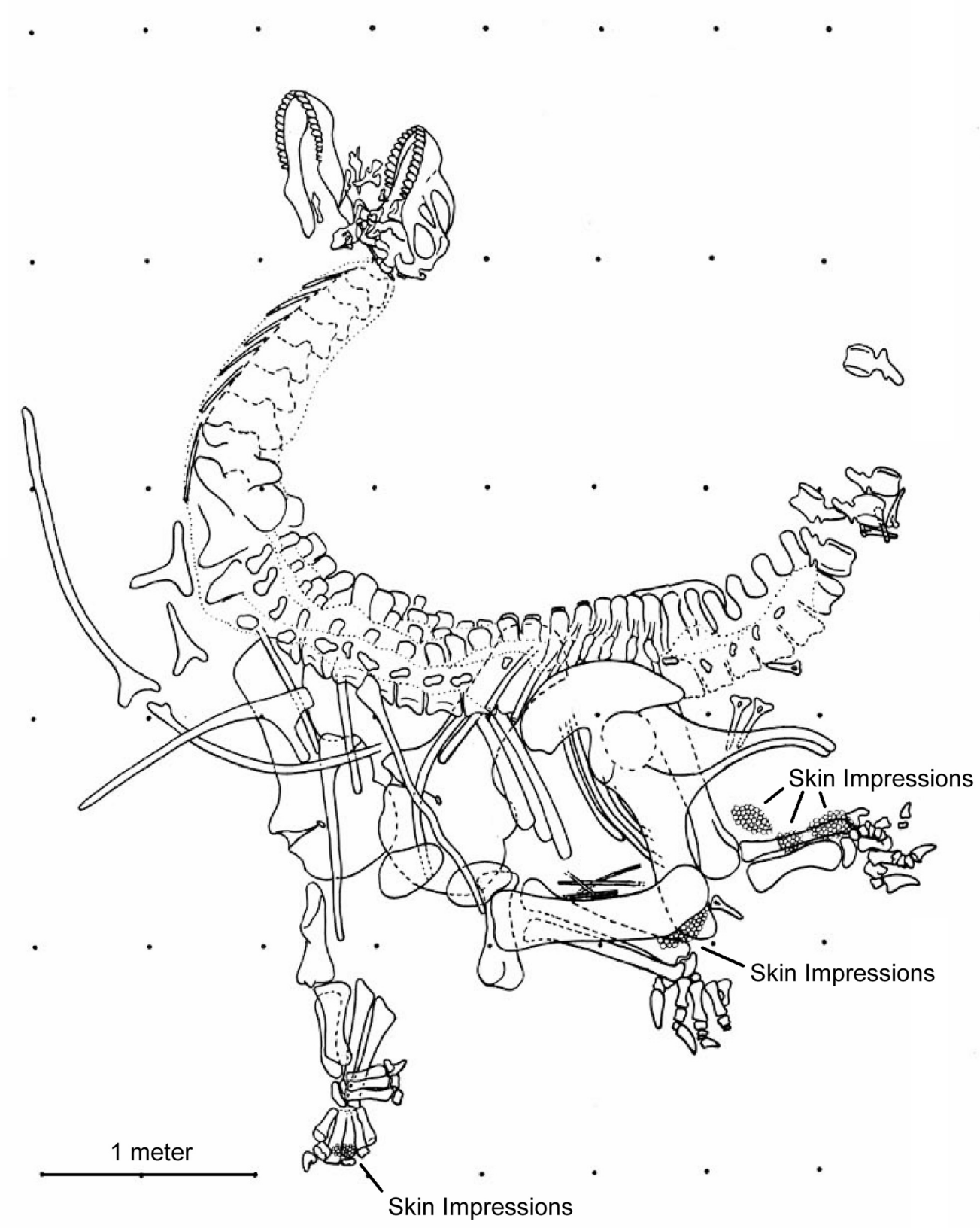

FIGURE 3. Detailed quarry map of the specimen SMA 0002 excavated in 1992-93 at the Howe-Stephens Quarry. Note the preservation of skin impressions in various regions of the skeleton. Modified from Ayer (2000).

nal arrangement in most parts. According to the quarry maps, only two manual phalanges and the second and the third claw of the left pes had previously been separated in the field (Figure 4). Given the additional information the autopodia potentially yield when in articulation, the two manus and the left pes have been partially left in the original matrix during preparation, in a way that for each set of manus and pedes in the mounted skeleton, one is displayed in posterior and the other in anterior view
(Figure 5). The major part of the right pes was fully prepared, and the recovered elements were photographed from all sides by E. Premru (Mönchaltorf, Switzerland). The articulated tarsals and first three metatarsals were not separated. Following preparation and photography of its constituent bones, the right pes was mounted in artificial matrix.

All the elements of the left autopodia are easily recognizable on their respective quarry maps and on pictures of the excavation. However, the 

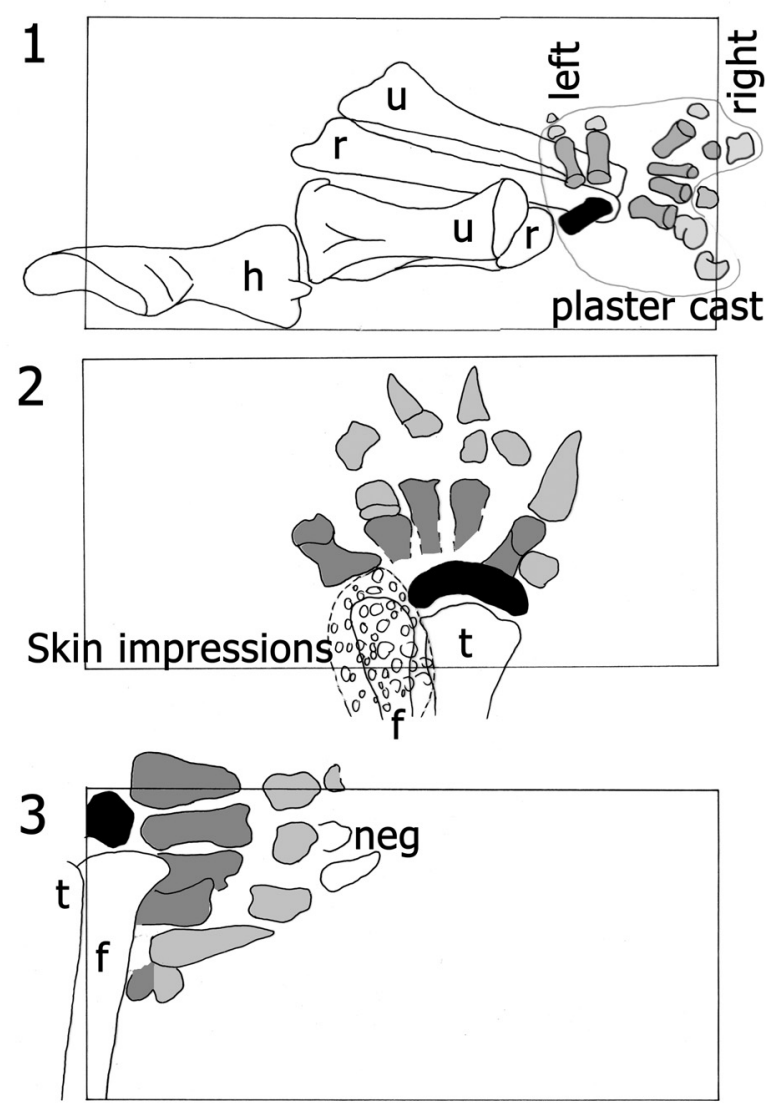

FIGURE 4. The original quarry maps of both manus (1), the right pes (2), and the left pes (3). Note the plaster cast in (1) that does not include all phalanges, the skin impressions in (2), and the bones labeled 'neg' (= negative) in (3). The latter were already separated during the excavation. Black elements are carpal or tarsal bones, dark gray marks metapodials, and light gray phalanges. Rectangles relate to grids on the detailed quarry map of SMA 0002 (see Figure 3). Abbreviations: f, fibula; h, humerus; r, radius; t, tibia; u, ulna.

position of four phalanges in the mounted right manus and pes is problematic: the right phm II-1 (as mounted) has a field number, which is identical with the one of a rib found several meters apart from the manus of SMA 0002. Additionally, by comparison with the same phalanx in the left manus, the mounted right phm II-1 is too small (Table 1). Therefore, we suggest it was erroneously assigned to SMA 0002, and probably belongs to a different specimen. On the quarry map and on photographs, another phm II-1 is visible in articulation with the right $\mathrm{mc}$ II. Moreover, there is a plaster cast indicated on the map, which does not include this phalanx (Figure 4.1). Where this element is at present, is unknown.
Vestigial terminal phalanges are mounted in the second and third digit of the right manus, as well as on digit II of the left manus (Figure 5.1-2). The left phm II-2 was found articulated with the left phm II-1. It is the first unambiguous evidence for the presence of a second phalanx in this digit in Camarasaurus (see below). In contrast, the two mounted, terminal phalanges of the right manus were recovered from the spoil pile at a time when only the two forelegs had been excavated. Therefore, and due to their similarity with the left phm II2 , these elements were identified by the preparators as phm II-2 and phm III-2 of the right manus. However, the bone mounted as right phm II-2 exhibits a morphology different from the mounted right phm III-2 and the unambiguous left phm II-2: it is bowed and all its surfaces show a distinct striated pattern like the diaphysis of a long bone, and its margins are thin and look as if they were broken. The phm II-2 (as mounted) was thus probably misidentified and represents a part of another bone. In contrast, the mounted right phm III-2 looks similar to the left phm II-2 and will therefore be interpreted herein as the actual right phm II-2. In addition, comparing the phalanges of the right pes with the ones of the left pes and with pictures in Ostrom and Mclntosh (1966) and Mclntosh et al. (1996a), we conclude that the right php III-1 and php IV-1 of SMA 0002 were swapped during their mounting. This assumption is supported by a comparison of the identification numbers of the bones with the arrangement on the quarry map and on pictures taken before preparing the right pes.

\section{METHODS}

\section{Terminology}

The directional terms used are based on the articulated state of the manus and the pes, following the proposed terminology of Upchurch (1994) and Bonnan (2001). Proximal and distal (upper and lower) correspond to the parts of each element that are closer or farther to the vertebral column, respectively. Anterior and posterior (front and hind) are used for the sometimes called dorsal and palmar (manus) or plantar surfaces (pes). Medial and lateral describe the sides facing the corresponding elements of the preceding or subsequent digit, respectively.

\section{Drawings}

Specimen SMA 0002 is at present only partially accessible, being on public display within the SMA. Hence, the drawings of the autopodia are 


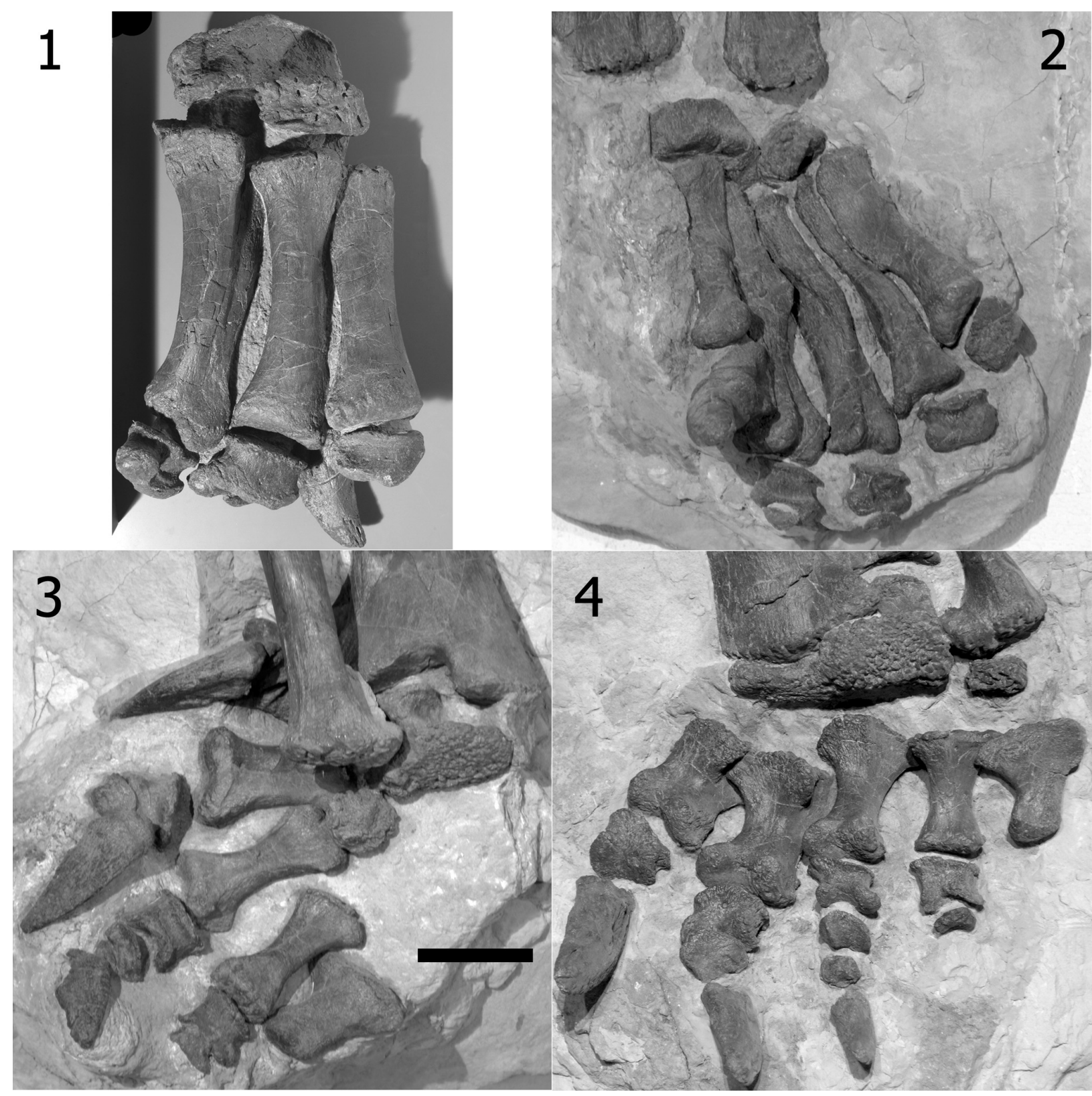

FIGURE 5. The autopodia of SMA 0002 as mounted. The left manus (1) and pes (3) are visible in anterior view, the right manus (2) and pes (4) in posterior view. The mounted unguals of the right manus and pes are casts, as well as the right php IV-2. The original unguals are stored separately at the SMA. Scale bar equals $10 \mathrm{~cm}$.

mainly based on photographs of the elements in their mounted positions. The right pes is an exception in having been prepared almost completely and photographed in all available views. For this study, the left manus was taken out of the mount as a whole unit, and photos of its bones were taken in all possible views.

The drawings were made with pigment liners of different widths. Thicker liners were used for morphological characters, whereas the finest pen was used for the shading. Figures were traced from photographs onto transparent paper. In the following, the drawings were scanned, reworked, and enhanced digitally to increase clarity. Finally, in the figures of bones that are still embedded in matrix or in articulation with other elements, different shades of gray were used for matrix and adjacent bones.

\section{Measurements}

Except for some bones of the right pes, the measurements were taken with a caliper from the 
TABLE 1. Measurements of the manual and pedal bones of SMA $0002 \mathrm{in} \mathrm{mm}$. Asterisks indicate measurements taken from photos. Humerus, femur, and left tibia length obtained from Klein and Sander (2008). Abbreviations: hg, dorsoventral height; gh, greatest proximodistal height; gl, greatest anteroposterior length; gpd, greatest proximodistal distance, measured straight; gw, greatest transverse width; inc, incomplete; min, minimum; prox, proximal; wd, transverse width.

\begin{tabular}{|c|c|c|c|c|c|c|c|c|c|c|c|c|c|c|c|c|c|c|c|c|}
\hline \multirow[b]{2}{*}{ Element } & \multicolumn{2}{|c|}{ gl } & \multicolumn{2}{|c|}{ gw } & \multicolumn{2}{|c|}{ gh } & \multicolumn{2}{|c|}{ prox wd } & \multicolumn{2}{|c|}{ prox hg } & \multicolumn{2}{|c|}{ dist wd } & \multicolumn{2}{|c|}{ dist hg } & \multicolumn{2}{|c|}{$\min w d$} & \multicolumn{2}{|c|}{ min hg } & \multicolumn{2}{|c|}{ gpd } \\
\hline & right & left & right & left & right & left & right & left & right & left & right & left & right & left & right & left & right & left & right & left \\
\hline humerus & 705 & & & & & & & & & & & & & & & & & & & \\
\hline radius & 464 & 434 & & & & & & & & & & & & & & & & & & \\
\hline femur & & 935 & & & & & & & & & & & & & & & & & & \\
\hline tibia & 604 & 615 & & & & & & & & & 221 & & & & & & & & & \\
\hline medial carpal & 47 & 63 & 125 & 144 & & 52 & & & & & & & & & & & & & & \\
\hline lateral carpal & 38 & 42 & 68 & 86 & & 49 & & & & & & & & & & & & & & \\
\hline astragalus & 103 & 95 & 201 & 158 & & & & & & & & & & & & & & & & \\
\hline calcaneum & 34 & 31 & 59 & 57 & & 64 & & & & & & & & & & & & & & \\
\hline $\mathrm{mcl}$ & 204 & 196 & & & & & 48 & 104 & & 32 & 62 & 80 & 57 & 39 & & 48 & & & & \\
\hline mc II & 266 & 236 & & & & & & 43 & & & 72 & 71 & 45 & 39 & & 35 & & 31 & & \\
\hline mc III & 255 & 228 & & & & & & 57 & & & 72 & 45 & 39 & 64 & & 35 & & & & \\
\hline $\mathrm{mc}$ IV & 236 & 225 & & & & & & 65 & & & 70 & 72 & 38 & 41 & & 37 & & & & \\
\hline $\mathrm{mc} \mathrm{V}$ & 208 & 193 & & & & & 67 & & 25 & 28 & 66 & 72 & 47 & 45 & 39 & 41 & & 29 & & \\
\hline $\mathrm{mt} \mathrm{I}$ & 113 & & & & & & 86 & & & & 79 & 85 & & & 48 & & & & & \\
\hline $\mathrm{mt}$ II & 134 & 140 & & & & & 84 & 72 & & & ${ }^{\star} 75$ & 85 & *38 & & 51 & 56 & & & & \\
\hline mt III & 133 & 145 & & & & & 63 & 67 & & & 74 & 75 & & & 35 & 36 & & & & \\
\hline $\mathrm{mt}$ IV & *112 & 140 & & & & & ${ }^{*} 92$ & 76 & ${ }^{*} 50$ & & ${ }^{*} 69$ & 63 & ${ }^{*} 47$ & & *38 & 34 & *24 & & & \\
\hline $\mathrm{mt} V$ & *108 & 107 & & & & & *103 & 110 & *37 & & ${ }^{*} 52$ & 50 & *34 & & ${ }^{*} 47$ & 47 & *29 & & & \\
\hline
\end{tabular}

mounted elements (Table 1). Some measurements of the elements of the right pes were taken from printed photographs (indicated with asterices in Table 1). Certain measurements were unobtainable from bones that are still partially embedded in matrix. Where possible, the following dimensions of each bone were measured: 1) greatest proximodistal length ( $\mathrm{gl}$; shortest vertical distance between horizontal lines through the proximal- and the distal-most points); 2) greatest transverse width (gw; shortest horizontal distance between vertical lines through the medial- and the lateral-most points); 3) greatest anteroposterior height (gh; shortest horizontal distance between vertical lines through the anterior- and the posterior-most points); 4) proximal width (prox wd; shortest transversal distance between vertical lines through the lateral- and the medial-most point of the proximal articular surface); 5) proximal height (prox hg; shortest distance between vertical lines through the anterior- and the posterior-most point of the proximal articular surface, perpendicular to the proximal width); 6) distal width (dist wd; shortest transversal distance between vertical lines through the lateral- and the medial-most point of the distal articular surface); 7) distal height (dist hg; shortest distance between vertical lines through the anterior- and the posterior-most point of the distal articular surface, perpendicular to the distal width); 8) minimum width (min wd; lateromedially, perpendicular to the longitudinal axis of the shaft); and 9) minimum height (min hg; anteroposteriorly, perpendicular to the longitudinal axis of the shaft). The length of the unguals was measured differently: in addition to the greatest length (defined above), the greatest proximodistal dimension (gpd) was recorded. This is the shortest distance between the proximal- and the distal-most point of the claw. 
TABLE 1 continued.

\begin{tabular}{|c|c|c|c|c|c|c|c|c|c|c|c|c|c|c|c|c|c|c|c|c|}
\hline \multirow[b]{2}{*}{ Element } & \multicolumn{2}{|c|}{ gl } & \multicolumn{2}{|c|}{ gw } & \multicolumn{2}{|c|}{ gh } & \multicolumn{2}{|c|}{ prox wd } & \multicolumn{2}{|c|}{ prox hg } & \multicolumn{2}{|c|}{ dist wd } & \multicolumn{2}{|c|}{ dist hg } & \multicolumn{2}{|c|}{$\min w d$} & \multicolumn{2}{|c|}{$\min \mathrm{hg}$} & \multicolumn{2}{|c|}{ gpd } \\
\hline & right & left & right & left & right & left & right & left & right & left & right & left & right & left & right & left & right & left & right & left \\
\hline phm I-1 & 59 & 55 & & & & & 65 & & 46 & 49 & 53 & & 48 & 55 & 53 & & 41 & & & \\
\hline phm l-2 & 117 & 125 & & & & & 49 & 30 & 56 & 65 & 0 & & 0 & & 0 & & 0 & & 121 & 136 \\
\hline phm II-1 & 51 & 51 & & & & & 57 & 78 & & & 69 & 83 & 40 & 31 & 54 & 56 & 27 & & & \\
\hline phm II-2 & 11 & 13 & & & & & 33 & 31 & 26 & 16 & & & & & & & & & & \\
\hline phm III-1 & 44 & 40 & & & & & 61 & 63 & & 37 & 70 & 71 & 23 & 32 & 56 & 58 & & 27 & & \\
\hline phm IV-1 & 43 & 45 & & & & & 64 & 70 & & & 66 & 75 & 31 & 24 & 57 & 61 & & 18 & & \\
\hline phm V-1 & 47 & 39 & & & & & 59 & 63 & 27 & 39 & 49 & 48 & 24 & 25 & 46 & 48 & & 22 & & \\
\hline php I-1 & *40 & 45 & & & & & ${ }^{*} 69$ & 62 & *59 & & *73 & 50 & *54 & 45 & *45 & & *37 & & & \\
\hline php I-2 & 140 & 144 & & & & & 42 & 54 & 93 & & 12 & & 24 & & & & & & 168 & \\
\hline php II-1 & ${ }^{*} 50$ & 56 & & & & & ${ }^{*} 71$ & 72 & *46 & 46 & 69 & 60 & *49 & 35 & 58 & 57 & *34 & 27 & & \\
\hline php II-2 & ${ }^{*} 22$ & 29 & & & & & *59 & 55 & $* 49$ & & *51 & 44 & ${ }^{*} 42$ & & 52 & & *37 & & & \\
\hline php II-3 & 130 & 120 & & & & & 26 & 24 & 64 & 63 & 14 & & 27 & & & & & & 133 & \\
\hline php III-1 & ${ }^{*} 52$ & 54 & & & & & ${ }^{*} 63$ & 65 & *37 & 38 & ${ }^{*} 53$ & 63 & *35 & & *45 & 55 & ${ }^{*} 20$ & & & \\
\hline php III-2 & *31 & 31 & & & & & ${ }^{*} 49$ & 55 & ${ }^{*} 51$ & & & 47 & *39 & & & & & & & \\
\hline php III-3 & ${ }^{*} 13$ & 17 & & & & & *38 & 36 & *33 & & & & & & & & & & & \\
\hline php III-4 & 99 & 100 & & & & & & & & $31 \mathrm{inc}$ & & & & & & & & & 100 & \\
\hline php IV-1 & *35 & 48 & & & & & ${ }^{*} 66$ & 58 & *44 & & ${ }^{*} 60$ & 61 & *31 & & *41 & 46 & ${ }^{*} 23$ & & & \\
\hline php IV-2 & & 17 inc & & & & & & & & & & & & & & & & & & \\
\hline
\end{tabular}

\section{Supplementary Analyses}

In addition to the description, supplementary analyses were undertaken. X-ray tomographies of the left manus were performed at the Institute of Diagnostic Radiography of the USZ. The manus was scanned using a medical CT scanner (Somatom Definition 64, Siemens, Germany), with a slice thickness of $1.5 \mathrm{~mm}$. Image stacks were stored in DICOM-III format and processed in 3mensio to separate the bones from the matrix. Whereas this yielded some general information on obscured views, resolution was not high enough to unambiguously recognize the distinction between most bones and surrounding matrix. Therefore, a virtual 3D model based on the CT-scans was only produced for the complete, embedded manus (Appendix 1). This complete, virtual model was produced with the freely available software 3D Slicer (www.slicer.org; version 4.4.0), following a how-toguide by Falkingham (2015). Threshold range in the Editor menu was set to 951 , and the 3D model was created with the default settings (Smooth 10, Decimate 0.25). The obtained STL file was then imported in the freely available software MeshLab (www.meshlab.org; 64bit, version 1.3.3), in order to delete small inaccuracies. Virtual, textured 3D models of the articulated and mounted right manus (Appendix 2) and the left pes (Appendix 3) were produced with photogrammetry. Photographs were taken with a Nikon D40 and a Nikon Coolpix L1. No tripod could be used because the specimen is currently on public display and mounted on a wall, approximately $3 \mathrm{~m}$ above ground. The photographs had to be taken with a flash and were subsequently processed in Agisoft PhotoScan (Professional 1.1.3 build 1847, 64 bit), following the procedures described by Mallison and Wings (2014).

Real 3D models of the manus and the pes with reconstructed soft tissues (Figure 6) were created in cooperation with scientific illustrator Beat Scheffold (Winterthur, Switzerland). At first, the skeletal elements (Figure 6.1) were sculpted out of styrofoam to reconstruct their physiological 


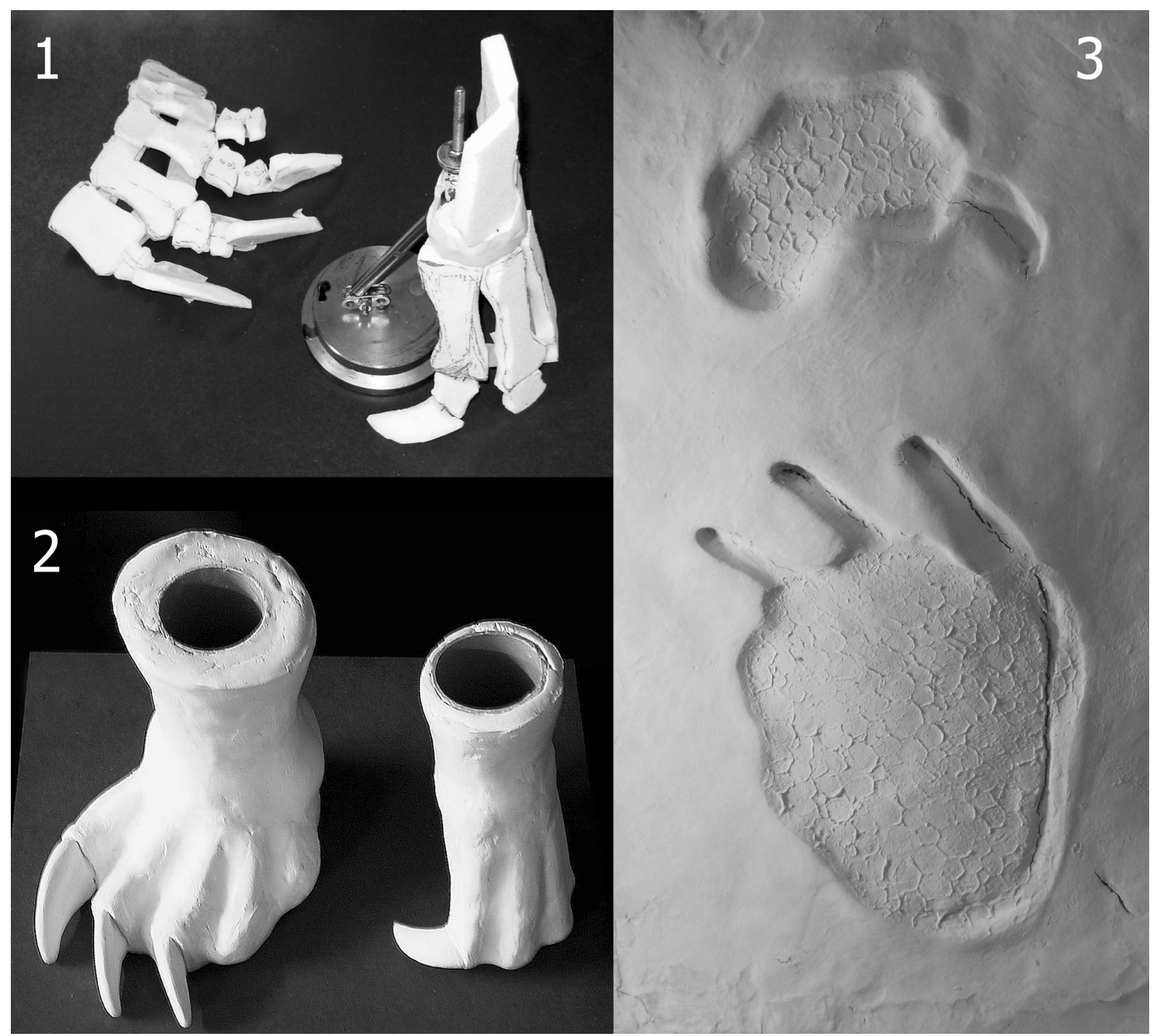

FIGURE 6. Process of preparing a real 3D model of the left manus and pes of Camarasaurus: skeletal model (1) as a pre-stage, (2) shows the finished model, (3) shows the imprints produced by the model.

arrangement and articulation in the autopodia, based on photos and drawings of SMA 0002 and other well-preserved manual and pedal remains of Camarasaurus individuals (BYU 9047, CM 11338, USNM 13786, WDC no catalog number). After that, the soft tissues were reconstructed with different modeling clays. Finally, imprints of the 3D models of the autopodia (Figure 6.3) were produced on a soft flat surface in order to provide a better understanding of the actual footprint shape of Camarasaurus. These artificial footprints were then compared to published data and figures of real fossil sauropod tracks. Heteropody rates were calculated using the measurement tool in Adobe Photoshop Extended ${ }^{\circledR}$.

\section{DESCRIPTION}

\section{Manus}

The left manus is still articulated, but mediolaterally compressed in a way that its posterior side is mostly hidden (Figure 5.1; Appendix 1). The right manus is mounted the way it was found (Figure 7; Appendix 2), except for phm II-1, phm II-2, and phm III-2 (see above). The anterior parts of the bones of this autopodium are still embedded in matrix. Therefore, mainly palmar views are available from the bones of the right manus.

Carpus (Figures 8-9). The carpus consists of two block-like bones: A large, medial carpal between the radius and at least the first two metacarpals, and a small, lateral element of approximately half 


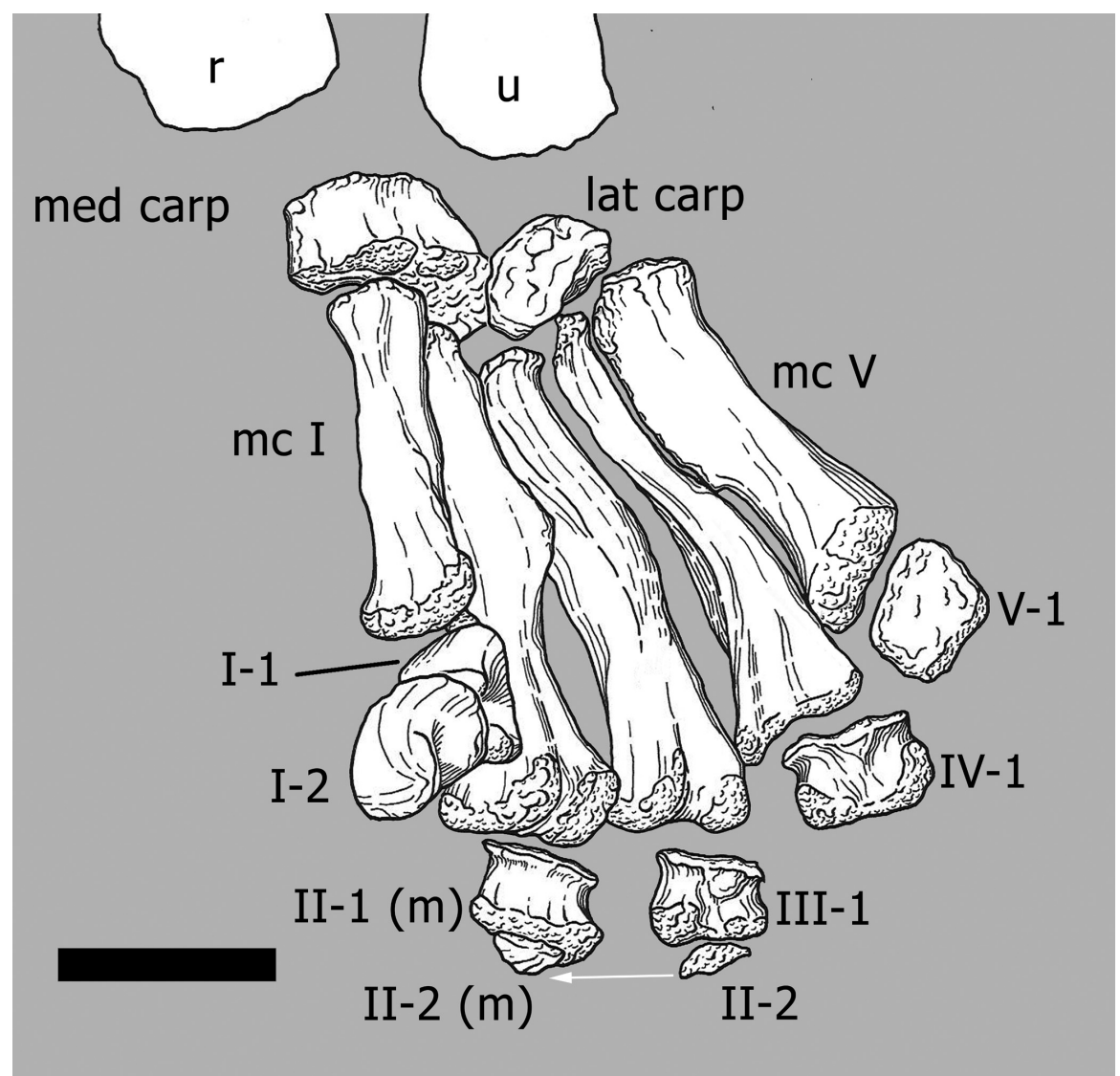

FIGURE 7. General drawing of the right manus in posterior view. Phm II-1 and II-2 are probably misidentified (indicated with an $(\mathrm{m})$, phm III-2 might actually be phm II-2 (arrow, see text for more detailed discussion). Scale bar equals $10 \mathrm{~cm}$.

the size of the first. In both manus, the lateral carpal is partially underlying the medial one and covers the tops of the metacarpals IV and V.

The proximal articular surface of the left medial carpal (Figure 8) is compressed anteroposteriorly, but appears to have had a subrectangular outline in proximal view originally. Its medial side is slightly shorter than the lateral one, but it remains unclear if that is the result of deformation. The posterior margin of the upper articular surface is more distinct than the anterior one and thus projects further proximally. The proximal-most point of the whole bone is located at midlength of the proximoposterior edge. Whereas the transition of the proximal into the anterior surface is continuous in their medial-most portions, a distinct anterior margin develops further laterally. The articular surface itself bears a weakly striated rugosity, which is directed toward a deep concavity in its center. Its lateral part is gently convex. The anterior surface of the medial carpal is quite thin at midlength and subequally expanded proximodistally at its medial and at its lateral end. The only distinct portions of the outline are at the center of the face, where the proximal and the distal borders are almost parallel to each other. In this region, the front side is slightly rugose and exhibits a deep pit just lateral to its center. Its medial and distal borders form a nearly right angle. The transition between the medial parts of the anterior and the proximal surface is unclear due to the vanishing border. The latter gets distinct in lateral direction after roughly one fourth of the mediolateral length of the bone and then extends straight toward its end. The lower border of the anterior face is gently concave mediolaterally. The transition between the distal and the lateral rim is smoothly rounded. The posterior surface has a pentagonal outline, with its horizontal distal margin representing the base of the pentagon. The medial and lateral borders stand almost perpendicular to the distal one. The proximal rim is overall convex, with its highest point at midlength, forming the apex of the pentagon. The medial half of the proximal margin is very distinct, whereas the lateral portion, as well as the other borders of the posterior surface, is not as accentuated. The distal margin of 


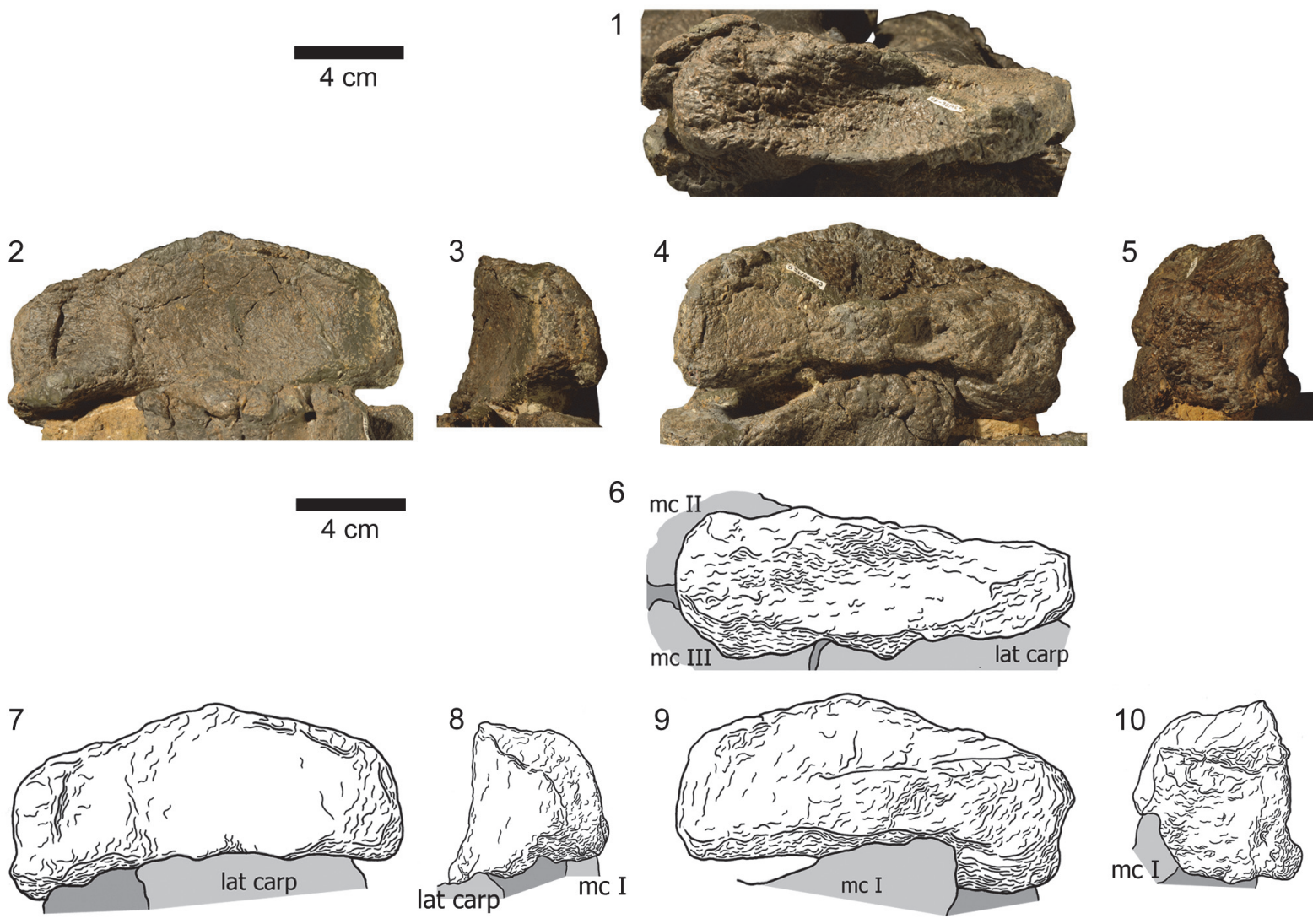

FIGURE 8. Photographs and drawings of the left medial carpal in proximal $(1,6)$, anterior $(2,7)$, medial $(3,8)$, posterior $(4,9)$, and lateral views $(5,10)$. Light gray represents adjoining bones, dark gray original matrix. Abbreviations: carp, carpal; lat, lateral; mc, metacarpal. Photographs taken by Rosemarie Roth.

the left element shows a large tuberosity at its midlength, which is less distinct in the right medial carpal. This knob is mainly expanded posteriorly but also slightly distally. The surface itself is subdivided into two concave parts: a somewhat wrinkled depression in its lateral third and a smooth one medially. The medial face is gently rounded proximally, with no clear border to the adjacent articular surface. The only distinct edge is at its anterior end. The surface itself is rugose and exhibits a vertical groove in its center. The lateral face is broader and more wrinkled than the medial one. It is convex anteroposteriorly, which makes it appear a gently rounded transition from the anterior into the posterior side, rather than a discreet surface in itself. Its proximal and distal borders are distinct. The visible parts of the distal articular surface are slightly concave. The face is subdivided into at least three sections: 1) an almost flat medial section; 2) a concave area in the central anterior portion of the surface formed by the concavity of the distal margin of the anterior side; 3 ) a third subdivision (only visible in the posterior part of the face) that is separated from the other sections by a shallow groove, which starts approximately at midlength of the posterior border and extends perpendicular to it toward the center of the distal articular surface.

The lateral carpal (Figure 9) has the shape of an anteroposteriorly compressed cylinder. Its smallest diameter is approximately half its mediolateral length. The proximal articular surface of the lateral carpal is smooth and flat. Its medial, anterior, and lateral margins are accentuated and project proximally. This accentuation is most strongly pronounced around midlength of the anterior border and fades toward the posterior rim. The anterior surface is rectangular in outline and convex mediolaterally. The transitions into the medial and the lateral sides are continuous. Proximally and distally, the borders are distinct and - especially the proximal one - accentuated. The distal edge 


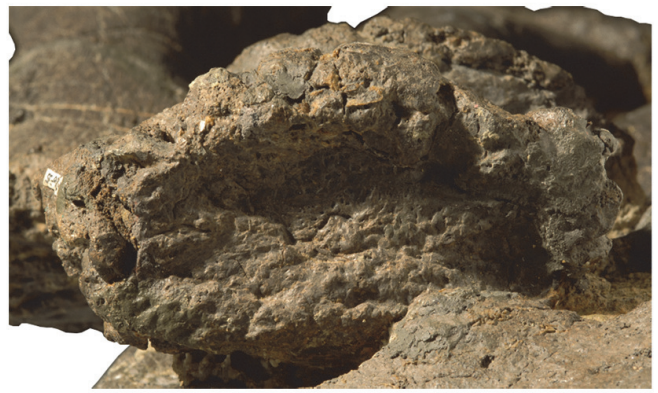

1

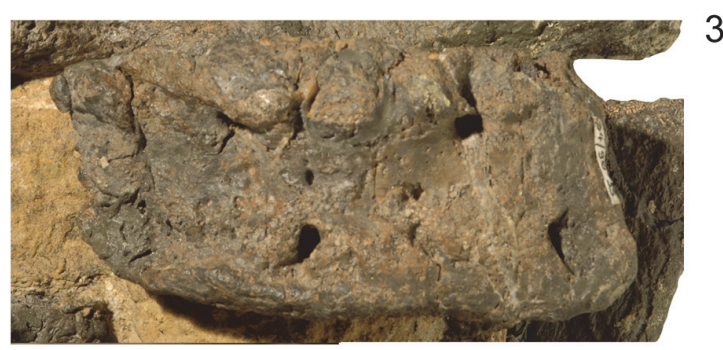

3

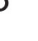
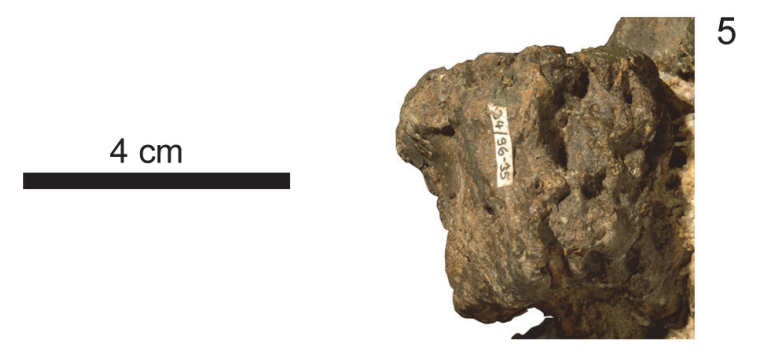

2
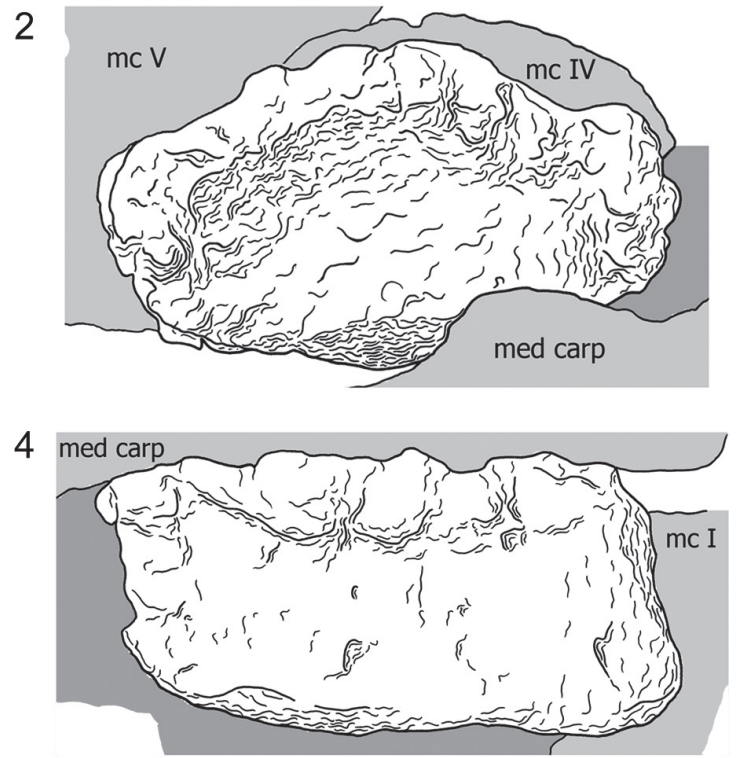

6

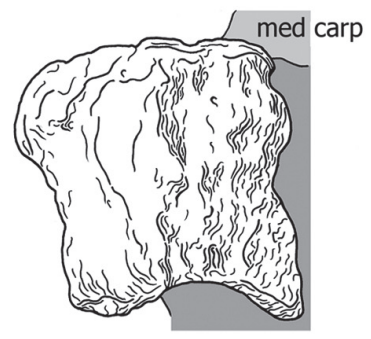

FIGURE 9. Photographs and drawings of the left lateral carpal in proximal $(1,2)$, anterior $(3,4)$, and lateral views $(5$, 6 ). Light gray represents adjoining bones, dark gray original matrix. Abbreviations: carp, carpal; mc, metacarpal; med, medial. Photographs taken by Rosemarie Roth.

curves weakly upwards medially, resulting in a shorter medial than lateral border. The entire face is pitted and seems to be partly eroded, exposing large areas of spongious bone. Where compact bone is preserved, it is very thin. The posterior side of the bone is even more rugose than the anterior one. It is convex mediolaterally, and has accentuated proximal and distal margins. Its medial and lateral rims are of similar lengths. The medial surface is short with deep grooves extending from the proximal to the distal end, with its posterior part still embedded in matrix. The lateral side is longer proximodistally than the medial one. In contrast to the latter, it does not show any grooves marking the whole surface, but it is highly rugose and pitted, especially so in its posterior part. The distal articular surface is concave and similarly smooth as the proximal facet. It has distinct margins, of which the posterior border is the most accentuated.

Metacarpus (Figures 10-14). The metacarpus is arranged in a more or less tubular structure. Although both manus are slightly deformed, all metacarpals are still in close contact proximally as well as distally. In both forefeet, the mc III is slightly separated from any carpal element, so that neither the medial, nor the lateral carpal, fully cover its proximal surface (Figure 7 ). The metacarpals are all different in length, the second element being the longest, followed by metacarpals III and IV. In the right manus, metacarpal $I$ is the shortest, in the left manus it is metacarpal V. All five metacarpals are long and slender and have divided distal ends with two nonparallel condyles.

Compared to the corresponding radius length, the metacarpals range from $44 \%$ (right $\mathrm{mc}$ I or left $\mathrm{mc} \mathrm{V}$, respectively) to $55 \%$ (left $\mathrm{mc}$ II) or $57 \%$ (right $\mathrm{mc}$ II) (Table 2). The distal end of each bone expands transversely, but to a different degree: it is getting wider from $\mathrm{mc} \mathrm{I}$ to $\mathrm{mc}$ IV. Given that in all the metacarpals, the lateral condyle is in nearly vertical prolongation of the diaphysis, this distal transverse expansion results mainly from the more pronounced medial condyle. Other features of the lower articular surfaces change as well: whereas 

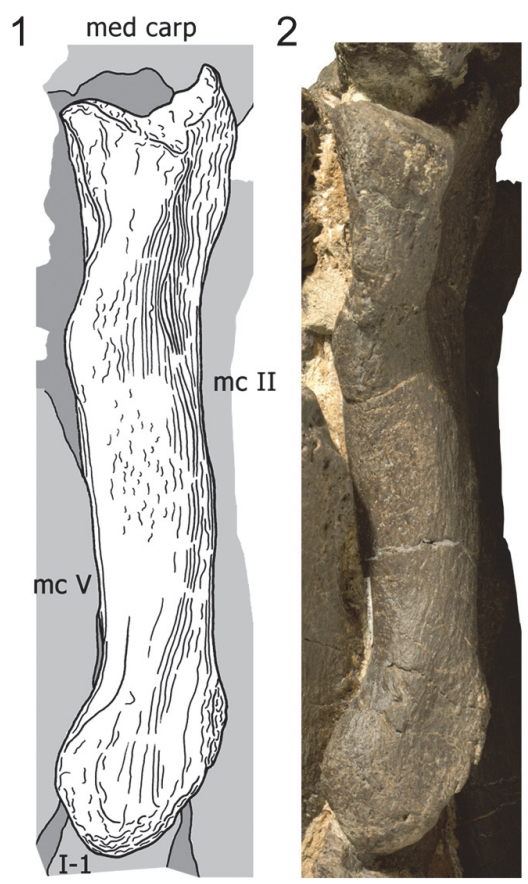

$4 \mathrm{~cm}$
3

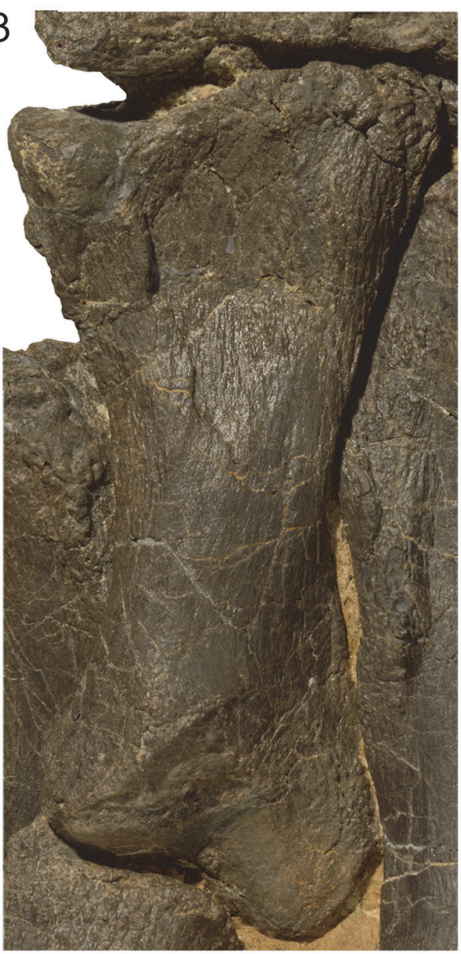

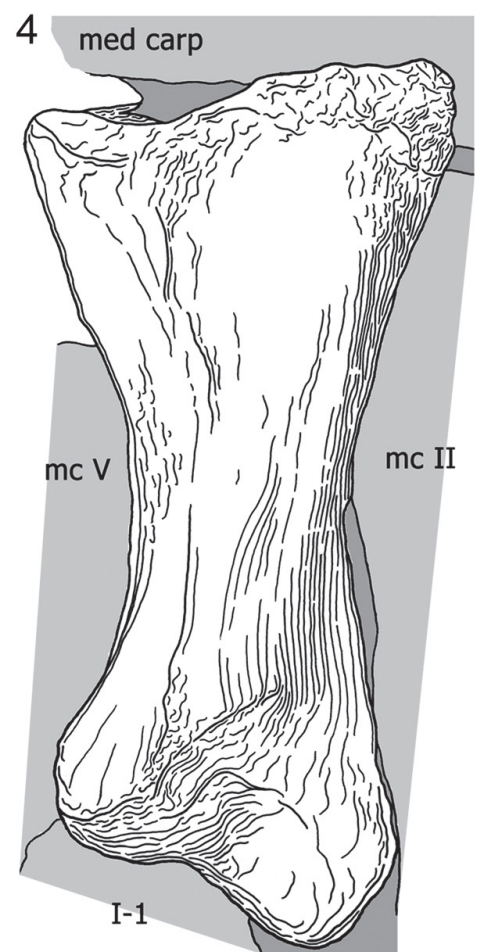

FIGURE 10. Photographs and drawings of the left metacarpal I in medial $(1,2)$ and anterior views $(3,4)$. Light gray represents adjoining bones, dark gray original matrix. Abbreviations: carp, carpal; I-1, first phalanx of digit I; mc, metacarpal; med, medial. Photographs taken by Rosemarie Roth.

the condyles of the distal articular surface of mc I are very distinct, these structures get more and more flattened moving toward $\mathrm{mc} \mathrm{V}$, where they are but hardly recognizable.

The metacarpal I (Figure 10) is short and stout, compared to the other metacarpals. At its midpoint, the shaft twists in an angle of $35^{\circ}$ to $40^{\circ}$. The proximal articular surface is convex mediolaterally and slightly rugose. Its anterolateral portion projects proximally into the cavity in the anterior part of the distal articular surface of the medial carpal. Further morphological information on this side is obscured due to deformations of the upper parts of both $\mathrm{mc} \mathrm{I}$. The anterior surface seems to be proximally more expanded transversely than at its distal end, but this might also be caused by deformation. The surface is mostly smooth with a small and slightly rugose convexity near its proximolateral edge. At its least width, somewhat distally from midlength, the shaft is mediolaterally and proxi-

TABLE 2. Ratios of metacarpal length to humerus and radius length in Camarasaurus. Data obtained from Mclntosh et al. (1996a: GMNH-PV 101; 1996b: BYU 9047) and Mclntosh (2005: AMNH 823 and 965). SMA 0002 has distinctively higher ratios than other Camarasaurus specimens.

\begin{tabular}{|l|c|c|c|c|c|c|c|}
\hline \multirow{3}{*}{} & \multicolumn{2}{|c|}{ Humerus } & \multicolumn{5}{c|}{ Radius } \\
\cline { 2 - 9 } & SMA 0002 & GMNH-PV 101 & \multicolumn{2}{c|}{ SMA 0002 } & AMNH 823 & AMNH 965 & BYU 9047 \\
\cline { 2 - 9 } & right & left & right & left & right & right & right \\
\hline Mc I & 0.29 & 0.25 & 0.44 & 0.45 & 0.39 & 0.43 & 0.38 \\
\hline Mc II & 0.38 & 0.29 & 0.57 & 0.55 & 0.44 & 0.48 & 0.42 \\
\hline Mc III & 0.36 & & 0.55 & 0.53 & 0.44 & 0.48 & 0.44 \\
\hline Mc IV & 0.33 & & 0.51 & 0.52 & 0.41 & 0.45 & 0.4 \\
\hline Mc V & 0.3 & & 0.45 & 0.44 & 0.37 & 0.41 & 0.37 \\
\hline
\end{tabular}


1

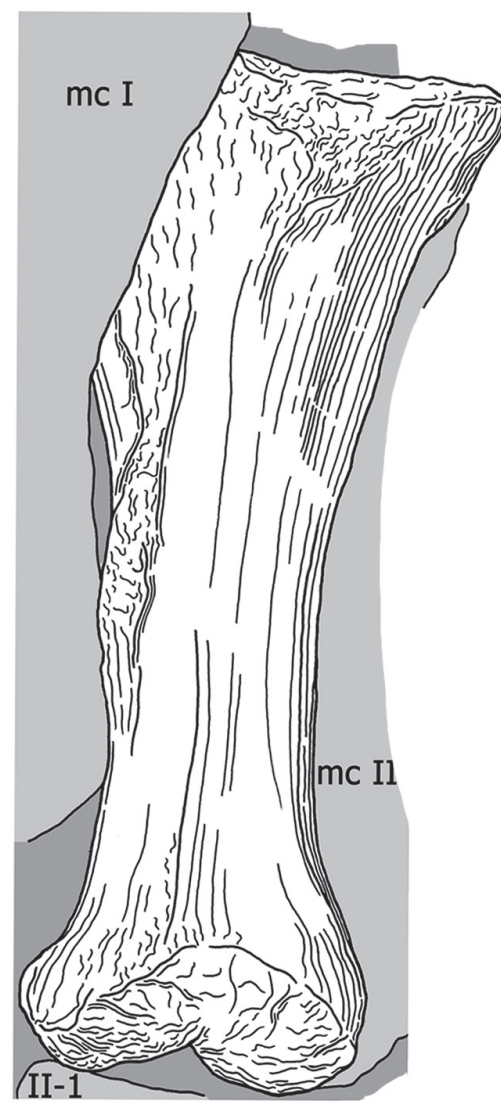

2

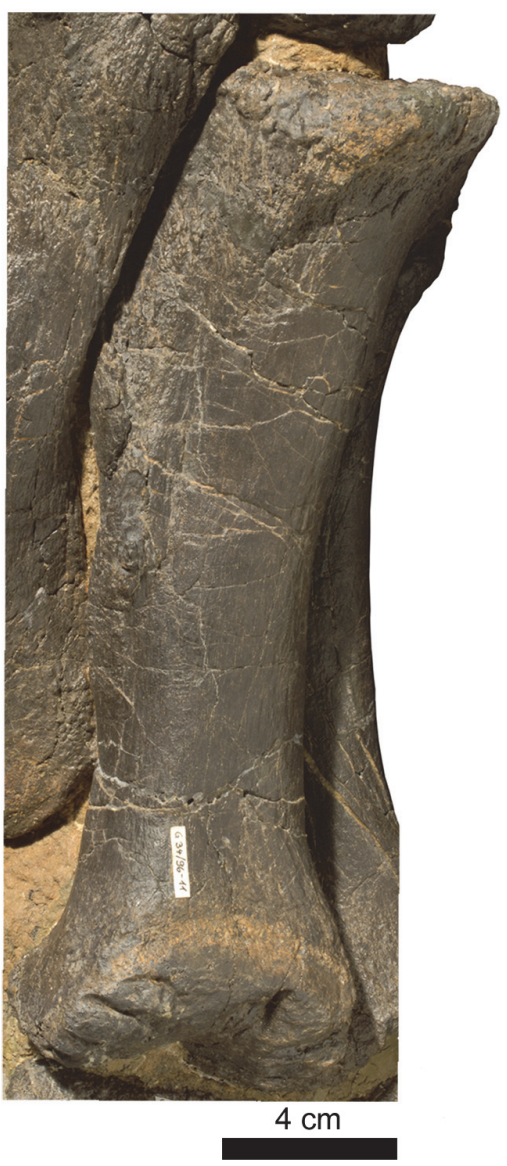

3

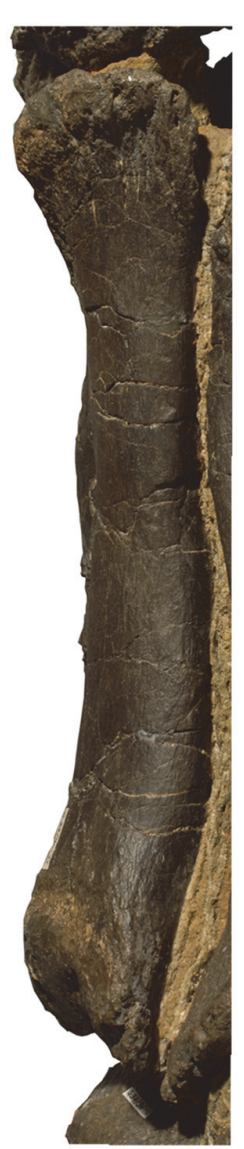

4

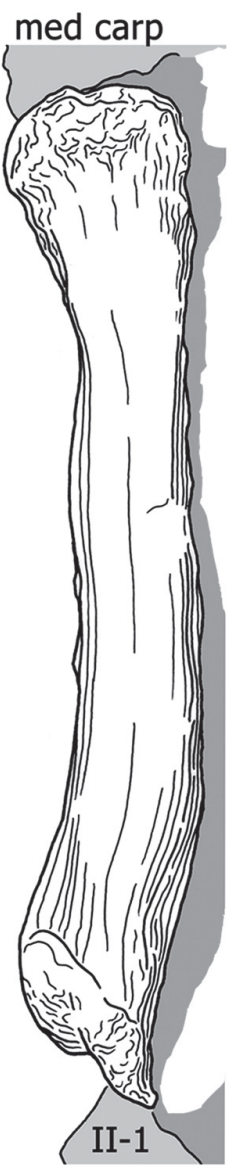

FIGURE 11. Photographs and drawings of the left metacarpal II in anteromedial $(1,2)$ and anterior views (3, 4). Light gray represents adjoining bones, dark gray original matrix. Abbreviations: carp, carpal; II-1, first phalanx of digit II; mc, metacarpal; med, medial. Photographs taken by Rosemarie Roth.

modistally convex. Toward its articular surfaces, the anterior side flattens and becomes even gently concave in both directions. The lower concavity passes into the intercondylar groove. Posteriorly, the rugosity of the proximal articular surface extends onto the diaphysis, becoming gradually less pronounced distally. The lower two thirds of the posterior face are smooth. Only at the lateral margin, where mc I overlies mc II, the proximal rugosity extends as far distally as midshaft. The medial side of $\mathrm{mc} \mathrm{I}$ is slightly S-shaped, which results from the fact that the distal condyles expand further posteriorly than anteriorly. Around midshaft, a relatively large rugose area marks the otherwise smooth surface. This rough area protracts but also thins toward the proximal end. The lateral face is obscured. Both in anterior and posterior view, the proximal portion of $\mathrm{mc} \mathrm{I}$ is overlying its corresponding part of $\mathrm{mc} \mathrm{II}$, indicating that the upper part of the lateral surface is at least gently concave. Two very distinct condyles form the distal articular surface. The intercondylar groove becomes deeper posteriorly. The lateral condyle projects much further distally than the medial one, which results in an oblique, slightly medially facing distal articular surface. Apart from its medial and lateral margins, the face is smooth.

The proximal articular surface of metacarpal II (Figure 11) is roughened and subtriangular in outline, being much shorter posteriorly than anteriorly. At the posterior end, the rugosity extends onto a downward running ridge. In anterior view, the shaft is slender and mediolaterally convex at midlength. Unlike the state in $\mathrm{mc} \mathrm{I}$, the proximal extremity of $\mathrm{mc} \mathrm{II}$ is less broad than the distal one. Toward the extremities, the diaphysis becomes flat, and its medial and lateral borders develop acute edges with their adjacent sides. As in $\mathrm{mc} \mathrm{I}$, the anterior surface of the second metacarpal is slightly twisted $\left(25^{\circ}\right.$ to $\left.30^{\circ}\right)$ and smooth. On the posterior surface, 


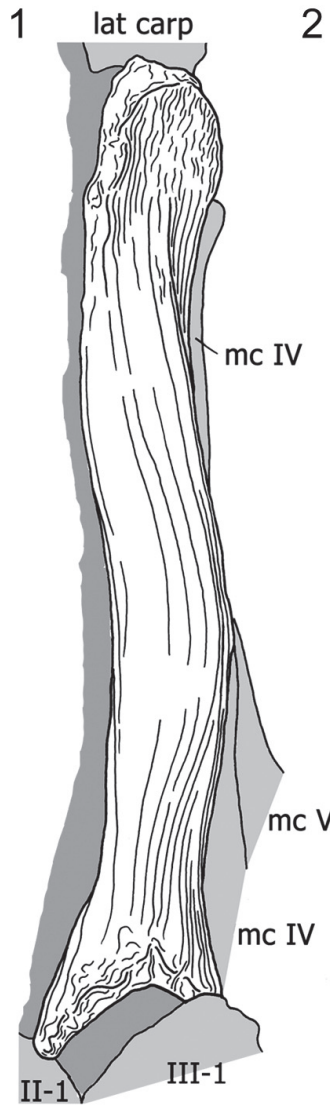

3

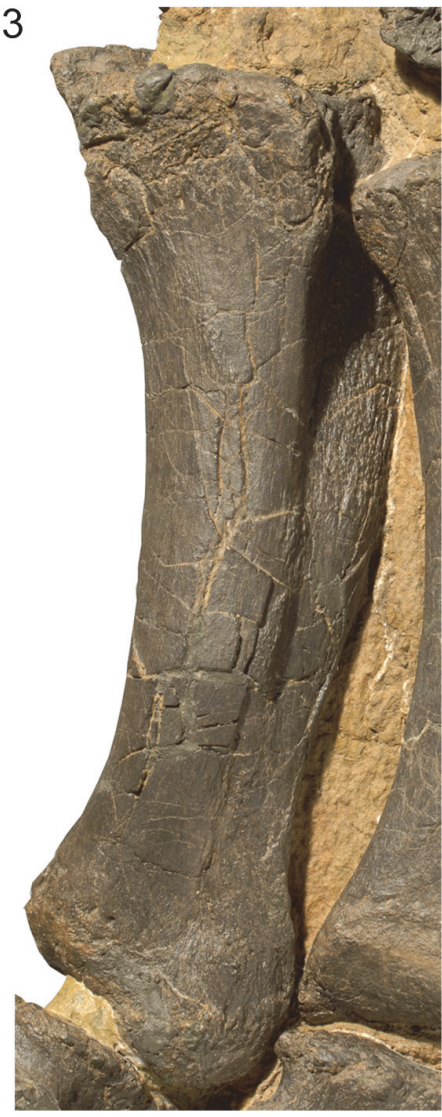

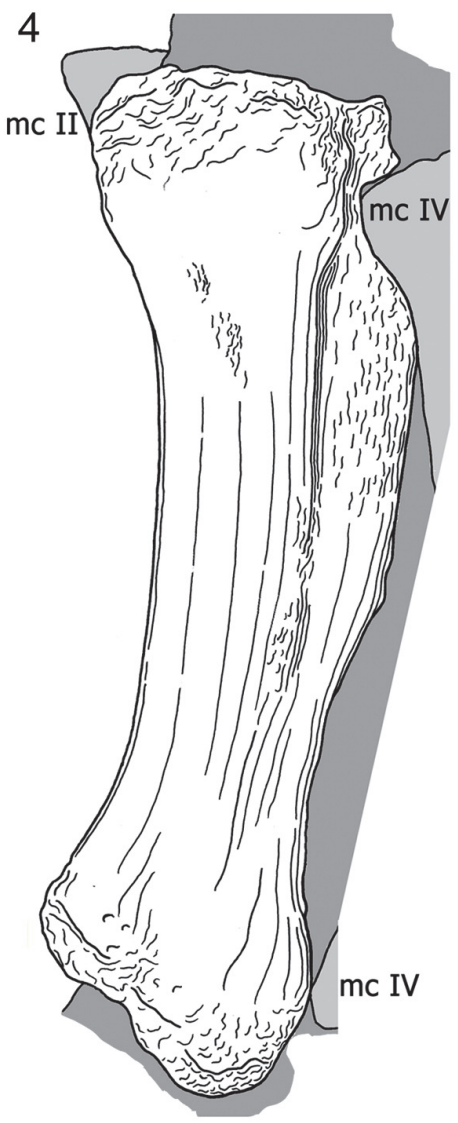

$4 \mathrm{~cm}$

FIGURE 12. Photographs and drawings of the left metacarpal III in medial $(1,2)$ and anterior views $(3,4)$. Light gray represents adjoining bones, dark gray original matrix. Abbreviations: carp, carpal; II-1, first phalanx of digit II; lat, lateral; mc, metacarpal. Photographs taken by Rosemarie Roth.

a ridge is proceeding down the diaphysis from the posterior corner of the proximal articular facet to a high prominence situated approximately at midshaft. The top of this protuberance bears some rugosity indicating soft tissue attachment. Below the prominence, the ridge divides into two shallow convexities, which proceed to the two condyles forming the distal articular surface for the phalanx. As in $\mathrm{mc} \mathrm{I}$, the upper third of the posterior side of the shaft is marked by the rugosity from the proximal articular surface. In both manus, the proximal portion of the medial side of $\mathrm{mc} \mathrm{II}$ is obscured by the corresponding end of the lateral side of the first metacarpal. This part is crushed in both elements. A weak, striated rugosity extends from a protuberance at the center of the surface toward its proximal end. The lower third of the medial side is mostly smooth. On its anterior half, close to the distal margin, there is a small, slightly roughened area. The distal articular surface is not as smooth as the one of $\mathrm{mc} \mathrm{I}$. Several grooves of varying depth connect its borders with the intercondylar groove. As in $\mathrm{mc} \mathrm{I}$, the condyles of $\mathrm{mc} \mathrm{II} \mathrm{expand}$ more posteriorly than anteriorly.

The proximal articular surface of metacarpal III (Figure 12) has a subtriangular outline, being much narrower posteriorly than anteriorly. The anterior margin is shorter than the medial and lateral edges, which are subequal in length. The posterior part of the surface bears the most accentuated border, followed by the anterior portion. The lateral margin is slightly concave for the reception of the medial edge of the upper part of $\mathrm{mc}$ IV. The surface itself is flat and only slightly rugose. At the anteromedial and anterolateral corners, this rugosity extends for a short distance downward onto the shaft. Despite the distortion of the anterior surface of $\mathrm{mc}$ III, it is obvious that both ends of this side are expanded, and that the face itself is predominantly convex mediolaterally. The transitions into the medial and the lateral surfaces are smooth. Proximally, the anterior side flattens, 
resulting in continuously more distinct medial and lateral borders toward the upper articular surface. This proximal end is slightly eroded: spongious bone is exposed in large areas and gives this side a rough appearance, which is especially strong at the upper portions of its medial and lateral margins. Except for one shallow tubercle in the center of its proximal half, the anterior surface is smooth. The proximally narrow posterior surface exhibits a considerable prominence at midshaft for soft tissue attachment. This prominence is less high but broader than the one in $\mathrm{mc} \mathrm{II}$. As in the latter, the surface between the protuberance and the proximal end of the posterior side of mc III bears a striated rugosity, which is more pronounced than in $\mathrm{mc}$ II. The surface distal to the prominence is smooth and divides gradually into the two condyles, which are less developed than in mc II. The medial face of $\mathrm{mc} \mathrm{III} \mathrm{has} \mathrm{very} \mathrm{distinct} \mathrm{anterior} \mathrm{and}$ posterior borders at its proximal end. The surface is marked by a striated rugosity that fades distally. The lower half of the medial face is smooth, and only at its distal border it becomes again slightly roughened. The lateral surface exhibits two similarly weak tubercles as does the proximal part of the anterior surface. They are located at midshaft and mark the beginning of the distinct margin that separates the anterior and the lateral surfaces proximally. At the same height, a faint concavity occurs on the outer surface. Toward its proximal end, this concavity gets wider and slightly deeper. Its posterior slope shows a weak striated rugosity extending proximally. The distal portion of the lateral surface resembles its medial analog. Although the distal articular condyles of $\mathrm{mc}$ III are subequal in width to the ones of $\mathrm{mc} \mathrm{II}$, they seem more extended, because the lower expansion of the shaft is more abrupt than in the second metacarpal. The intercondylar groove is not as deep as in the previous elements of the series, but still clearly visible. In mc III as well as in mc IV, the oblique alignment of the medial condyle contributes most to the transverse expansion of the articular surface. The outer side of the lateral condyle is almost in line with the corresponding face of the shaft. The distal articular surface itself is only slightly rugose and does not show accentuated margins at its anterior nor at its posterior ends.

The proximal articular surface of metacarpal IV (Figure 13) is subtriangular, with a slightly convex anterior margin. The posterolateral corner of the lateral concavity points posteriorly, such that the proximal portion of $\mathrm{mc} \vee$ fits into this depression. The proximal surface of $\mathrm{mc}$ IV is mostly flat and only slightly rugose. It is oblique with respect to the main axis of its shaft, sloping down from its posterior edge to the anteromedial one. In anterior view, the element is nearly straight with the exception of the expanded extremities. It is mediolaterally strongly convex at midshaft and flattens distally somewhat more and earlier than proximally. The upper part of the anterior surface bears a similar but slightly weaker tubercle than the one in mc III. Like in mc III, distinct medial and lateral margins only occur in the proximal portion of the anterior face of $\mathrm{mc} \mathrm{IV}$, and become very pronounced toward the upper extremity. Whereas the medial rim is smooth throughout its length, the lateral border exhibits a striated rugosity extending in the same direction. The upper margin of the anterior side is not very accentuated but slightly rugose and still much more distinct than the lower one, where the transition into the distal articular surface is continuous. The upper portion of the posterior surface of $\mathrm{mc}$ IV is very thin. It forms a ridge extending from the pointed posterior end of the proximal face down the diaphysis, with its highest elevation around midshaft. In its lower portion, the ridge is confluent with the prominent medial margin of the surface, which curves outwards towards its distal end. The lateral border of the posterior face is less distinct and remains subparallel to the longitudinal axis of the diaphysis. Along the top of the entire ridge, the surface is slightly rugose. The sides of the ridge and especially the lateral part of the broadened distal portion of the posterior side are smooth. The visible areas of the medial surface do not have distinctive features. The face is smooth with no clear separation from the anterior side except for its extremities. It is convex anteroposteriorly and concave proximodistally. The lateral surfaces of both mc IV are almost entirely hidden by matrix or adjacent elements. Only the anterior margin of the lateral surface of the left mc IV is visible. As in $\mathrm{mc}$ III, there are two small and slightly rugose protuberances close to midshaft, which mark the beginning of the concavity for the reception of $\mathrm{mc} V$ in the proximal portion of this side. In distal view, the lateral condyle of the distal articular surface of $\mathrm{mc}$ IV is not recognizable: unlike the distally projecting medial condyle, the outer part of the facet is formed by a smooth and squared, neither anteriorly nor posteriorly expanded, area. The intercondylar groove is very shallow. Whereas the anterior rim of the distal rticular facet is nearly straight, the posterior border of the distal articular surface is faintly sickle-shaped. 

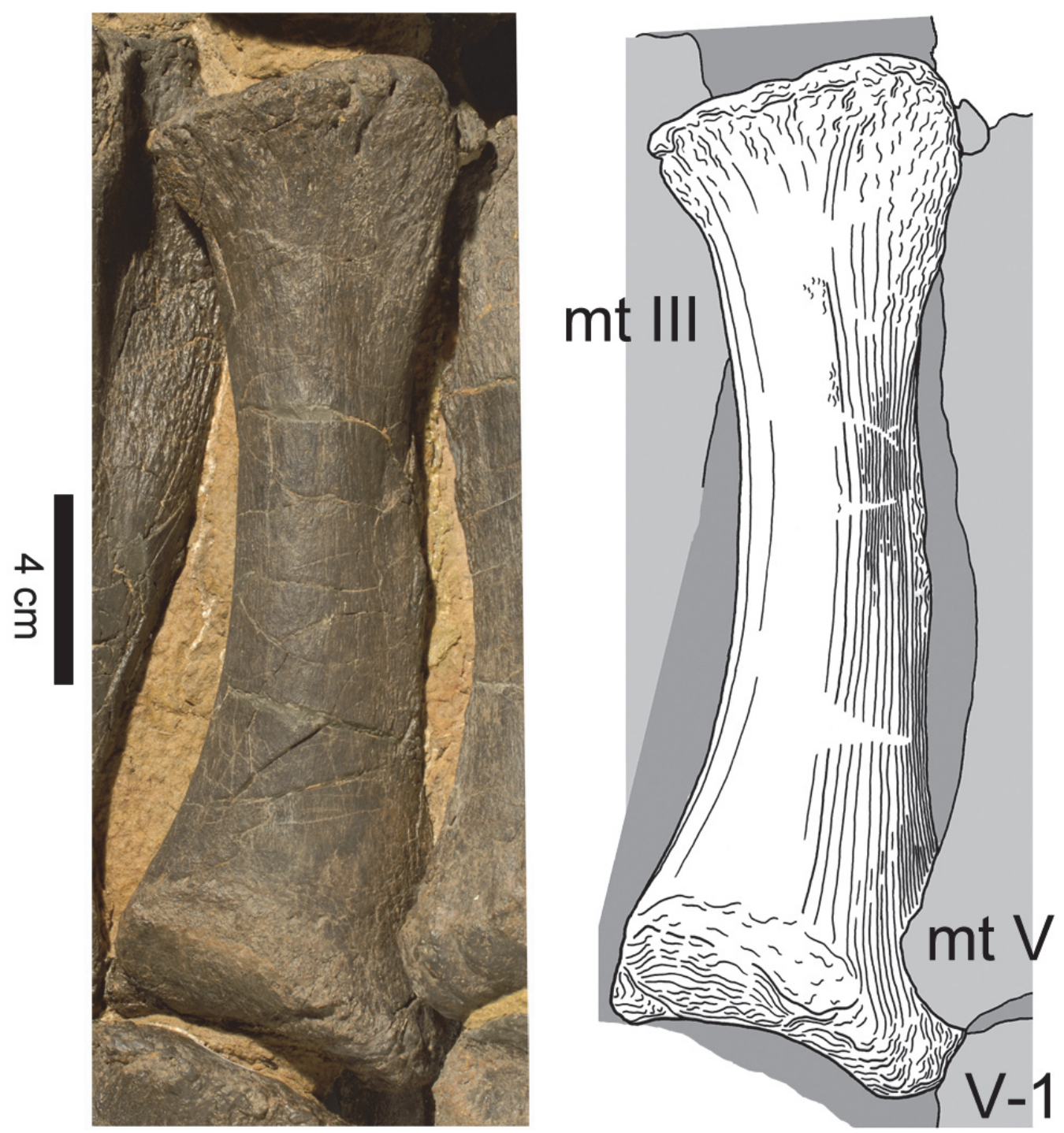

FIGURE 13. Photograph and drawing of the left metacarpal IV in anterior view. Light gray represents adjoining bones, dark gray original matrix. Light gray represents adjoining bones, dark gray original matrix. Abbreviations: mc, metacarpal; V-1, first phalanx of digit V. Photographs taken by Rosemarie Roth.

The metacarpal $V$ (Figure 14) is subequal in size to $\mathrm{mc} \mathrm{I}$ and of similar robusticity (Table 1). The whole shaft is slightly twisted. In anterior view, the distal extremity is contorted approximately $25^{\circ}$ toward the medial side, compared to its proximal end. The proximal articular surface of $\mathrm{mc} V$ is much more roughened than the ones of the precedent metacarpals. Its lateral portion is convex with the anterior part projecting slightly more proximally than the posterior one. About $25 \mathrm{~mm}$ from its lateral end, the posterior margin curves sharply distally. The same occurs in the anterior margin somewhat further medially. The upper articular surface is therefore obliquely divided into a lateral, proximally facing and a medial, proximomedially and slightly posteriorly facing portion. The transition from the latter into the medial side of the bone is indistinct. The extremities of the anterior surface are less expanded than in the other metacarpals. Only its mediodistal edge projects considerably medially. As in the precedent elements, the surface is convex in its distal half and flattens proximally. Approximately $25 \mathrm{~mm}$ beneath the upper articular facet, there is a small, slightly roughened area near its lateral border. At the opposite rim, three other rugose areas are observable. One area extends from the distal end upwards for approximately 60 $\mathrm{mm}$, the other two are protuberances that lie side by side in the proximal part of the medial margin of the otherwise smooth anterior face. A prominent 

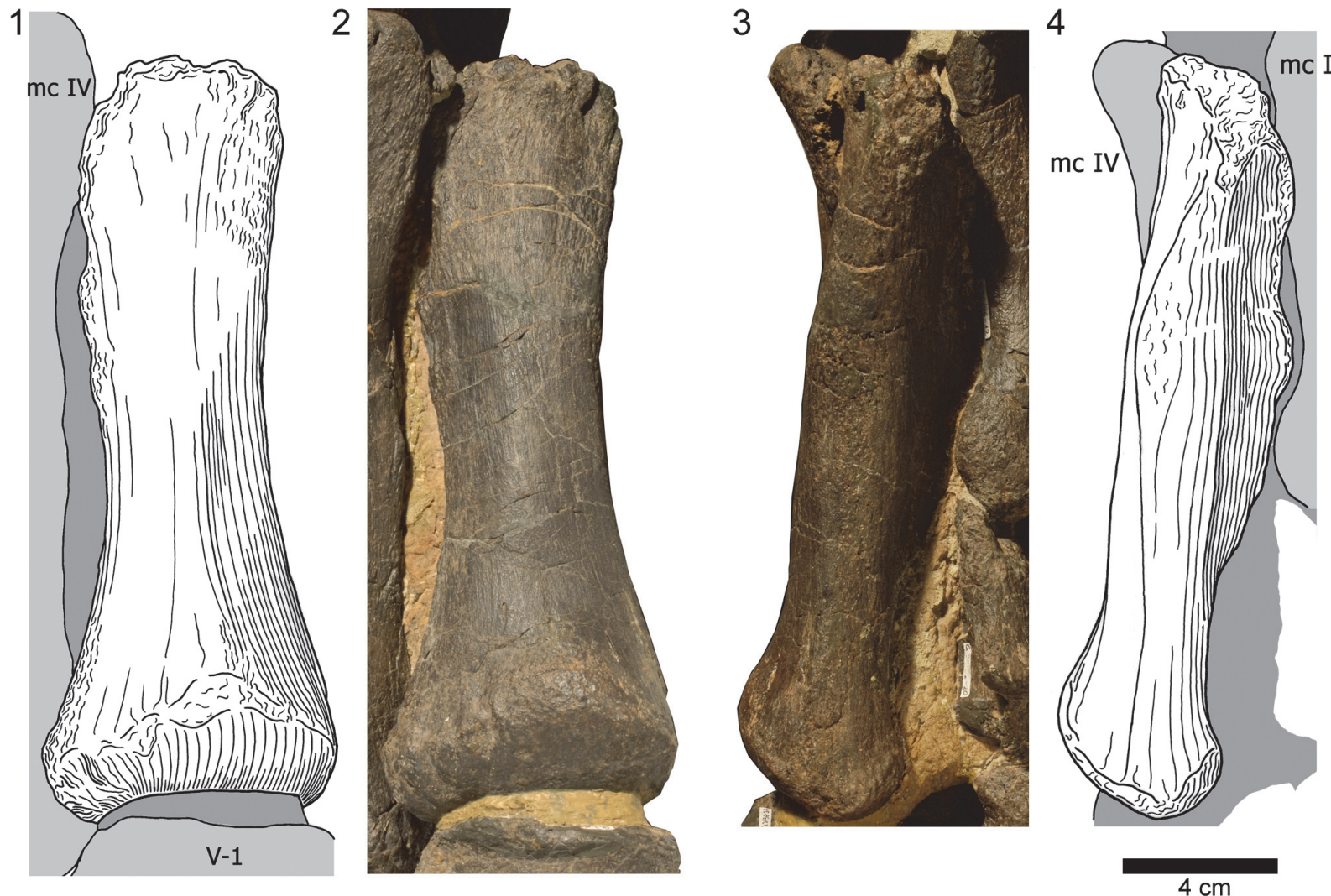

FIGURE 14. Photographs and drawings of the left metacarpal $V$ in anterior $(1,2)$ and lateral views (3, 4). Light gray represents adjoining bones, dark gray original matrix. Abbreviations: mc, metacarpal; V-1, first phalanx of digit $\mathrm{V}$. Photographs taken by Rosemarie Roth.

ridge marks the posterior side of $\mathrm{mc} \mathrm{V}$. This structure extends from the oblique part of the proximal surface distally and slightly medially until it ends abruptly close to midshaft. The ridge is broad initially and tapers toward its distal end. Whereas the transition into both the medial and the lateral surfaces is smooth but distinct in the distal portion of the shaft, no border is distinguishable in the proximal part, where the slopes of the ridge gently continue into the adjacent surfaces. The surface itself is smooth except at the roughened ridge. The medial face is mostly obscured. Its anterior margin is marked by the rugose areas, which represent the two neighboring protuberances in the proximal part of the medial margin of the anterior side. The lateral surface is nearly straight. Close to midshaft, there is a similar but slightly less roughened area as in the medial face of the first metacarpal. Whereas the transition into the posterior side of $\mathrm{mc}$ $V$ is - particularly proximally - smooth to indiscernible, the anterior border is distinct. The distal articular surface is undivided and smooth. It is anteroposteriorly convex and extends further anteriorly than posteriorly. Although it does not exhibit any traces of condyles, it expands somewhat transversely. As in the other metacarpals, this expansion mainly occurs medially. At this end, few short grooves are visible, extending from the anteromedial corner toward the center of the articular facet.

Manual phalanges (Figures 15-20). The manual phalanx I-1 (Figure 15) is the longest and stoutest of the five proximal phalanges. In both manus it is slightly shifted out of articulation but still closely associated with its adjacent elements. The proximal articular surface of phm I-1 has a subtrapezoidal outline. It is slightly rugose and saddle-shaped with its posterior margin projecting much higher than its anterior one. Due to this lip-like extension, the articular face of phm I-1 fits well into the posterior portion of the intercondylar groove of $\mathrm{mc} \mathrm{l}$. The diaphysis of phm I-1 is considerably longer than the shafts of the other manual phalanges. Its anterior surface is smooth and almost flat. It is slightly longer laterally than medially. Distally, the inner and the outer border of the anterior surface curve lightly to the front, marking the origin of the distal condyles. The proximal rim of the posterior face of 

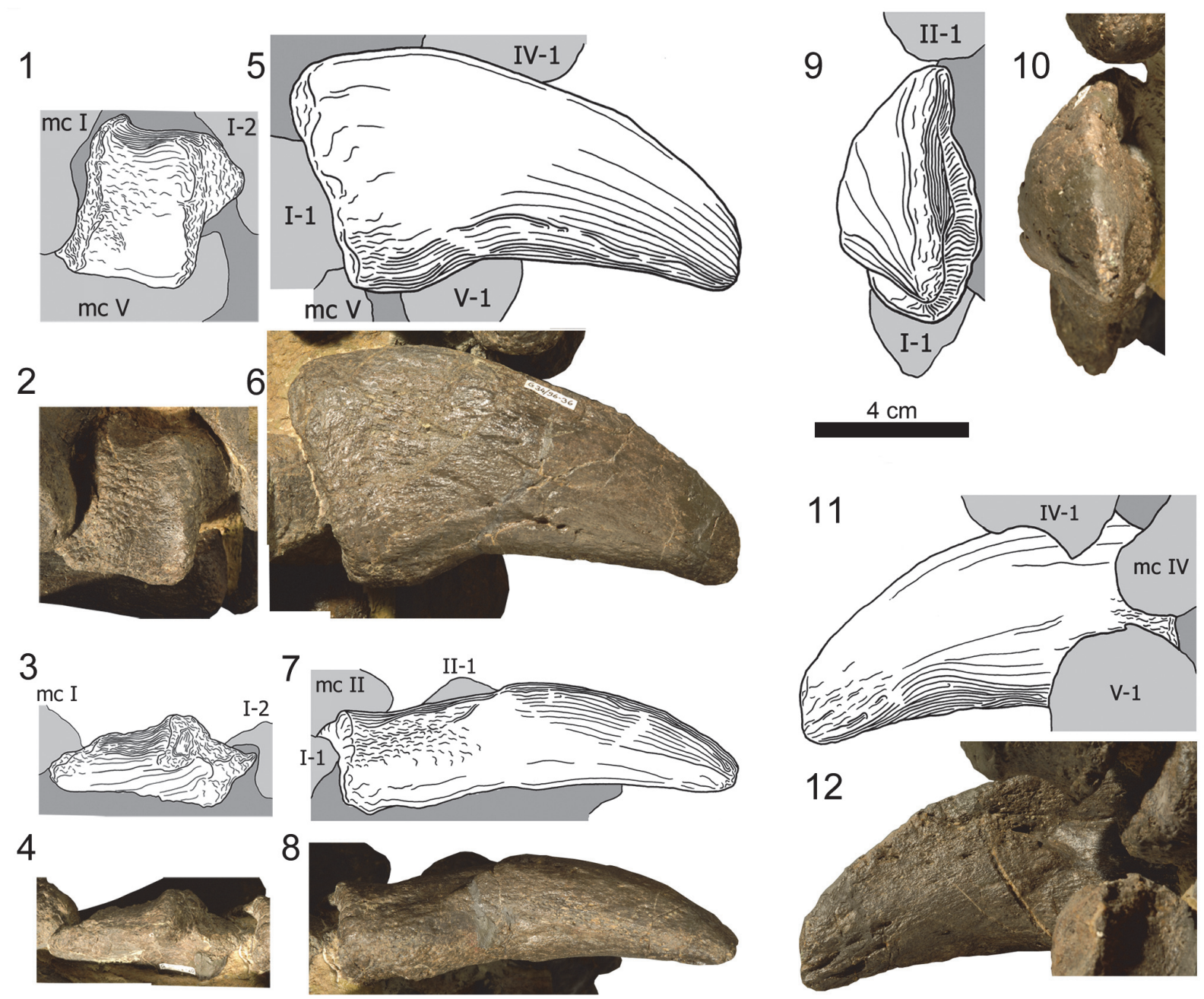

FIGURE 15. Photographs and drawings of the phalanges of the left manual digit I. Manual phalanx I-1 in medial $(1,2)$ and posterior views $(3,4)$. Manual ungual $(\mathrm{phm} \mathrm{I-2)}$ in medial $(5,6)$, posterior $(7,8)$, distal $(9,10)$, and medial views $(11,12)$. Light gray represents adjoining bones, dark gray original matrix. Abbreviations: mc, metacarpal; $\mathrm{V}-1$, first phalanx of digit V. Photographs taken by Rosemarie Roth.

phm $\mathrm{I}-1$ is transversely expanded, other than extending strongly proximally at its center, forming the already mentioned 'lip' of the hind rim of the proximal articular surface. The posterior side is almost flat proximally, and becomes mediolaterally deeply concave at its distal extremity, leading into the intercondylar groove. Like the anterior one, the posterior face stands nearly perpendicular to the medial and the lateral face. Slightly distally of the center of the surface, there is a small foramen nutricium. The medial side has a curved proximal border with a steep posterior and a flat anterior part. Especially in the left manus, this margin is weakly roughened, and the rugosity extends into the upper portion of the medial surface, disappearing in its distal half. Whereas the medial side of the shaft of phm I-1 is slightly convex, the lateral one is deeply concave. The distal articular surface shows a similar pattern as the one of $\mathrm{mc} \mathrm{I}$ : two distinct condyles that expand further posteriorly than anteriorly, with the lateral one being more pronounced. The surface itself is weakly roughened, except for a small irregular area on the posterior half of the medial condyle of the left phalanx. This smooth area is slightly indented with sharp margins toward the larger wrinkled part of the surface.

The only manual claw (Figures 15-16) has a stout appearance. It is slightly curved and has a blunt tip. The articular region of phm I-2 is concave and does not occupy the entire proximal surface. However, due to different diagenetic compression of the right and the left element, it is difficult to 

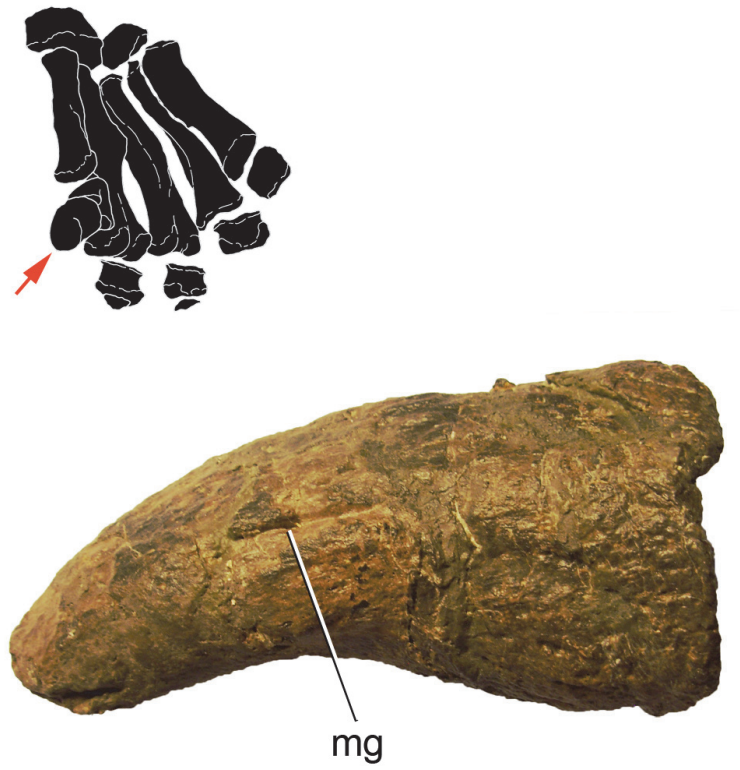

$5 \mathrm{~cm}$
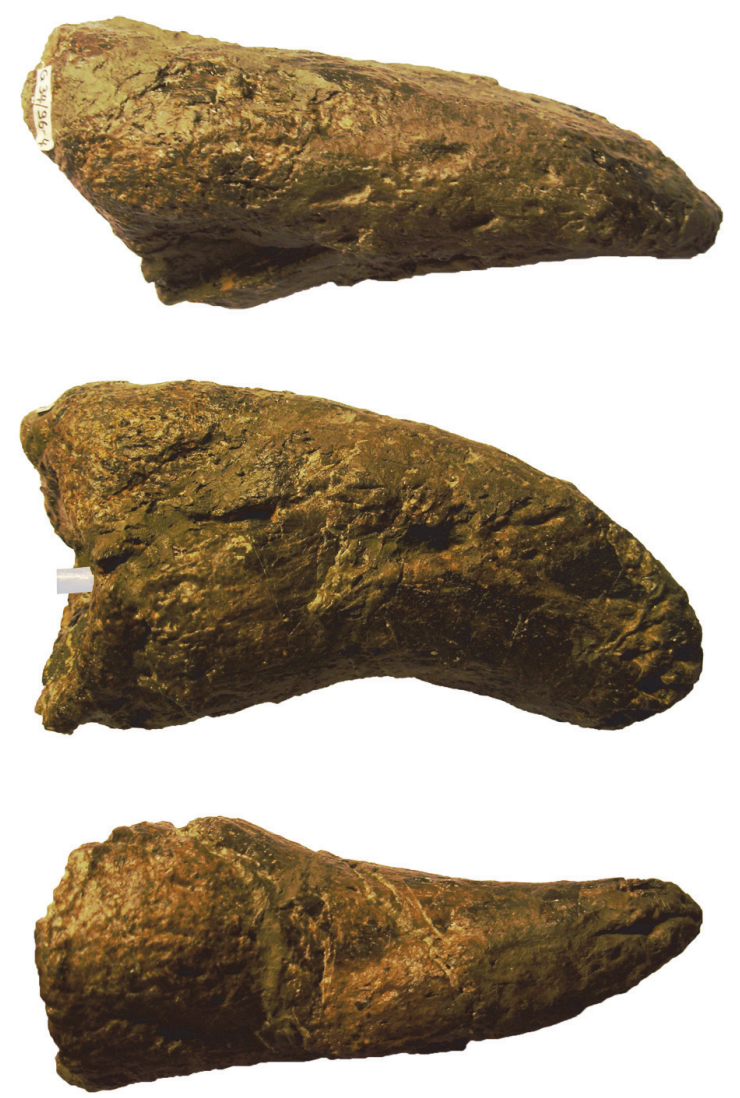

FIGURE 16. Right manual ungual phm I-2 of the Camarasaurus SMA 0002 in medial (left), dorsal, lateral, and palmar (right, top to bottom) views. Schematic drawing indicates location of the claw. The metal bar overlain with semi-transparent white in the photo of the lateral view functions as support for the mount. Abbreviation: mg, medial groove. Scale bar equals $5 \mathrm{~cm}$.

determine the exact area of the side that it occupies. In both manus, its rims are slightly broadened and more rugose than the surface. The anterior side is narrow due to the mediolateral compression of the respective portion of the ungual. It stands in an oblique angle to its proximal articular surface, pointing slightly laterally with its thin distal end. The proximal half of the posterior surface exhibits subparallel medial and lateral borders. It is slightly roughened and curves posteriorly. In its tapering distal portion, the posterior surface is gently rounded, with a continuous transition into the lateral side of the element. Due to the laterally pointing tip, the medial surface is both anteroposteriorly and proximodistally convex. It is smooth and bears many small nutrient foramina distributed among the entire face. A large foramen nutricium is located at midlength near the posterior margin. It is accompanied by a clearly visible canal leading there from the proximal end. The lateral surface of the ungual is anteroposteriorly convex as well, but to a much lesser degree than the medial side. Unlike the latter, it is proximodistally slightly concave and does not show as many small foramina nutricii. Whereas the medial side of the tip retains the smoothness of the medial surface, large and deep cavities occur especially on the lateral side of the tip of the right element, giving this extremity a very rugose appearance.

The manual phalanx II-1 (Figure 17) is the broadest of the manual phalanges. Its proximal articular surface is mostly flat and has an ellipsoid outline. The anterior margin is rugose, but not accentuated. In contrast, its medial and especially its lateral border project relatively far outwards. Of the face itself, a large area of the anterior part is smooth. In some parts of this area, the periost is eroded. As in the distal surface of the first proximal phalanx, the smooth region is faintly indented and therefore separated from the other, slightly rugose parts of the proximal side by a sharp but irregular margin. The anterior face is almost flat and longer 

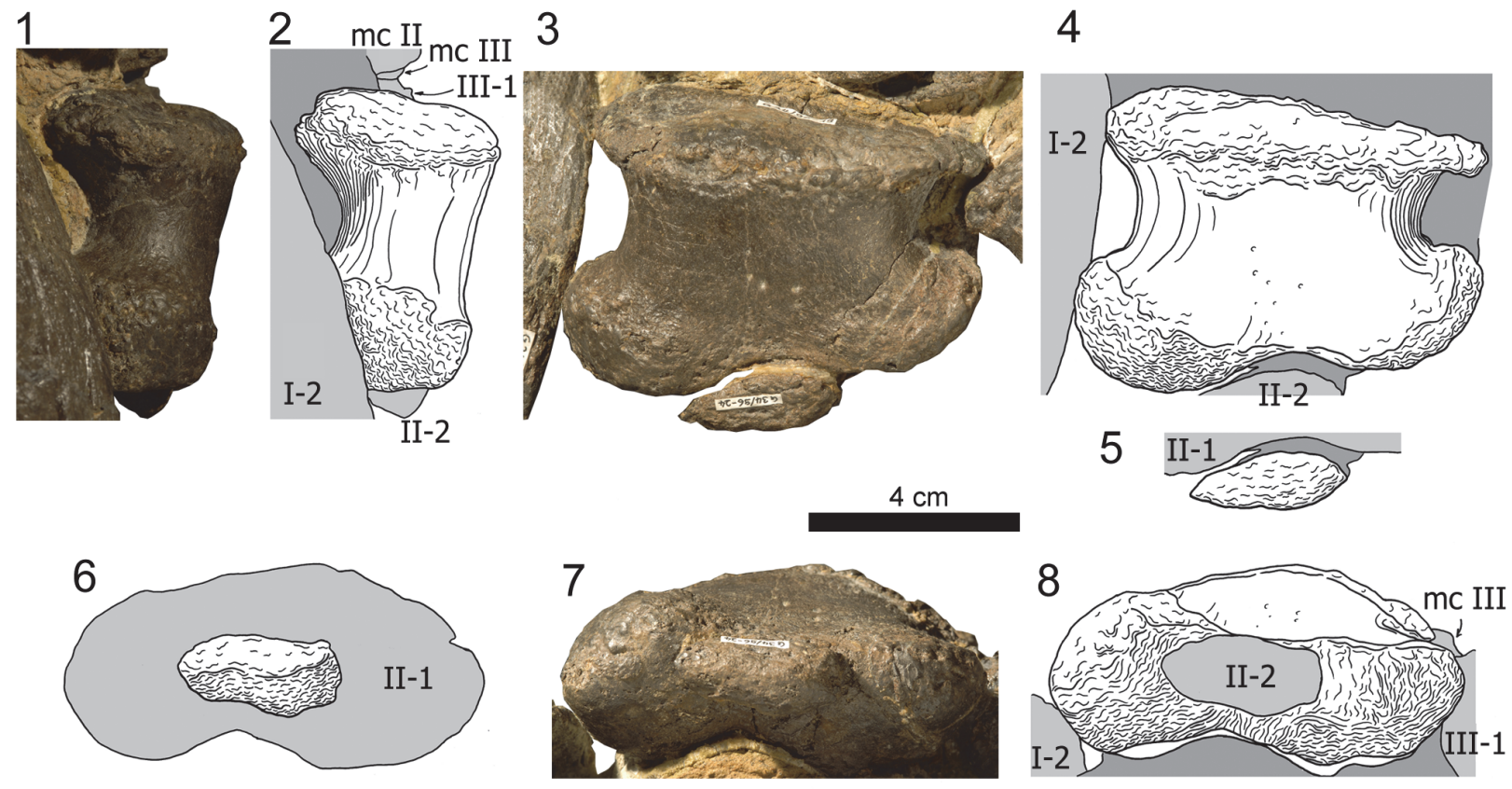

FIGURE 17. Photographs and drawings of the phalanges of the left manual digit II. Manual phalanx II-1 $(1-4,7,8)$ and II-2 $(3,5,6)$ in medial $(1,2)$, anterior (3-5), and distal views (6-8). Light gray represents adjoining bones, dark gray original matrix. Abbreviations: II-1, first phalanx of digit II; mc, metacarpal. Photographs taken by Rosemarie Roth.

medially than laterally. It is expanded at both ends, but whereas the medial and the lateral border gradually curve outward distally, the proximal expansion is very abrupt. Thus, the inner as well as the outer rim of the surface are strongly concave. Proximally and distally, the margins are nearly straight. Only at the lower extremity, a shallow intercondylar groove occurs. The transition from the shaft to the condyles is distinct and extends from the outermost edge of the medial as well as the lateral rim obliquely toward the center of the distal border of the anterior face. Proximally to the transition, the surface is smooth with some small foramina nutricii at its center and in its distal portion. The medial surface of phm II-1 does not show any distinct characteristics. It is deeply concave proximodistally and convex anteroposteriorly. Except for its roughened proximal border and the transition into the distal articular surface, the surface is smooth. The lateral face is shorter and even more concave proximodistally than the medial one. Whereas on the latter, this concavity is more or less regular, the proximal end of the lateral depression is marked by a distinct and extremely accentuated margin, which stands almost perpendicular to the long axis of the shaft. Distally, the lateral side describes a sharp but gradual curve toward the outermost point of the distal facet, where it becomes rugose. The large smooth portion of the lateral surface is more clearly separated from the anterior face than the medial side, which passes gently into the former. The distal articular surface of phm II-1 has an outline like a transversely orientated eight. Its anterior part is slightly less indented than its posterior one, and its medial end is more regularly rounded than its lateral one. The face is oblique, with its anterior margin projecting further distally than the posterior one. In distal view, a large part of the side is smooth, but as the indistinct condyles curve backwards, they get slightly rugose.

The left manual phalanx II-2 (Figure 17) is a small, rugose, button-shaped bone. In anterior view, its proximal border fits well into the shallow notch of the distal articular surface of the preceding phalanx. The anterior surface itself is lens-shaped, with pointed medial and lateral ends. From the distal margin of the anterior face, the bone curves gently toward the posterior border of the proximal articular surface.

The proximal articular surface of the manual phalanx III-1 (Figure 18) is almost flat. It has a subelliptical outline, with a less curved anterior than posterior border. All the margins are accentuated and rugose, but not to such a degree as in phalanx II-1 of the left manus. The surface itself is slightly roughened. The anterior face of phm III-1 has a 

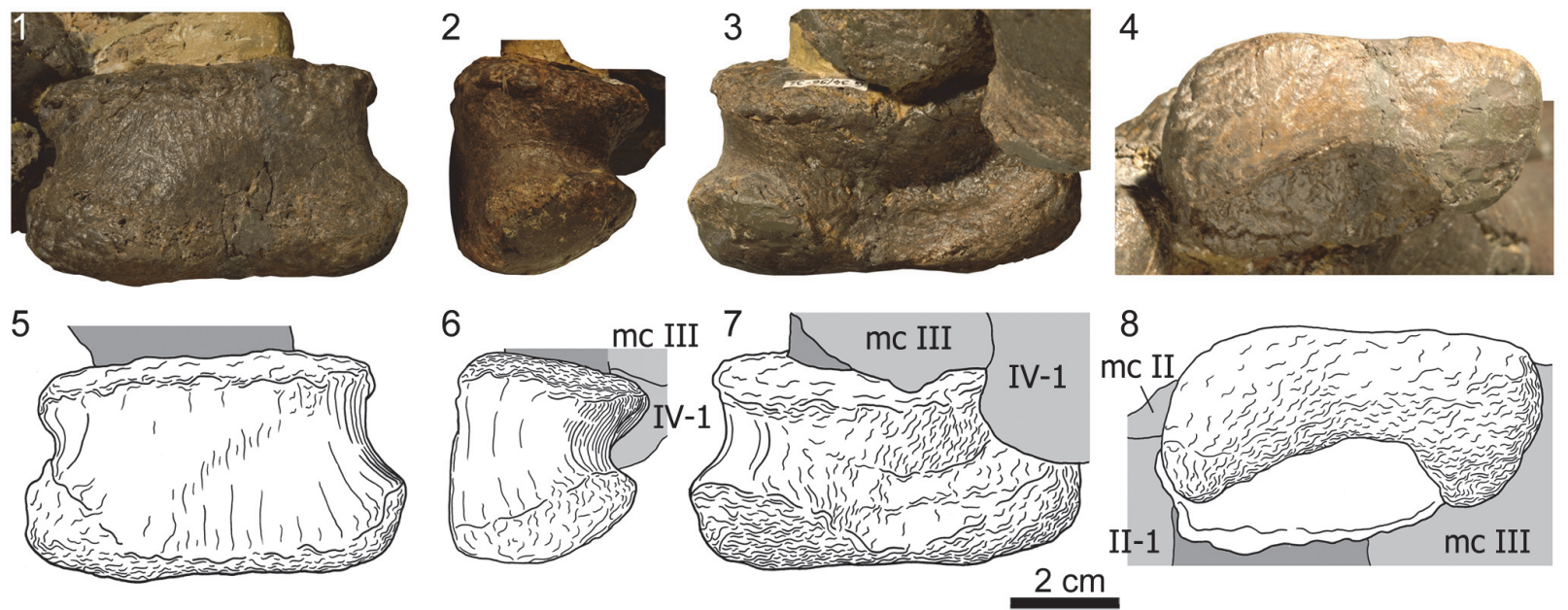

FIGURE 18. Photographs and drawings of the left phm III-1 in anterior $(1,5)$, lateral $(2,6)$, posterior $(3,7)$, and distal views $(4,8)$. Light gray represents adjoining bones, dark gray original matrix. Abbreviations: IV-1, first phalanx of digit IV; mc, metacarpal. Photographs taken by Rosemarie Roth.

subrectangular outline. Its proximal and distal rims are nearly straight. Its medial and lateral margins are much less concave than their corresponding borders in phm II-1. However, as in the latter, the lateral rim of phm III-1 is slightly more curved than the medial one and the transition into the adjacent surface is more distinct laterally than medially. Apart from the proximal and distal margins, the anterior surface is mostly smooth. Only on its proximolateral portion, a weak rugosity occurs. The posterior surface of phm III-1 is marked by a mediolateral convexity of its proximal border, which fades toward the center of the face. It is therefore divided into a semicircular, convex proximal part and a concave distal one. The latter is again separated by a straight and shallow ridge, which extends transversely from the end of the medial knob of the distal surface to the end of the lateral condyle. Proximally from this ridge, the surface is slightly rugose, whereas the distal portion is smooth. The medial surface between the rough proximal margin and the backwards projecting distal condyle is short and smooth. It is strongly convex anteroposteriorly, forming a gently rounded transition from the anterior into the posterior face. The lateral side is longer than the medial one. Other than the distinct separation from the anterior and the posterior face, the surface looks like its medial counterpart. The distal articular surface of phm III-1 is almost flat at its anterior portion, but exhibits a deep notch in its posterior part. The medial and the lateral end of the face are slightly expanded transversely and more so posteriorly, creating two distally flattened knob-like condyles.
Whereas their external extremities are slightly rugose, the center of the distal articular surface shows a similarly indented smooth area as some of the previous phalanges.

The manual phalanx IV-1 (Figure 19) looks almost like phalanx III-1. Compared to the latter, the margin of the proximal articular surface of phm IV-1 is more rugose and more expanded posteriorly. On the anterior face, three small foramina nutricii are clearly visible somewhat distally of its center. Although the posterior border of the proximal surface of phm IV-1 is more expanded than in phalanx III-1, the convexity on the upper part of the posterior surface diminishes faster. Thus, the concave distal portion of the posterior face takes relatively more space than the proximal one. The former part furthermore shows a similar transversely extending ridge as present in phm III-1, but in phm IV-1 it is located slightly more proximally. A last mentionable difference is observable on the lower articular surface of the left phm IV-1. Close to the center of its anterior border, a small but distinct protuberance projects distally. It is strongly accentuated posteriorly, whereas its anterior side is oblique. There is no similar prominence in any of the other phalanges of SMA 0002.

The manual phalanx V-1 (Figure 20) is unlike all other phalanges. It is very irregularly shaped. All the surfaces are differently formed than their analogs in the other phalanges. The proximal articular surface of phm V-1 seems rotated $180^{\circ}$ compared to the proximal faces of the previous phalanges: its anterior margin is rounded and its posterior one nearly straight. As in the other phalanges, the sur- 

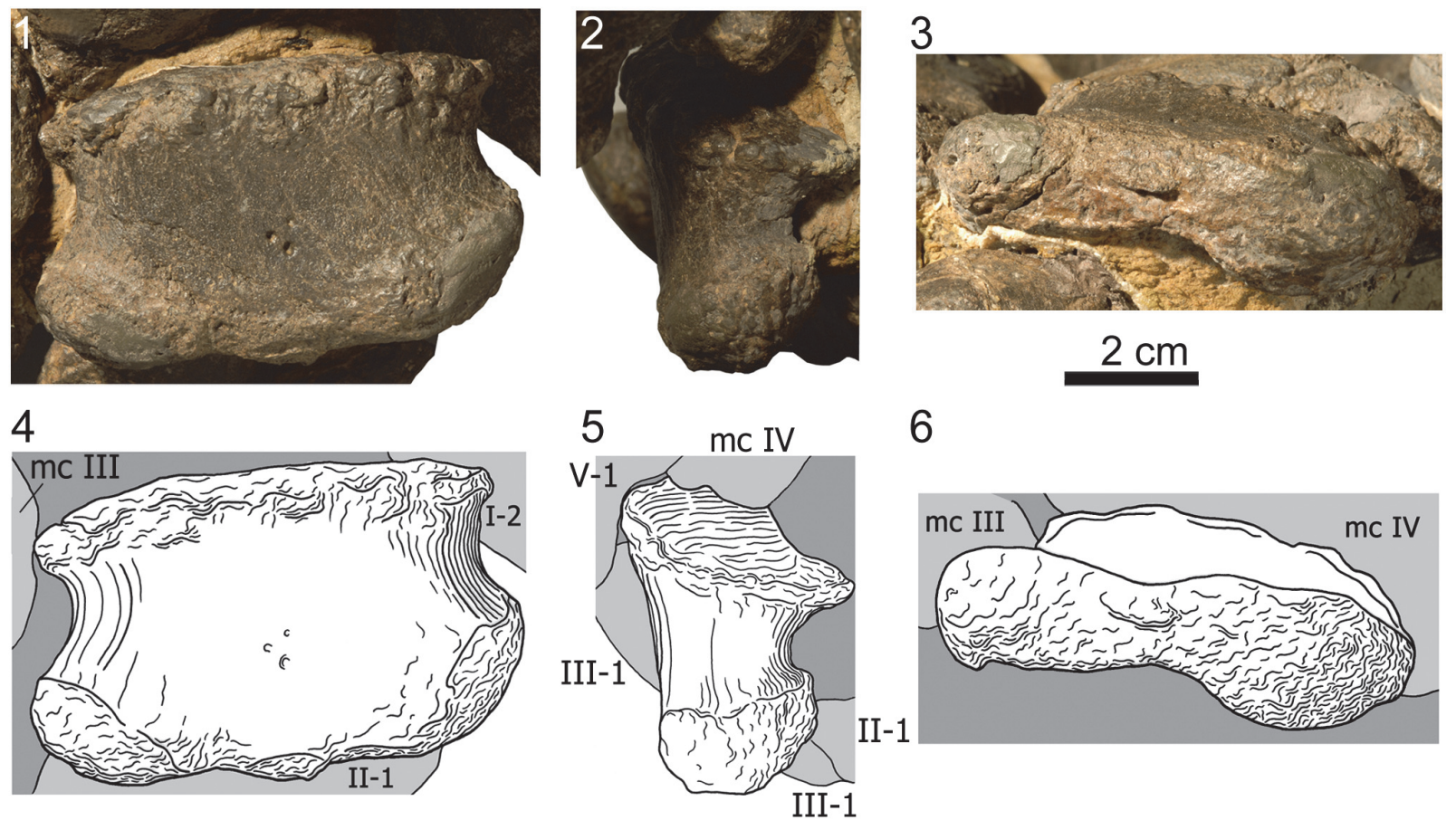

6

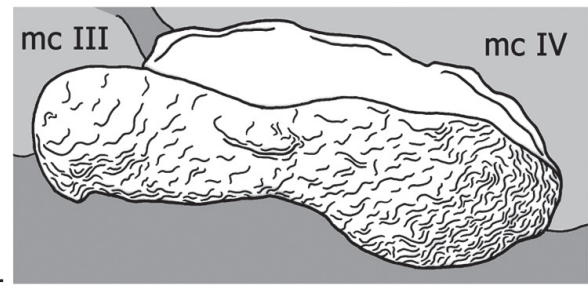

FIGURE 19. Photographs and drawings of the left phm IV-1 in anterior $(1,4)$, lateral $(2,5)$, and distal views $(3,6)$. Light gray represents adjoining bones, dark gray original matrix. Abbreviations: III-1, first phalanx of digit III; mc, metacarpal. Photographs taken by Rosemarie Roth.

face itself is almost flat and slightly rugose. The smooth anterior surface of phm $\mathrm{V}-1$ has a trapezoidal outline. Its proximal border forms the base of the trapezoid and is strongly accentuated but, unlike in the other phalanges, mostly smooth. The medial rim is shorter and less oblique than the lateral one. In contrast to the state in the other phalanges, the transitions into the adjacent surfaces are more distinct at the medial border than laterally. Like the proximal margin, also the distal one is
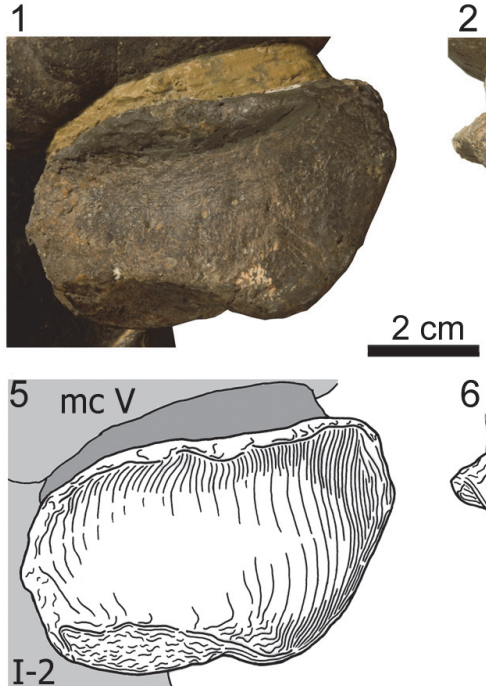

2

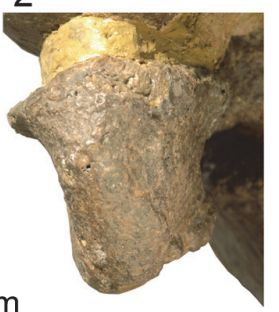

6

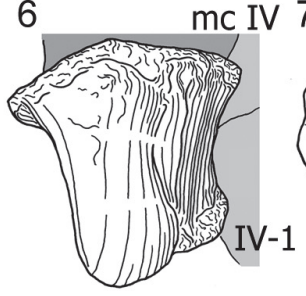

3

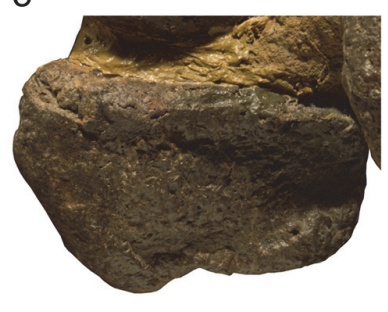

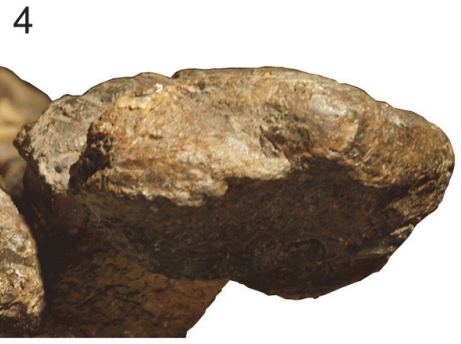

8

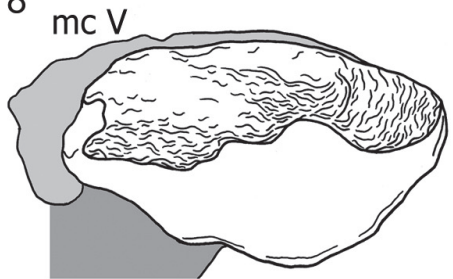

FIGURE 20. Photographs and drawings of the left phm V-1 in anterior $(1,5)$, lateral $(2,6)$, posterior $(3,7)$, and distal views $(4,8)$. Light gray represents adjoining bones, dark gray original matrix. Abbreviations: IV-1, first phalanx of digit IV; mc, metacarpal. Photographs taken by Rosemarie Roth. 


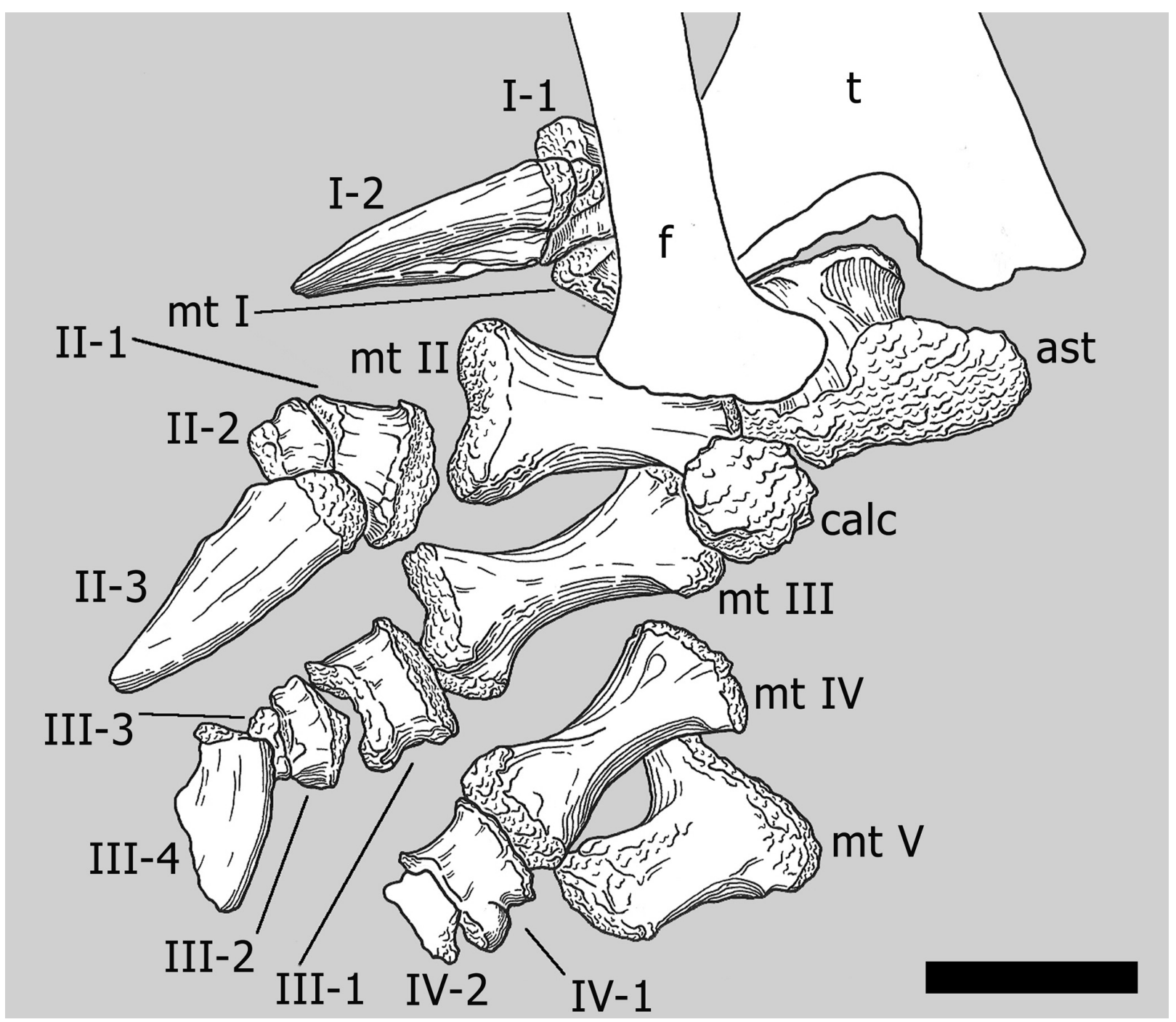

FIGURE 21. General drawing of the left pes in anterior view. Abbreviations: ast, astragalus; calc, calcaneum; f, fibula; IV-1, first phalanx of digit IV; mt, metatarsal; t, tibia. Scale bar equals $10 \mathrm{~cm}$.

expanded anteriorly. Thus, the anterior side is concave proximodistally and slightly convex mediolaterally. The entire posterior face of phm V-1 is roughened. Its outline is similar to the one of the anterior surface, except for the distal border, which is slightly indented, so that two shallow knobs are visible in posterior view. The medial surface is short and very rough. It looks truncated, with very sharp margins toward the anterior and the posterior side. Unlike its opposing surface, the lateral face is not much more than a smooth, gently rounded ridge separating the anterior from the posterior side. Whereas a proximal border is easily distinguishable, the transition into the distal face is continuous. The distal surface of phm V-1 is more or less lens-shaped. The indentation of its posterior portion diminishes toward its anterior border. The entire side is essentially smooth and surrounded by a low but distinct ridge.

\section{Pes}

The bones of the left pes are mounted as they were found and are still partly embedded in matrix (Figure 21; Appendix 3). Hence, only the dorsal (anterior) portions of the elements of the left pes are visible. The tarsal bones are mostly articulated with the tibia and the fibula, and can be seen in posterior (astragalus) and proximal (calcaneum) view. The phalangeal formula of the left pes is 2-34-2-0.

Given the slightly disarticulated state of the elements of the right pes (Figure 4.2), the bones were moved back into articulation for the mount (Figure 5.4). Based on the pictures taken before 

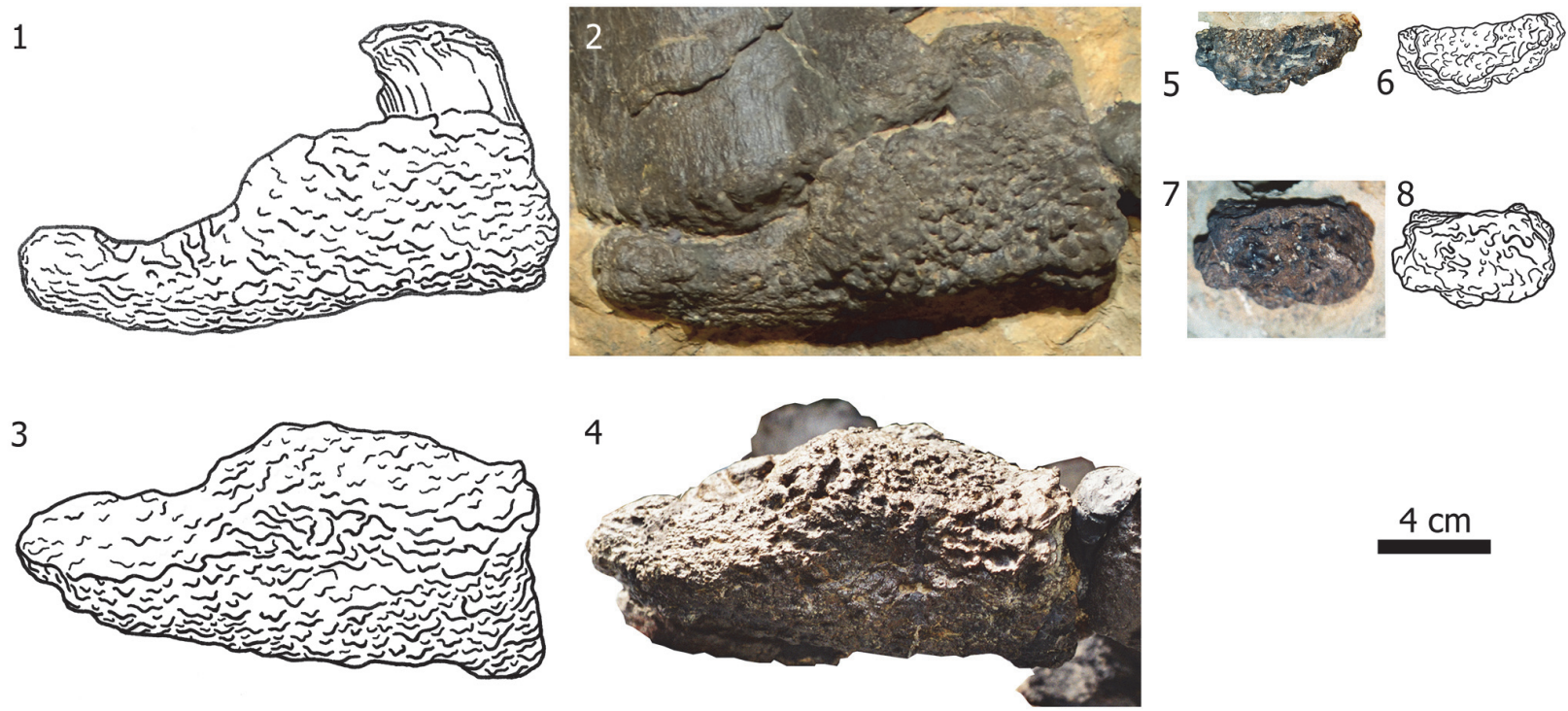

FIGURE 22. Photographs and drawings of the right astragalus (articulated with the tibia) in posterior (1,2), and distal views $(3,4)$, and of the right calcaneum (still partly embedded in matrix) in proximal $(5,6)$, and posterior views $(7,8)$. Photographs taken by Rosemarie Roth (2) and Esther Premru (4, 5, 7).

mounting, the major part of the bones of the Camarasaurus pes can be figured and described from all directions. The recovered elements add to a phalangeal formula of 2-3-4-1-0.

Tarsus (Figure 22). The tarsus consists of two elements: a large, irregularly shaped astragalus, which articulates tightly with the tibia and covers the tops of at least the first three metatarsals, and a small, globular calcaneum between the fibula and the fourth and fifth metatarsal.

The astragali (Figure 22.1-4) are firmly attached to the distal ends of the corresponding tibiae. In both pedes, these bones were not separated during preparation. The observable portions of the astragalus indicate that it is wedge-shaped both in posterior and distal view. In posterior view, it has a subquadrangular lateral half, with right angles at its proximo- and distolateral corners, and a triangular medial half, with a very acute medial end. The distal margin is gently convex. The posterior surface is separated into two parts: the medial portion is still closely associated with the distal end of the tibia, and mostly retains the rugose condition of the proximal and distal surfaces of this bone. The lateral part bears a well-defined, proximodistally deeply concave, smooth surface. This concavity is laterally confined by a thin, vertical ridge between the posterior and the lateral surfaces, which supports the ascending process. The thin ridge separates the proximodistal, smooth concavity of the posterior surface from another, slightly roughened depression on the lateral side of the astragalus, which receives the distal end of the fibula. The anterior edge of the lateral concavity is obscured by matrix on both sides. In distal view, the outline of the astragalus is almost a right triangle. Its most acute angle faces medially and the posterior border of the distal face forms its base. The medial part of the latter is S-shaped, so that the lateral portion extends nearly parallel to the straight anterior margin. The distal surface of the astragalus is heavily rugose and exhibits a considerable anteroposterior, irregular convexity. A pronounced bend occurs at its medial tip, giving rise to a ridge that extends laterally in more or less the same distance to the posterior margin. The rugosity increases in the center and toward the lateral end of the surface, where it blurs the previously distinct ridge. Anterior to the ridge, a small lensshaped concavity is visible in the center of the distal surface.

In proximal view, the calcaneum (Figure 22.58 ) is a rounded bone with a slightly convex surface. A large area in the center of the surface is smooth compared to the rest of the bone and forms a circular facet that corresponds nicely to a similar structure in the distal end of the fibula. Toward the margin, the surface becomes continuously more rugose in all directions. The globular shape of the calcaneum makes the anterior, posterior, medial and lateral sides difficult to interpret. They are all deeply pitted and distinct borders are missing. Due to the preservation in articulation, it can be seen that the calcaneum is slightly wedge-shaped in 
1
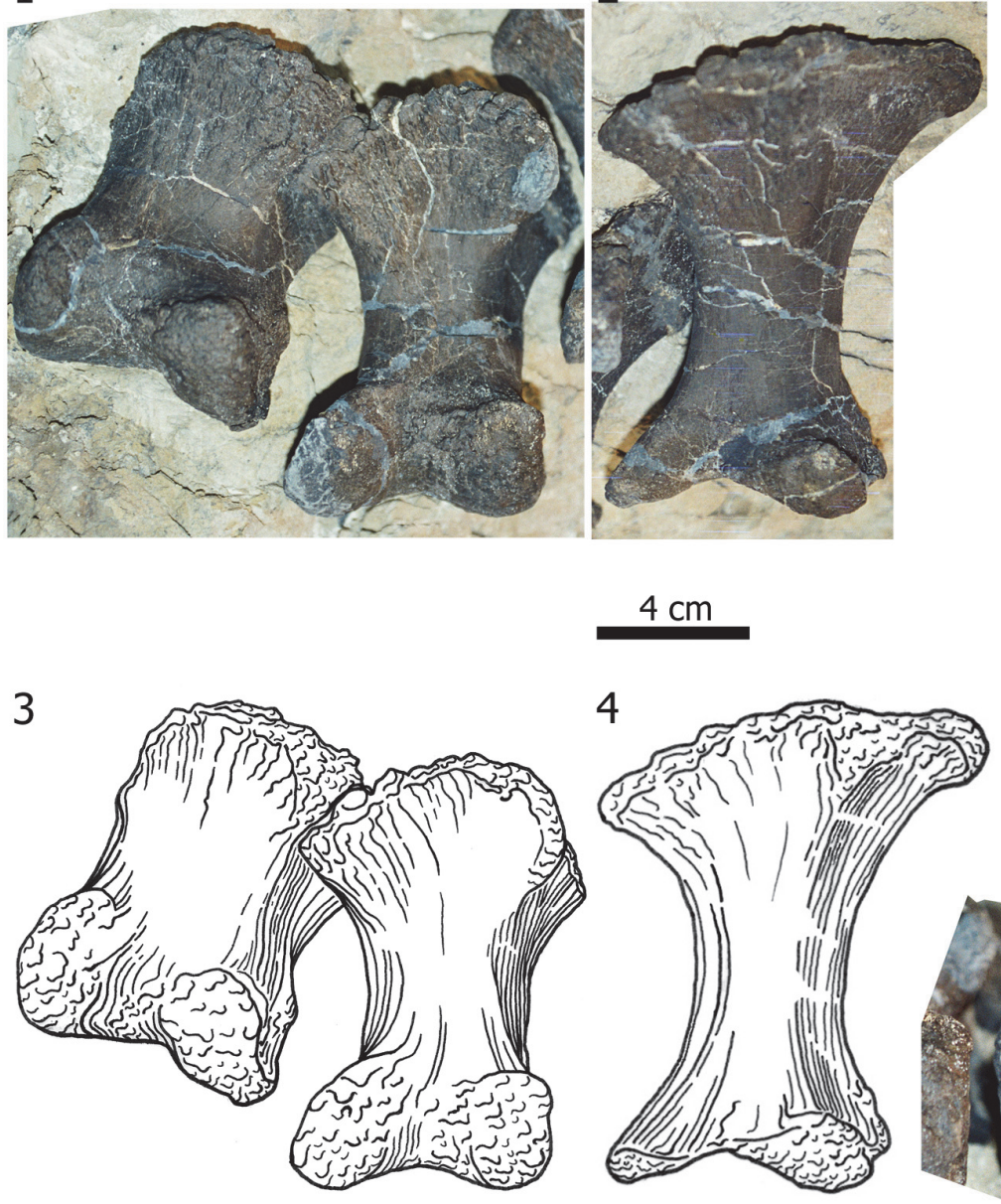

4

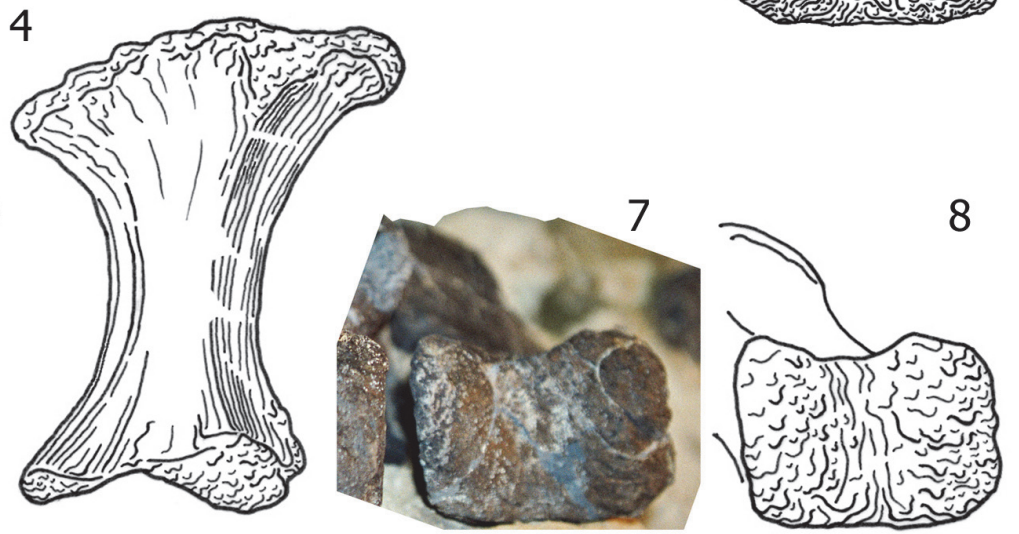

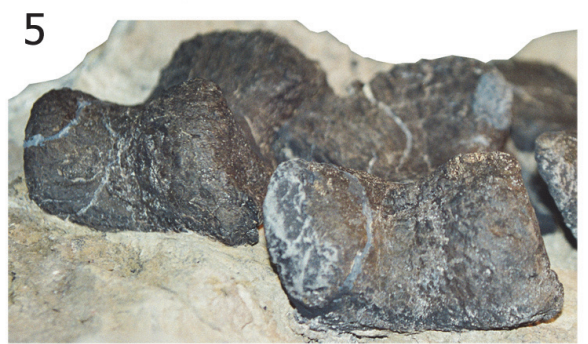

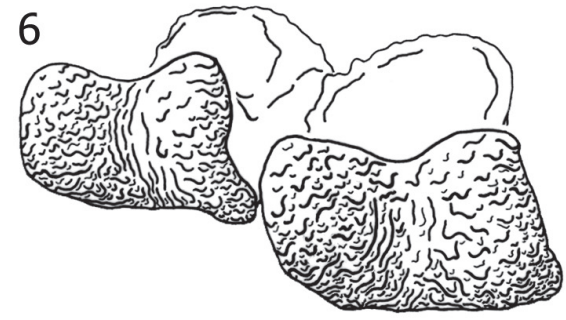

FIGURE 23. Photographs and drawings of the articulated right metatarsals I and II $(1,3,5,6)$, and $\mathrm{mt} I I I(2,4,7,8)$ in posterior (1-4) and distal views (5-8). Posterior surface in 5-8 faces upwards. Photographs taken by Esther Premru.

what is supposed to be the posterior view. It becomes thinner from laterally to medially, where it articulates with the astragalus. Along the posterolateral side of the left calcaneum extends a small ridge, which disappears in medial and anterior directions. The visible parts of the distal surface are heavily rugose and without any characteristics. Metatarsus (Figures 23-25). The metatarsals are short bones compared to the metacarpals. They are of similar lengths, but vary much in stoutness. The metatarsal I with its almost cuboid shape is the sturdiest bone of the series, whereas $\mathrm{mt} \mathrm{III} \mathrm{and} \mathrm{mt}$ IV are the slenderest. Near the proximal ends, all metatarsals show facets for the reception of the neighboring elements of the metatarsus. When articulated, they form a shallow arch.

The proximal articular surface of metatarsal I (Figure 23) appears to be trapezoid and more proximally extended at its posterior border than at its anterior one, enclosing an anteroposteriorly concave surface. The visible portions of the margins of the proximal articular surface are accentuated and very rugose. At the posterolateral corner of the surface, the rim extends into a tapering vertical ridge that extends over a short distance distally. The visible distal portion of the anterior surface is smooth and flat. Whereas its medial margin is straight, the lateral border expands very suddenly approximately $10 \mathrm{~mm}$ proximally from its distal end, and then extends in a right angle to the distal margin. The proximal half of the posterior surface is marked by a striated rugosity, extending from its slightly convex and heavily rugose proximal border distally. The striation gradually disappears until midshaft, so that the lower half of the posterior face is smooth. Both the lateral and the medial margins are weakly concave; the lateral one slightly more so. Both the proximal end and the distal condyles 
are expanded transversely and posteriorly, thus creating a proximodistally concave posterior surface. The medial surface of $\mathrm{mt} \mathrm{I}$ is flat around midshaft and smooth. Its distal end is expanded both medially and anteroposteriorly, so that the surface becomes concave in this part. The proximal portion of the lateral surface is marked by a distinct concavity, which is separated from the posterior surface by the short vertical ridge mentioned above. Distally, the lateral surface expands suddenly into a slightly rugose, distinct facet. This abrupt expansion is more pronounced and occurs more proximally in the anterior portion of the lateral surface than in the posterior one, resulting in an oblique and sharp ridge that separates the facet from the more proximal part of the lateral face. The anterior margin of the distal articular surface of $\mathrm{mt} \mathrm{I}$ is accentuated and bent somewhat in proximal direction. It is slightly depressed in the middle to allow articulation with its adjacent phalanx. This emargination deepens in posterior direction, forming the two more or less distinct and slightly rugose condyles, which are equally long.

The visible area of the proximal articular surface of metatarsal II (Figure 23) indicates a subquadrangular outline. In the articulated metatarsus, the two proximal surfaces of $\mathrm{mt} \mathrm{I}$ and $\mathrm{mt} \mathrm{II} \mathrm{form} \mathrm{a}$ large, continuous facet, which is slightly rugose and flat, but becomes somewhat concave laterally. In anterior view, $\mathrm{mt}$ II is relatively broad, but less stout than $\mathrm{mt}$ I. Both its proximal and distal extremities are strongly expanded, so that they are subequal in width to their equivalents in $\mathrm{mt} \mathrm{I}$ (Table 1). However, unlike in $\mathrm{mt} \mathrm{I}$, the shaft of $\mathrm{mt}$ II gradually expands distally, resulting in a regularly concave medial and an alike lateral rim. The entire anterior surface of $\mathrm{mt} \mathrm{II}$ is flat and smooth. The transition of the anterior face into the medial side of the bone is much more rounded than the one into the lateral surface. At midlength of the inner margin of the anterior face, there is a small foramen nutricium. The posterior surface of $\mathrm{mt}$ II has a similar outline as the anterior one. In addition to the transverse expansions of the extremities of this bone, its ends also exhibit distinct deflections in posterior direction, resulting in a proximodistally concave posterior side. This bending of the bone is most remarkable proximally, and accentuated by the proximal margin, whose heavy rugosity extends to a slightly lesser degree onto the shaft, gradually vanishing toward midlength. The distal portion of the surface is smooth. The medial side of $\mathrm{mt} \mathrm{II}$ is proximodistally concave, due to the above mentioned expansion of the ends of the bone. Proxi- mally, it shows a slightly rugose, flat facet. Besides the latter, the medial face of the element is smooth and anteroposteriorly convex. The morphology of the lateral side is much like the one in $\mathrm{mt} \mathrm{I}$ : there is a slightly roughened, but less distinct facet than the one in $\mathrm{mt} \mathrm{I}$ at the distal end of $\mathrm{mt} \mathrm{II}$. In the proximal half of $\mathrm{mt} \mathrm{II}$, the anterior and the posterior margin extend far anterolaterally and posterolaterally respectively, including a marked concavity for the reception of $\mathrm{mt}$ III. The distal portion is flat and not as expanded as the upper one. In anterior view, the distal articular surface of $\mathrm{mt}$ II looks saddle-shaped as in $\mathrm{mt} \mathrm{I}$. The condyles of $\mathrm{mt} \mathrm{II}$ are much less distinct in this aspect than when seen in posterior view, where they are separated by a considerably deep intercondylar groove. Laterally, the plane of the distal face and the longitudinal axis of $\mathrm{mt} \mathrm{II}$ include an angle of approximately $80^{\circ}$. The surface itself is mostly smooth. Only at its margins, some rugosities can be found, but to a much lesser degree than at the rims of the proximal articular surface.

The proximal articular surface of metatarsal III (Figure 23) is rugose and mediolaterally convex. Its posterior margin extends further in proximal direction than its anterior one. Medially and, to a higher degree, laterally, the rugosity passes onto the diaphysis, where it forms flattened facets for the articulation with the neighboring metatarsals. The anterior portions of these facets are more strongly developed than their posterior ones. Like $\mathrm{mt} \mathrm{II,} \mathrm{mt}$ III is almost symmetrical in anterior view, regarding its longitudinal axis. Both extremities are expanded anteriorly and mediolaterally to a similar degree. Therefore, a shallow longish depression dominates the anterior surface of the element. This concavity is deepest proximally and distally. The surface of the shaft is smooth as in $\mathrm{mt} \mathrm{II}$, and it also exhibits a small nutrient foramen at its medial margin. This foramen is situated slightly more distally than in $\mathrm{mt}$ II. The posterior side of $\mathrm{mt} \mathrm{III} \mathrm{resembles} \mathrm{its} \mathrm{anterior}$ counterpart: it shows similar expansions of its extremities, and therefore also an alike concavity of the surface. Other than in the anterior face, where the upper area is only slightly wrinkled, the heavily rugose pattern of the proximal articular surface extends onto the proximal portion of the posterior side, fading slowly toward midlength. The distal half of this surface remains smooth. The medial and the lateral side of $\mathrm{mt} \mathrm{III} \mathrm{are} \mathrm{smooth} \mathrm{and}$ anteroposteriorly convex at midshaft. They both become concave distally, forming the medial and the lateral wall of the condyles. The concavity on the lower medial surface is much less developed 

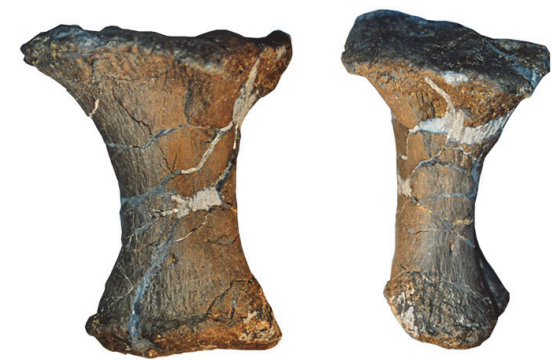

1

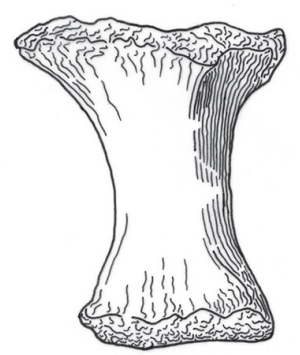

2

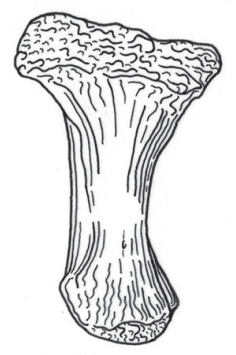

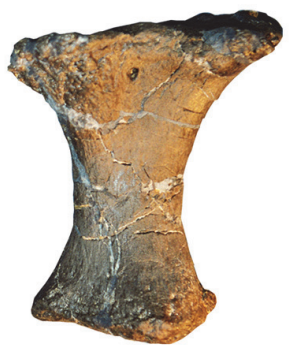

3

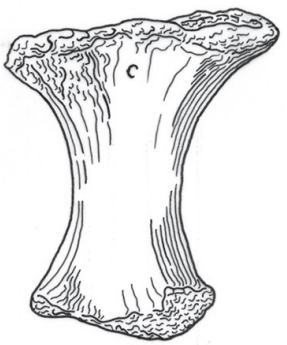

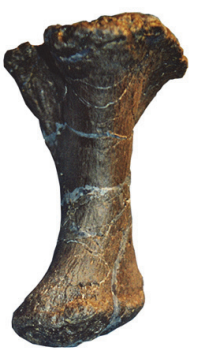

4

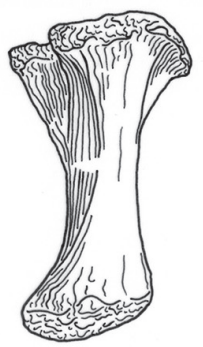

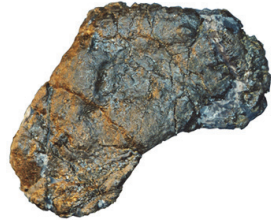

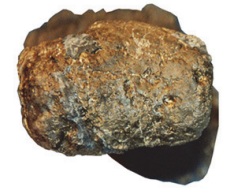

5

6

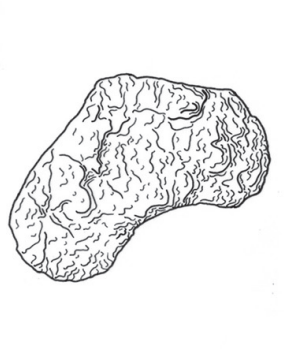

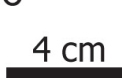

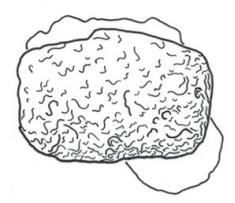

FIGURE 24. Photographs and drawings of the right metatarsal IV in anterior (1), medial (2), posterior (3), lateral (4), proximal (5), and distal views (6). Photographs taken by Esther Premru.

than the one in the same area of the lateral face. Since none of the metatarsals III were prepared entirely, it is difficult to determine how their medial and lateral sides change shape toward their proximal ends. However, it is clearly visible that they expand medially and laterally, respectively, and that at least the proximal portion of the lateral surface becomes slightly concave, like the distal end of the same face. The distal articular surface of $\mathrm{mt}$ III stands in an angle of approximately $85^{\circ}$ to the long axis of the shaft. It has an outline that is narrower than the one of its analogous face on the second metatarsal, and the intercondylar groove is not as deep as in $\mathrm{mt} \mathrm{I}$ and $\mathrm{mt}$ II. Contrary to the gently rounded lateral condyles of the latter element, the outer condyle of mt III is strongly curved anteroposteriorly and ends in both directions in a small pointed tubercle.

The proximal articular surface of metatarsal IV (Figure 24) has a wide V-shaped outline. Its two legs are of unequal length and stand at an angle of approximately $115^{\circ}$. The inner rim of the slightly longer shank of the ' $\mathrm{V}$ ' borders a flattened medial facet for the reception of the corresponding lateral facet of $\mathrm{mt}$ III. The somewhat shorter shank faces anteriorly. Overall, the proximal articular surface is flat and weakly rugose. In anterior view, the shaft of $\mathrm{mt}$ IV is mediolaterally convex at midlength and broadens toward both extremities, with the proximal expansion being much more accentuated than the distal one. Especially the proximolateral corner of the anterior face is strongly expanded. Thus, its lateral margin is much more concave than its medial one, which has a very distinct proximal end in the angled region of the $\mathrm{V}$-shaped anteromedial rim of the upper articular surface. The anterior side itself is mostly smooth but becomes slightly rugose in its upper part. The posterior face exhibits a marked concavity in its proximal portion, resulting from the V-shaped outline of the upper articular surface. At the deepest point of this depression, there is a rather large foramen nutricium. Toward midshaft, the concavity flattens, but deepens again further distally, although to a lesser degree than in the proximal part of the posterior side. Proximomedially, the otherwise smooth surface is slightly rugose. The medial side of mt IV carries two articulation facets: a major, proximal one, which is only slightly rugose at its outermost part, and a distal one, which is of approximately half the size of the former, and bears a distinct, weakly striated rugosity. Between those facets, the shaft is flat and smooth. The nutrient foramen, which can be found at the medial margins of the anterior surfaces of $\mathrm{mt}$ II and $\mathrm{mt} \mathrm{III,} \mathrm{marks} \mathrm{the} \mathrm{medial} \mathrm{side} \mathrm{of} \mathrm{mt} \mathrm{IV}$, and is shifted more distally in respect to its position in $\mathrm{mt}$ III. The upper part of the lateral face borders the end of the short leg of the V-shaped proximal articular surface and is thus not much expanded anteroposteriorly. Whereas its anterior margin is 

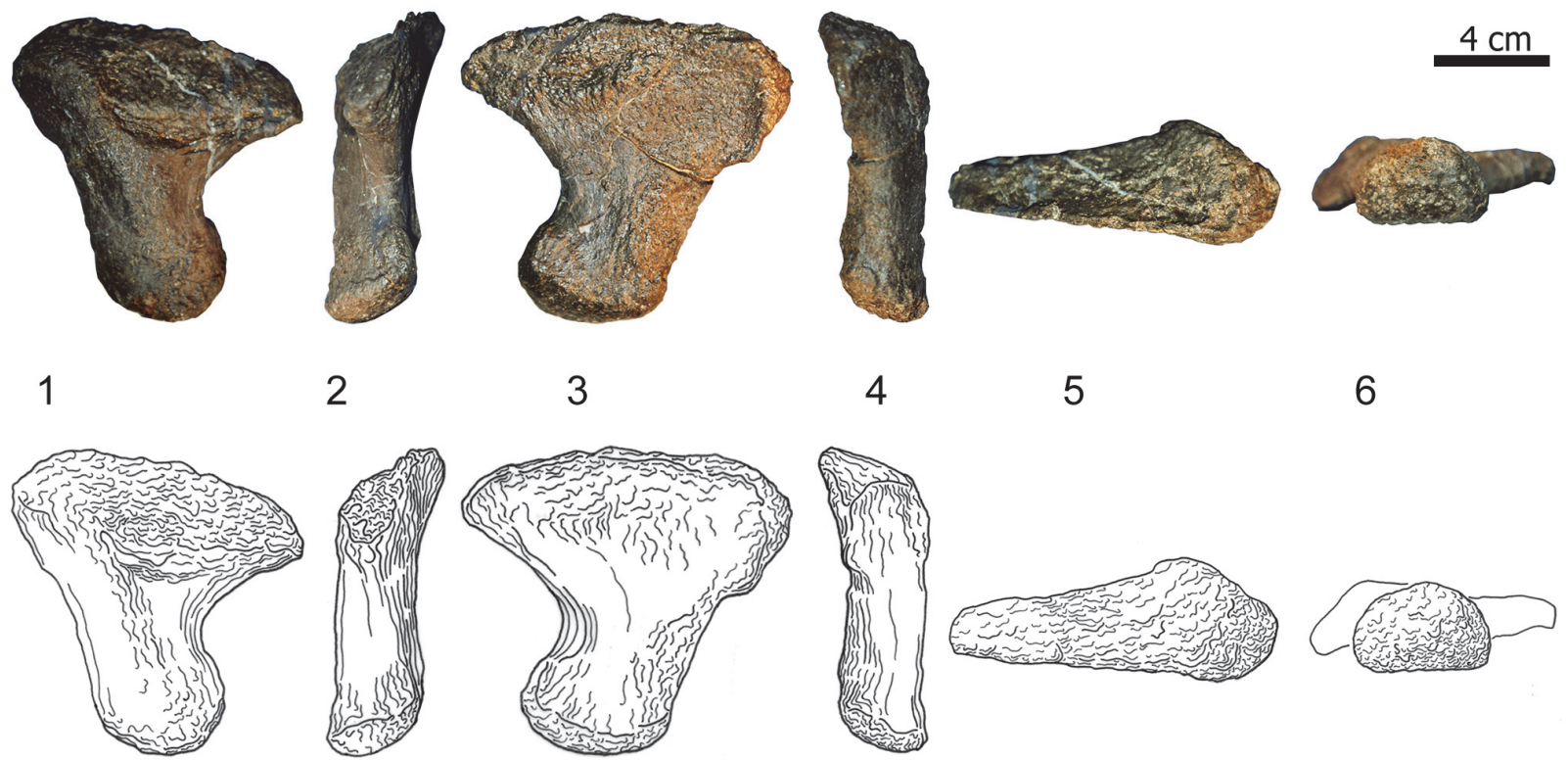

3

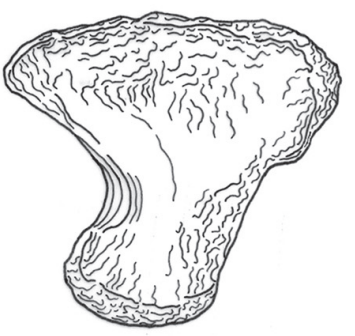

4

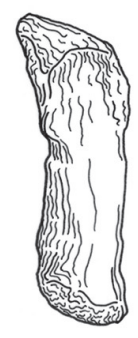

5

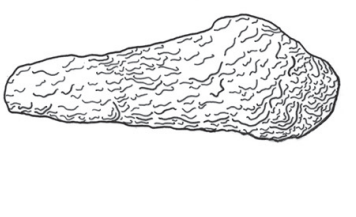

6

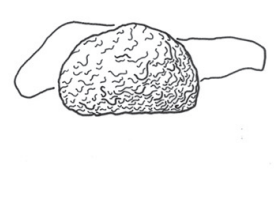

FIGURE 25. Photographs and drawings of the right metatarsal $V$ in anterior (1), medial (2), posterior (3), lateral (4), proximal (5), and distal views (6). Photographs taken by Esther Premru.

straight, the posterior rim is curved, due to the posterior expansion of the distal articular condyles. Unlike the medial surface of $\mathrm{mt} I \mathrm{~V}$, the lateral one is smooth, convex anteroposteriorly, and without any distinct rugosities at its ends. The condyles of the distal articular surface are only vaguely developed, and are separated by a shallow intercondylar groove. The surface stands perpendicular to the long axis of the shaft, has a transverse rectangular outline, and is only slightly rugose.

The proximal articular surface of metatarsal $\mathrm{V}$ (Figure 25) is greatly expanded mediolaterally, with a stronger medial than lateral component. This results in a paddle-shaped bone in anterior as well as posterior view. The expanded medial corner of its proximal articular surface is underlying metatarsal IV. The outline of the entire articular face of $\mathrm{mt}$ $\mathrm{V}$ is subtriangular. The base of the triangle forms the posterior rim of the surface and its shortest leg is directed anterolaterally. The lateral edge of the proximal articular surface is gently rounded without a distinct border with the lateral side. The surface itself is flat, rugose and slightly oblique, with the posterior margin expanding more proximally than the anterior one. The anterior face of the shaft is convex transversely, and on its highest point and at its extremities, it bears very faint rugosities. Given the medially greatly expanded proximal end, the medial margin of the diaphysis is strongly concave, whereas its lateral border is almost straight. In con- trast, both the proximal and the distal rims are convex. Except for its medialmost part, the entire posterior surface of $\mathrm{mt} \mathrm{V}$ is at least slightly rugose. In its lateral area, it exhibits a ridge that proximally forms the outer margin of the bone, but then suddenly curves inward onto the distal portion of the plantar surface, mirroring almost exactly the medial margin of the shaft. Because of this ridge, the surface is mostly concave. The medial and lateral faces of $\mathrm{mt} V$ are not much more than smooth, thin margins over most of their length. Only distally, they expand slightly anteroposteriorly. The only remarkable feature concerns the proximal half of the lateral side, the distal end of which is formed by the rugose ridge described above. Toward the proximal end of the bone, this thin ridge expands into the more or less blunt lateral tip of the upper articular surface. The distal articular surface has a semicircular outline, with the straight edge facing posteriorly. It is twisted $5^{\circ}$ to $10^{\circ}$ in respect to the base of the proximal articular surface. The circular portion of the outline of the lower face corresponds largely to the convexity of the anterior side of the shaft. The entire distal surface is anteroposteriorly and mediolaterally convex and only slightly rugose. The medial edge of the lower articular surface projects farther distally than the lateral one, so that the facet stands in an angle of approximately $105^{\circ}$ to the long axis of the element in anterior view. 
Pedal phalanges (Figures 26-31). The proximal articular surface of the pedal phalanx I-1 is almost flat medially but concave laterally, where it is also narrower anteroposteriorly than at its medial margin. The posteromedial corner is the most pronounced of this side. The medial border thus shows a notch at midlength. In contrast to the rugose margins, the surface itself is smooth. The anterior face has a trapezoid outline with expanded ends. Its lateral rim is shorter than its medial one. The surface is marked by a slightly developed rugosity extending obliquely from the lateral half of its heavily protruding proximal border to a point close to the medial margin of the distal articular face. There, the rugosity indicates the medial margin of a concavity in the distal portion of the anterior side. This depression starts close to midlength of the anterior surface and spreads out toward the distal extremity of php $\mathrm{I}-1$, leading smoothly and gradually into the concavity of the distal articular face. In posterior view, the difference in length of the medial and the lateral margins is more pronounced than anteriorly. The sigmoid curve of the proximal border, which is very distinct and rugose, can be clearly observed. The entire surface is concave mediolaterally, and more rugose laterally than medially. The concavity passes into the intercondylar groove. The medial face of php l-1 is relatively smooth. Its proximal rim is flat and more expanded plantarly than anteriorly. The distal margin is convex, shorter, and inversely extended compared to the proximal edge. The narrow lateral face bears some proximal rugosities. Its upper margin is concave, whereas its lower one is convex. Posteriorly, the distal condyle is not clearly accentuated and passes into the oblique but plane plantar margin of the lateral face. In contrast, the anterior rim extends subparallel to the long axis of the bone, and is bordered by very distinct proximal and distal ends. The distal articular surface is dominated by two relatively large condyles. The medial condyle projects further distally than the lateral one. The intercondylar groove is much more pronounced posteriorly than anteriorly. Except for the rugose margins, the lower articular surface is almost smooth.

The first pedal ungual (php I-2) is the largest of three claws present in the pes. The entire claw is anteroposteriorly tall and mediolaterally narrow. It is strongly curved such that its blunt and pitted distal tip pointed plantarly and slightly laterally. The proximal surface of php I-2 is broad at its base, but tapers toward its anterior end. Its broad posterior portion bears an articulation facet, which occupies approximately the lower half of the entire proximal side. The articular facet is divided into a small, almost flat medial and a slightly larger, concave, lateral area, which - in respect to the medial one is somewhat shifted distally and anteriorly. Therefore, the posterior edge of the proximal face is oblique and the two areas of the facet look like two adjacent steps of a spiral staircase. This arrangement increases the lateral deflection of the ungual in respect to the orientation of the digit. The narrow anteriormost part of the proximal side of php I-2 is curved laterally and projects slightly proximally. On these narrow upper portions of both the right and the left ungual I-2, there is a tiny bone fused with the proximal surface, which was described in detail and interpreted to represent ossified tendon insertions by Tschopp et al. (in press). The proximal portion of the medial face of the first ungual is gently convex as a result of the widening of the base of the proximal surface. Toward the distal tip, the convexity flattens. The entire surface is structured with several discreet grooves. In the posterior fourth of the medial side, approximately at midlength, a deep canal leading distally into a nutrient foramen is visible. On the proximal part of the lateral surface of php I-2, there is a very constricted convexity at its base. The anterior third of the outer face is flat or even gently concave. Toward the distal tip of the first ungual, the flat anterior area passes into the convexity, which occupies the distal approximately three fourths of the almost smooth lateral side. The posterior surface shows a distinct ridge extending from its proximomedial corner obliquely to the center of its lateral margin. Further distally, the face is almost flat and thins out toward the tip, where it curves very slightly medially and also exhibits a distinct canal leading from the tip along the lateral rim for approximately one fourth of the length backwards into a nutrient foramen.

The pedal phalanx II-1 is proximodistally longer, mediolaterally wider, but anteroposteriorly less deep than php I-1. The proximal articular surface of php II-1 has very rugose margins, but is otherwise rather smooth. Its posterior portion projects further in proximal direction than the anterior part. The medial and the lateral ends of the facet curve somewhat distally. As in php I-1, the lateral part of the proximal face is shorter than the medial one, and the posteromedial corner is the most pronounced of all corners of the surface. In the left pes, a very deep concavity occupies the upper articular face (see Tschopp et al., in press). The 

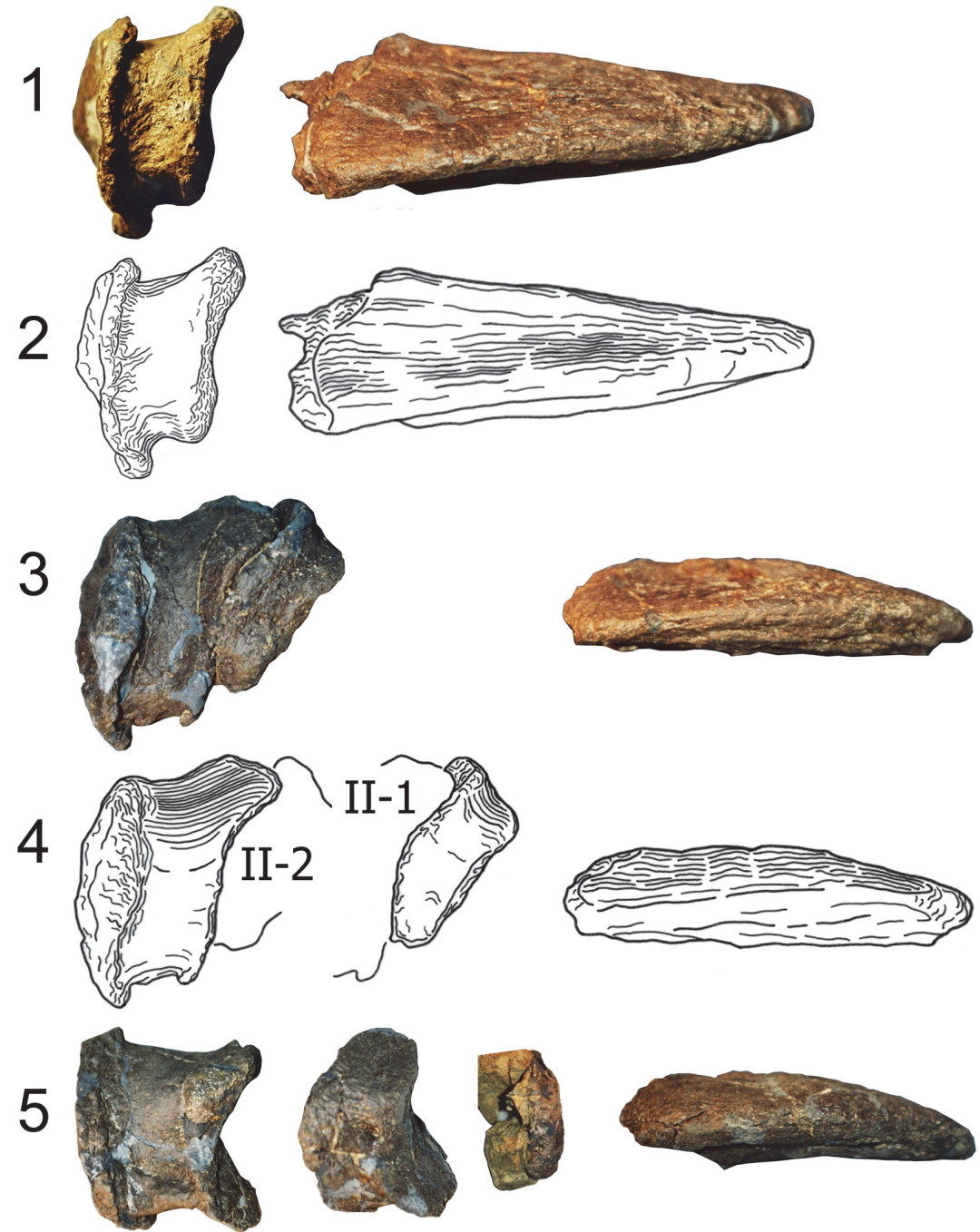

6
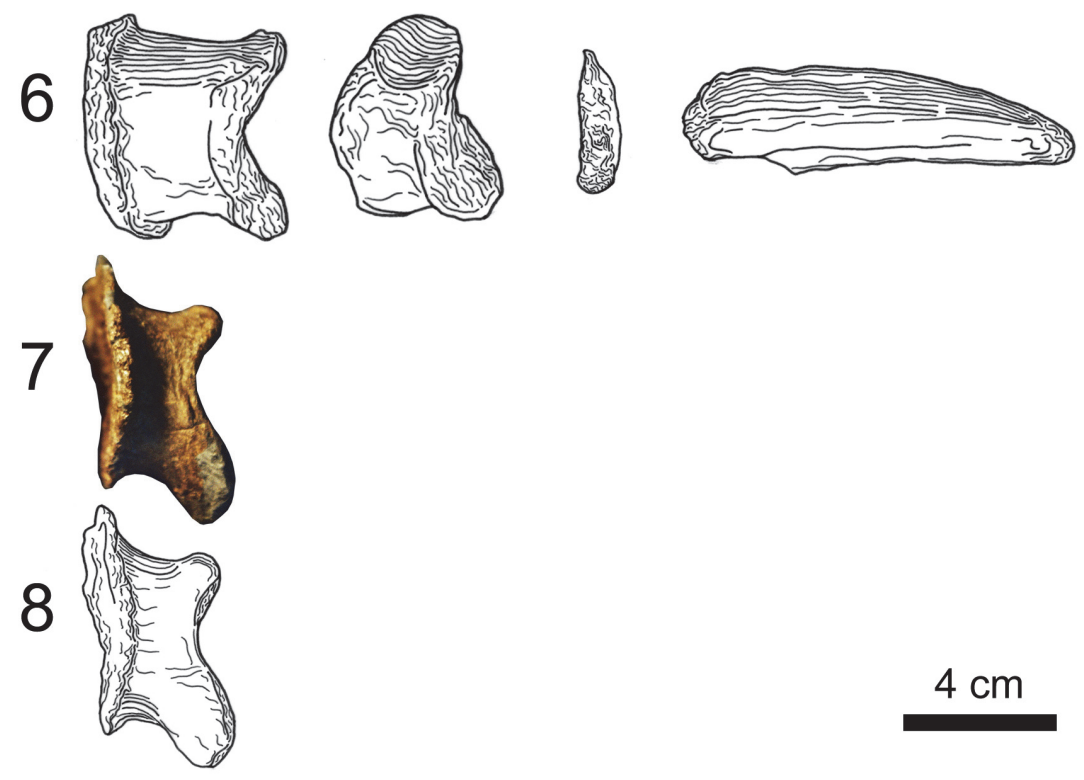

$4 \mathrm{~cm}$

FIGURE 26. Photographs and drawings in anterior view of the phalanges of the right pedal digit I $(1,2)$, digit II $(3,4)$, digit III $(5,6)$, and digit IV $(7,8)$. Abbreviations: II-1, first phalanx of digit II. Photographs taken by Esther Premru. 

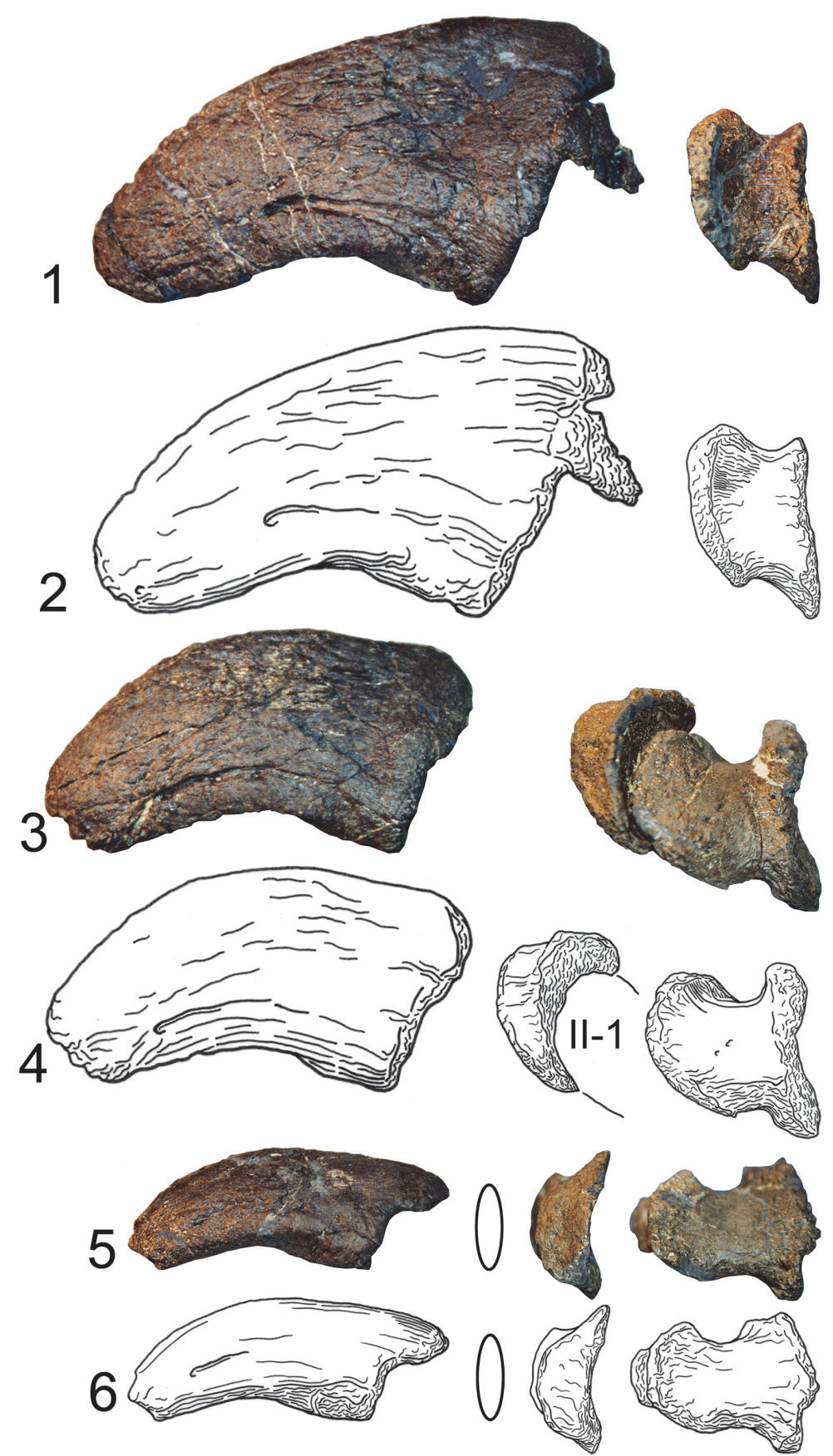

$4 \mathrm{~cm}$
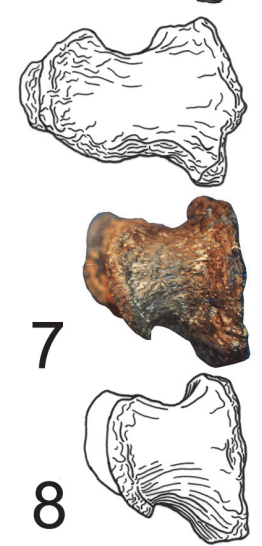

FIGURE 27. Photographs and drawings in medial view of the phalanges of the right pedal digit I $(1,2)$, digit II $(3,4)$, digit III $(5,6)$, and digit IV $(7,8)$. The oval outlines in (5), (6) indicate an element where no photographs were available in medial view (php III-3). Abbreviations: II-1, first phalanx of digit II. Photographs taken by Esther Premru. 


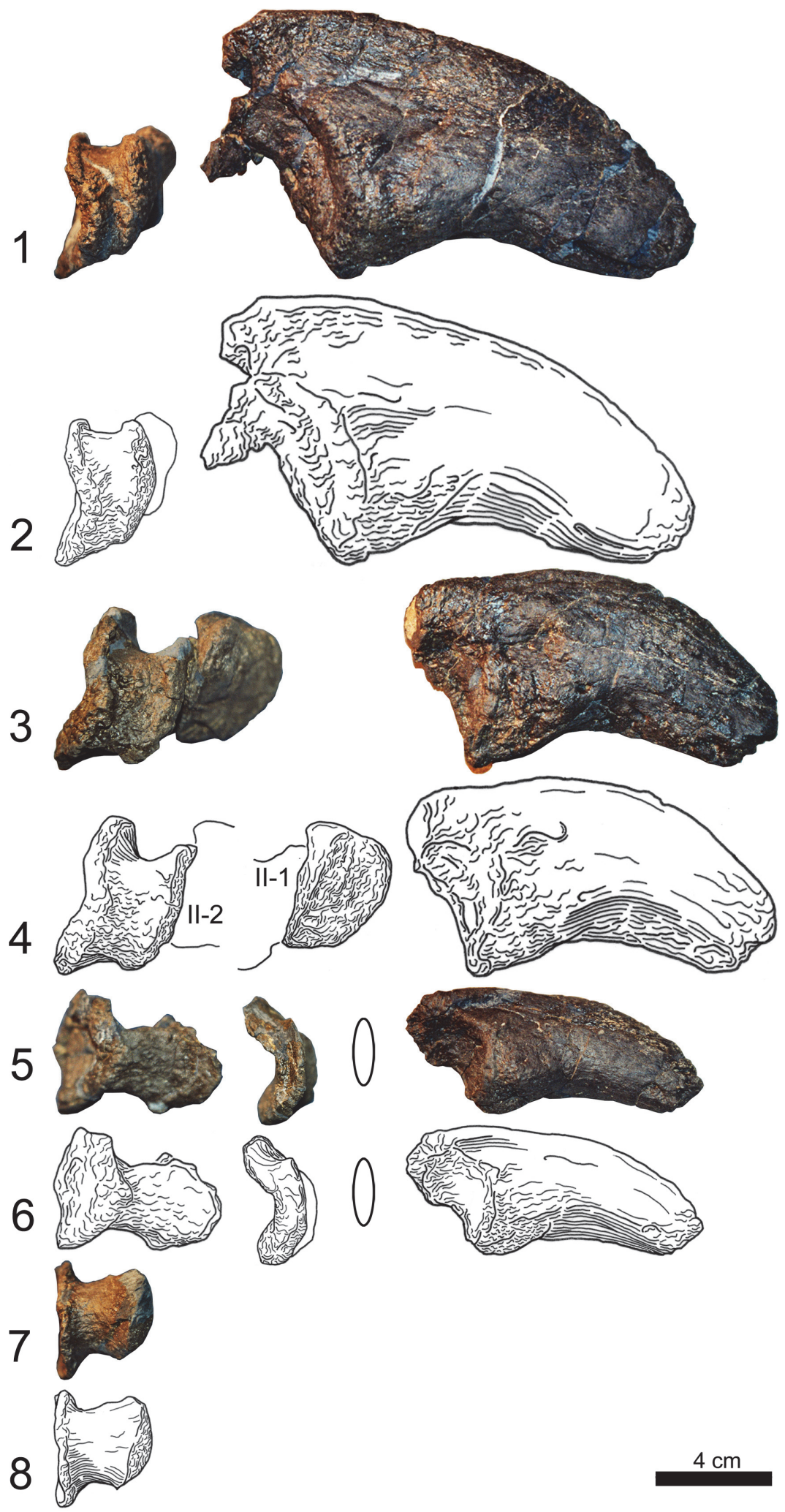

FIGURE 28. Photographs and drawings in lateral view of the phalanges of the right pedal digit I $(1,2)$, digit II $(3,4)$, digit III $(5,6)$, and digit IV $(7,8)$. The oval outlines in $(5),(6)$ indicate an element where no photographs were available in lateral view (php III-3). Abbreviations: II-1, first phalanx of digit II. Photographs taken by Esther Premru. 

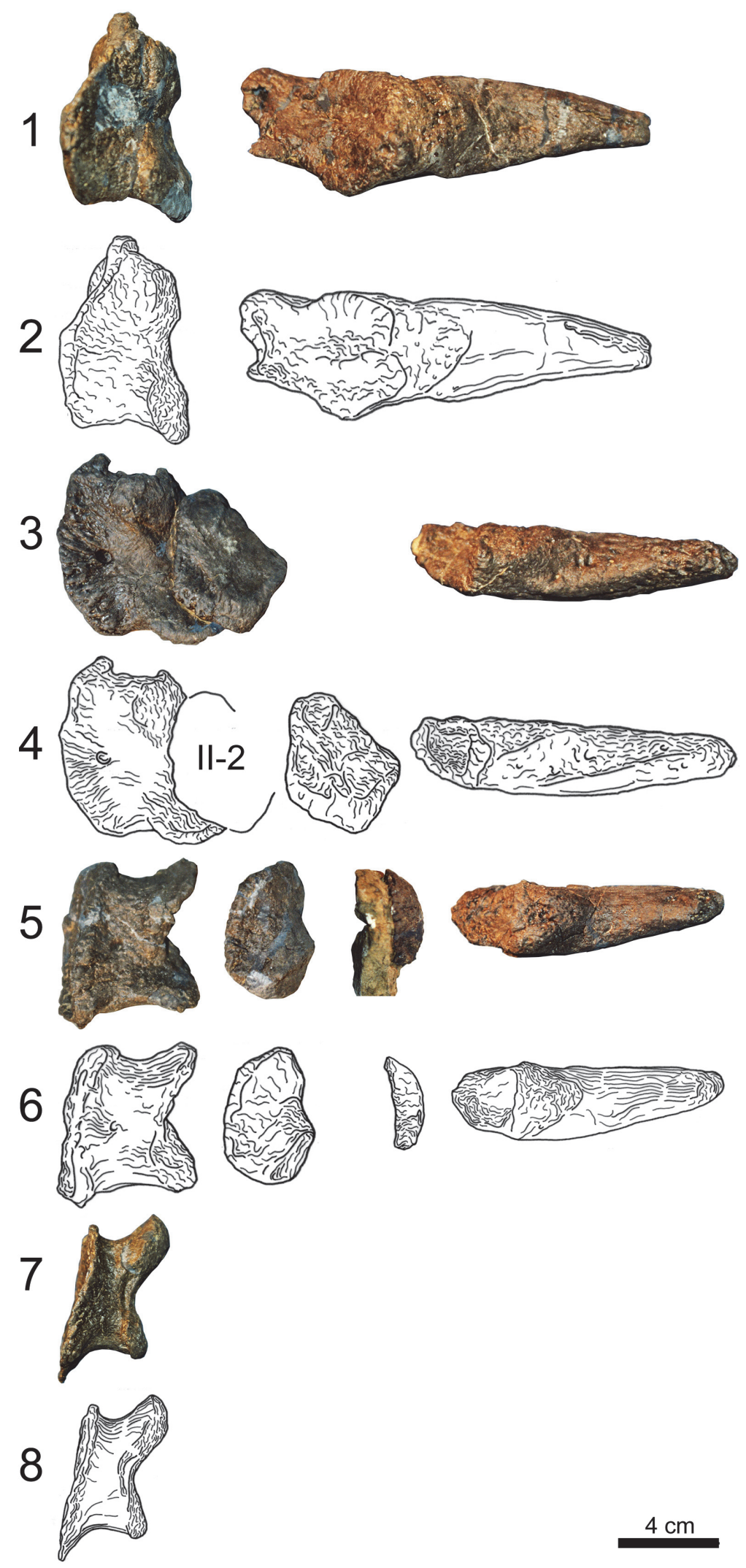

FIGURE 29. Photographs and drawings in posterior view of the phalanges of the right pedal digit I $(1,2)$, digit II $(3,4)$, digit III $(5,6)$, and digit IV $(7,8)$. Abbreviations: II-2, second phalanx of digit II. Photographs taken by Esther Premru. 

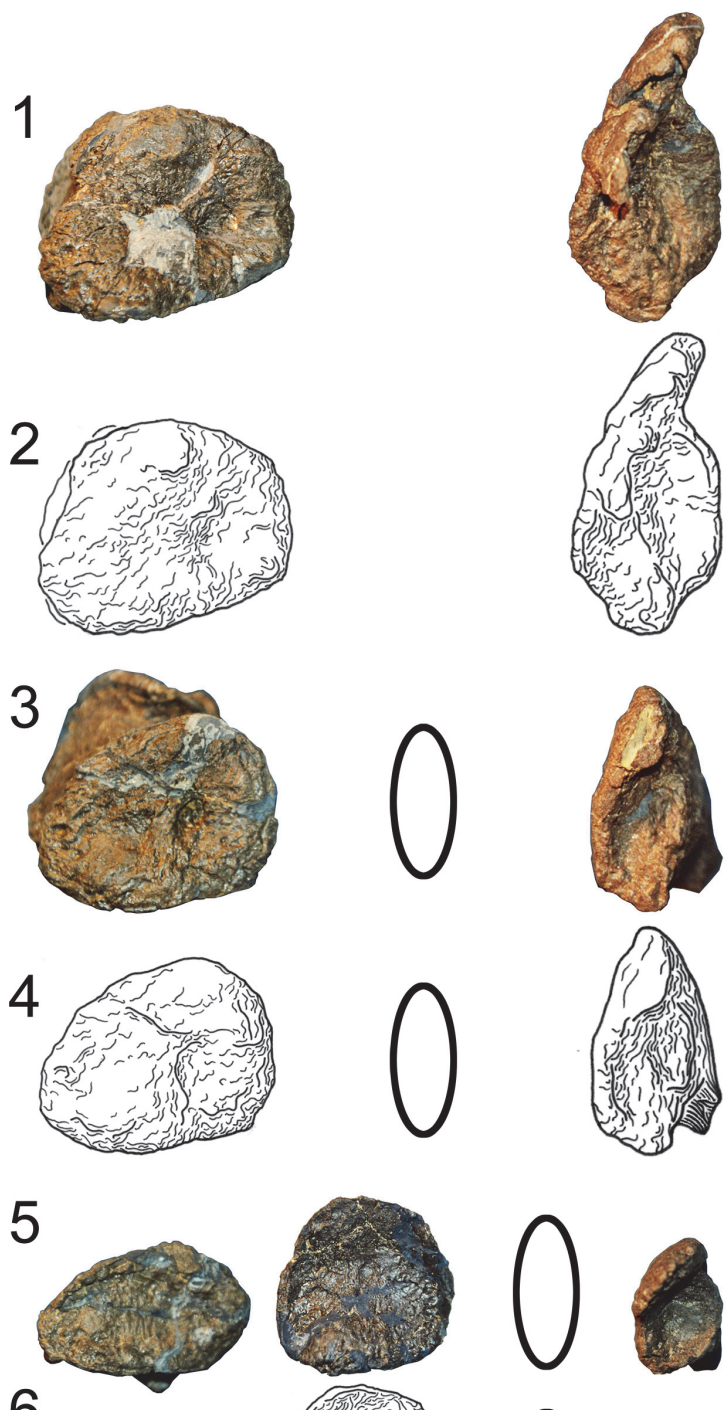

6
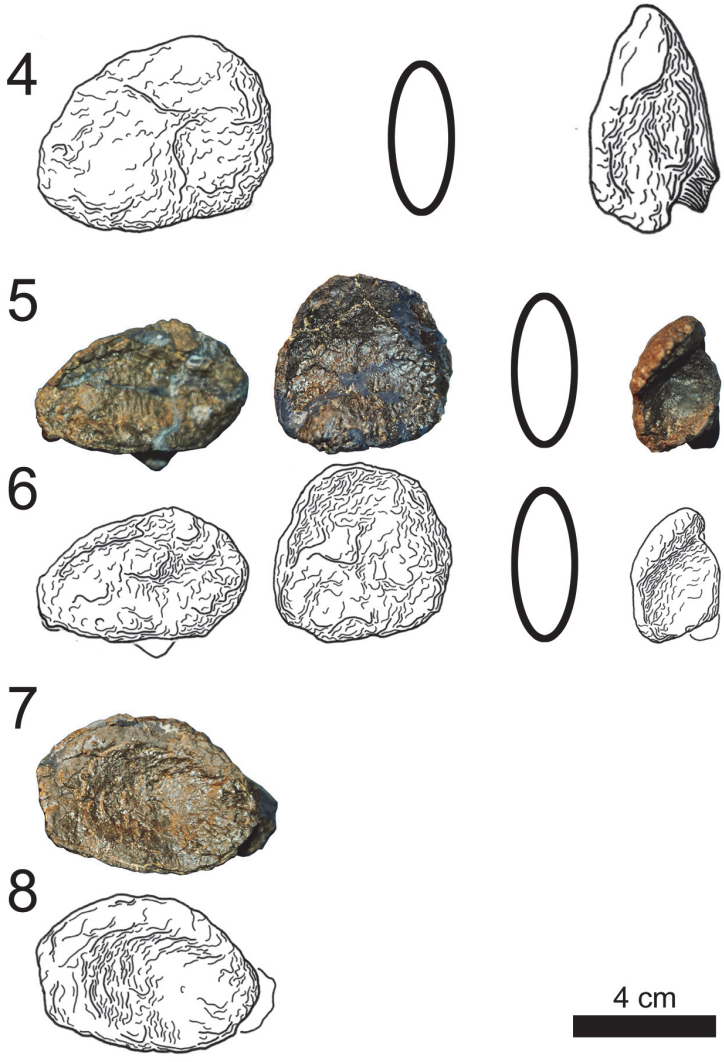

FIGURE 30. Photographs and drawings in proximal view of the phalanges of the right pedal digit I $(1,2)$, digit II $(3,4)$, digit III $(5,6)$, and digit IV $(7,8)$. The oval outlines in 3-6 indicate an element where no photographs were available in proximal view (php II-2 and III3). Photographs taken by Esther Premru. right php II-1 also exhibits a distinct depression at the same place, but less deep than in the left element. The anterior surface is longer medially than laterally. It has distinct edges on all sides, but only the proximal rim is accentuated. Whereas the distal margin is formed by the articular condyles and therefore concave mediolaterally, its proximal, medial and lateral borders are nearly straight. The anterior surface itself is almost flat and smooth. The posterior face is less smooth than the anterior one. Especially toward its proximal and lateral margins, its rugosity increases. The medial rim and the shorter lateral margin are rounded, in contrast to their condition in the anterior surface. Distally, the intercondylar groove is more pronounced on the plantar side than anteriorly, and leads to a distinct, deep, and rounded foramen nutricium, which lies slightly proximal to the center of the surface. Further proximally, the bone curves gently in posterior direction. In medial view, the proximal border of php II-1 is concave and greatly expanded anteroposteriorly, but does not project much in medial direction. In contrast, due to the presence of the distal condyles, the distal end of the medial surface is strongly convex anteroposteriorly. The surface itself is smooth and flat. Its distal end is anteriorly expanded. The lateral side exhibits a concave proximal margin that is strongly pronounced anteriorly, but less so posteriorly. In contrast to its state in the medial surface, the proximal rim is rugose and extended laterally. The laterodistal end is similar again to its medial counterpart in that it is convex and anteriorly more accentuated than plantarly. The distal articular surface of php II-1 is formed by two condyles. The intercondylar groove is less distinct anteriorly than posteriorly, where it passes continuously into the adjacent surface. The medial condyle expands further distally than the lateral one.

The box-like pedal phalanx II-2 is tightly attached to php II-1 in both pedes, so that its proximal side remains obscured. However, it is obvious that the articular surface has a saddle-shaped proximal articular surface that fits very well onto the corresponding distal face of its preceding element. The anterior face of php II-2 is smooth. Its distal, medial, and lateral margins are almost perpendicular to each other. The medial part of the proximal rim extends parallel to the distal one. At midlength the proximal rim curves slightly distally, resulting in a lateral border that is half the length of the medial one. The posterior surface is slightly rugose. Its lateral margin is pointed, because the lateral side tapers in plantar direction. As is the case on the 

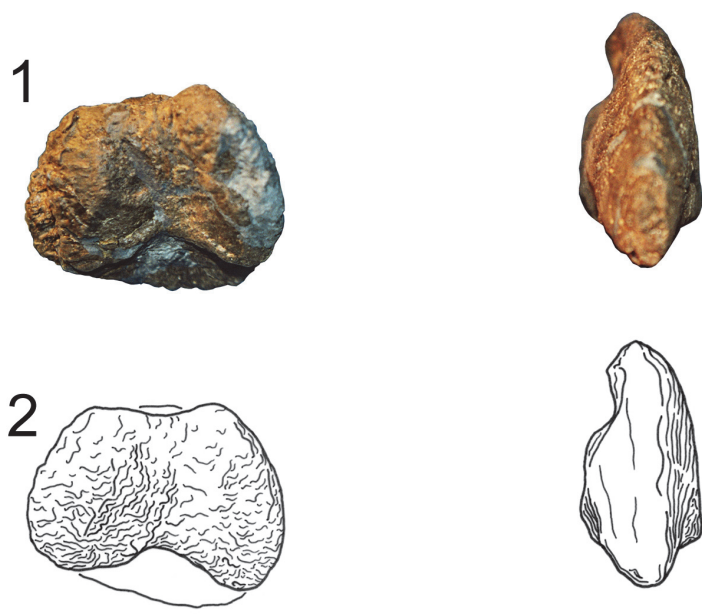

3
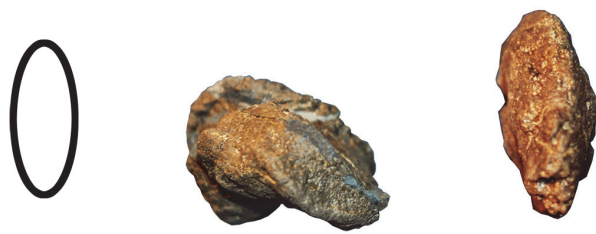

4
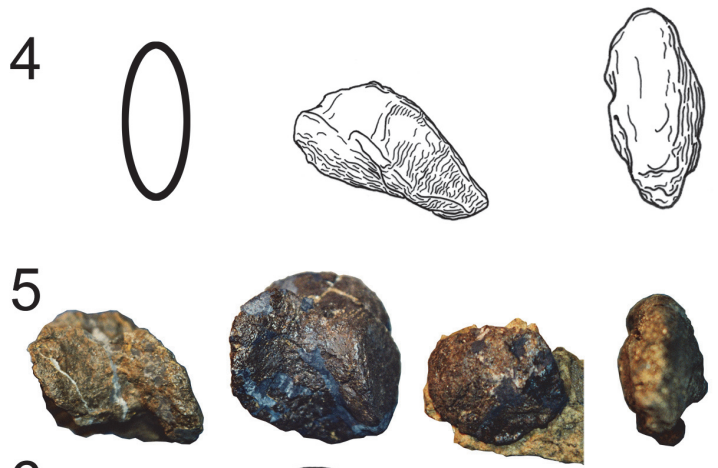

6
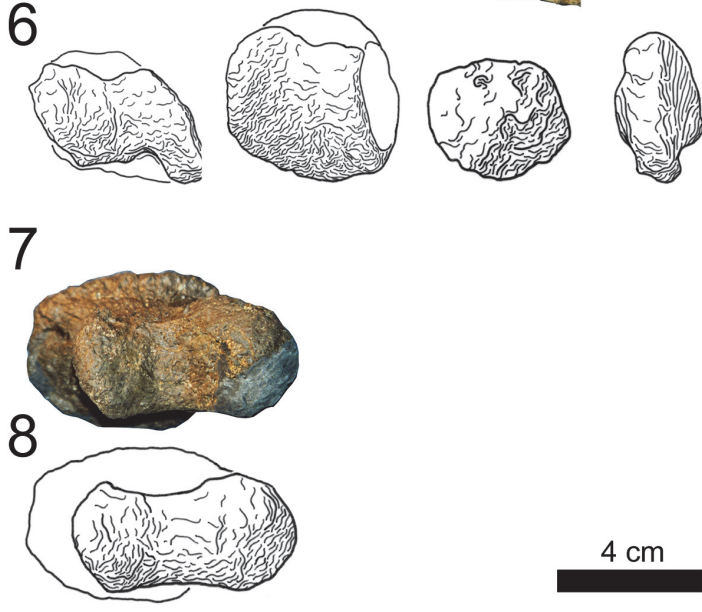

FIGURE 31. Photographs and drawings in distal view of the phalanges of the right pedal digit I $(1,2)$, digit II $(3$, $4)$, digit III $(5,6)$, and digit IV $(7,8)$. The oval outlines in (3), (4) indicate an element where no photographs were available in distal view (php II-2). Photographs taken by Esther Premru. anterior face, the medial portions of the proximal and the distal border are parallel to one another. Then, the proximal rim is curving distally at midlength. Given the already unequally long sides of php II-1, the unequally long medial and lateral faces of php II-2 result in a distal articular surface that stands at an angle of $40^{\circ}$ to $45^{\circ}$ to the upper articular surface of php II-1.

The proximal face of the second pedal ungual (php II-3) is slightly compressed mediolaterally, compared to the first ungual. Like the upper surface of the first ungual, it carries two facets on its posterior portion resembling two steps of a spiral staircase. Contrary to the state in php I-2, both 'steps' of php II-3 are concave, and the lateral facet is smaller than the medial one. The margins of the proximal face of the second ungual are pronounced, but there is no bony overgrowth as in php I-2. Nevertheless, the anterior, thin part of the upper surface of php II-3 projects proximally in a way that the lateral border almost forms a semi-circle. The medial surface shows a similarly grooved pattern as the first ungual and exhibits also a nutrient foramen. The canal leading to the foramen is of approximately the same length in both elements, and thus appears to be relatively longer in php II-3 than in php I-2. Moreover, the foramen is situated more distally in the second claw than in the first one. On the lateral face of php II-3, the proximal margin is much more curved and the surface itself is less convex anteroposteriorly than in the first ungual. In the upper part of the lateral side of the second claw, a gentle depression with a small tubercle on its anterodistal rim occurs somewhat anterior to the center. The posterior surface is much like that of php I-2 as well. However, the oblique proximal ridge of this side is slightly more pronounced in php II-3 than it is in the first ungual, resulting in a steeper lateral and a flatter medial part of the plantar face. Toward the tip of this surface, it shows the same curvature as in php I-2. There is no canal at the distal end of php II-3, but some deep cavities which are probably foramina nutricii. The blunt tip is deeply pitted.

The proximal articular surface of the pedal phalanx III-1 has an ellipsoid outline. Posteriorly and medially, it projects slightly proximally, whereas its lateral margin curves faintly distally. The articular surface itself is concave. In contrast to its accentuated and roughened margins, the facet is rather smooth. The anterior surface is shorter laterally than medially as is the case in all other nonungual phalanges described so far. It is smooth with the exception of the medial half of the 
anterior face of the left specimen, where a slight rugosity is visible at its proximal portion. The transition into the medial face of php III-1 is more rounded than the one into the lateral side, whereas the medial margin of the anterior face is straighter than its lateral one. The posterior surface is much more rugose than the anterior one. In the same region as in php $\mathrm{II}-1$, a distinct foramen nutricium can be seen. The two phalanges II-1 and III-1 are the only ones in the pes that bear such a distinct foramen on their posterior surfaces. In medial and lateral view, the accentuated proximal borders of the corresponding sides are nicely visible. The posterior rim of the medial surface extends straight to the anteroposteriorly convex distal margin formed by the articular condyles. The medial condyle is clearly expanded anteriorly, so that the anterior margin of the medial side is proximodistally concave. The entire face is smooth and slightly convex anteroposteriorly. The lateral surface of php III-1 is rugose and mostly flat anteroposteriorly. Both its antero- and posterodistal ends are slightly expanded. The anterior and plantar margins of the lateral side are therefore gently concave proximodistally. The lateral condyle is less expanded anteriorly than the medial one. The distal articular surface is again dominated by the two condyles. Unlike in other nonungual phalanges, its anterior margin is accentuated and almost flat. The intercondylar groove develops only behind its anterior margin.

The proximal articular surface of the pedal phalanx III-2 is the perfect counterpart of the distal face of its preceding phalanx. Its plantar portion projects proximally, fitting well into the intercondylar groove of php III-1. In contrast to the anteroposteriorly deeply concave lateral margin of the proximal articular surface of php III-2, the medial one is accentuated and almost straight. The surface itself is slightly rugose. The anterior face is wider proximally than distally. It is almost smooth with an anteriorly expanded upper end. Its medial border is straight and stands roughly perpendicular to the innermost part of its mediolaterally convex proximal rim. The anterior surface is slightly depressed near the center of its distal rim. The latter as well as the lateral border of the face are concave. The posterior side of php III-2 is developed as a weak, mediolaterally convex ridge. The entire bone therefore has a wedge-like shape with its thinnest part at the proximal end of the plantar face. The medial surface is smooth and trapezoidal. The base of the trapezoid is equivalent to the nearly straight proximal margin. The anterior bor- der of this side stands at an angle of $40^{\circ}$ to $45^{\circ}$ to the proximal one, being much more oblique than the posterior rim. The distal margin is gently convex. The medial face of php III-2 is longer and stands more oblique in respect to the longitudinal axis of the third digit than the lateral one. Therefore, the distal articular surface is orientated laterally. In lateral view, the ridge representing the plantar side widens in anterior direction, thereby forming a continuously broadening lateral surface. Both its proximal and anterior margins are strongly concave anteroposteriorly and proximodistally, respectively, including a very acute angle where they meet. At its distal end, the anterior border stands perpendicular to the anterior part of the convex lower rim. The distal articular surface is saddleshaped, being concave mediolaterally and convex anteroposteriorly. It is almost smooth and does not exhibit any condyles.

The pedal phalanx III-3 continues the tapering and the narrowing of php III-2 in distal and lateral direction, respectively. The element is pyramid-like, articulating at its base with the more proximal phalanx, and at its blunt tip with the ungual. Due to its rounded shape, all but the proximal and the distal surface are difficult to distinguish. The mostly obscured proximal surface is nearly flat and appears to have a subcircular outline. The distal side as well is almost flat, and is shorter than the proximal one in every direction, thus forming the blunt tip of the 'pyramid'. The entire bone is rugose and its sides are very thin.

The outermost and smallest pedal ungual III (php III-4) is also the most laterally rotated. This outward rotation increases constantly from the first ungual to the third one. The proximal articular surface of php III-4 bears only one concavity, contrary to the state in the previous unguals. This single depression is quite deep, and gets even more accentuated by the large proximally pointing projection on the anteromedial end of the upper face. Whereas the rims of the concavity are slightly rugose, the facet itself is smooth. The shape of the medial surface looks much alike the corresponding faces in php I-2 and php II-3. The medial surface of php III-4, however, is lacking a similar, striated pattern and is thus mostly smooth. The anterior part of its upper margin projects more proximally than in the other unguals. As the two previous claws, the third ungual exhibits a canal leading to a nutrient foramen in the posterior portion of the face. In contrast to the first two unguals, a similar canal leading to another nutrient foramen can be observed on the anterior part of the lateral surface of php III-4. 
$5 \mathrm{~cm}$
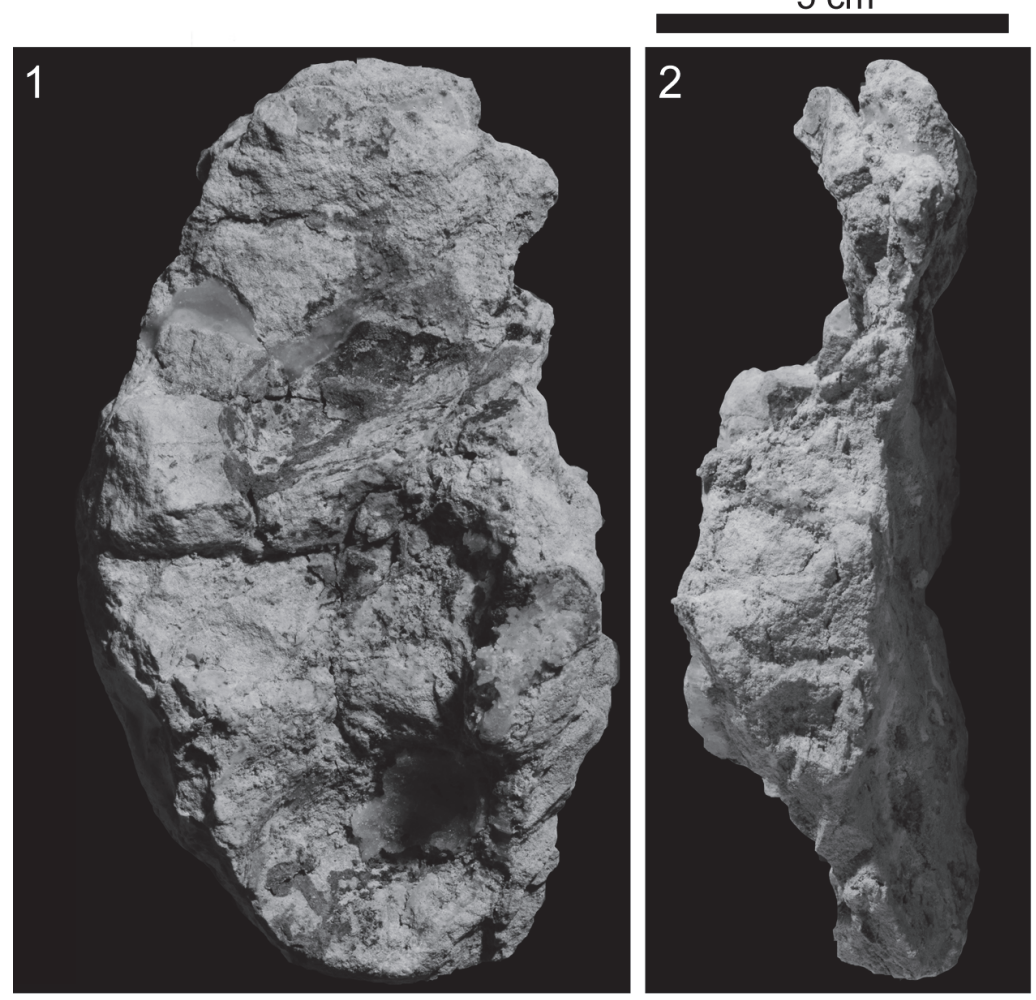

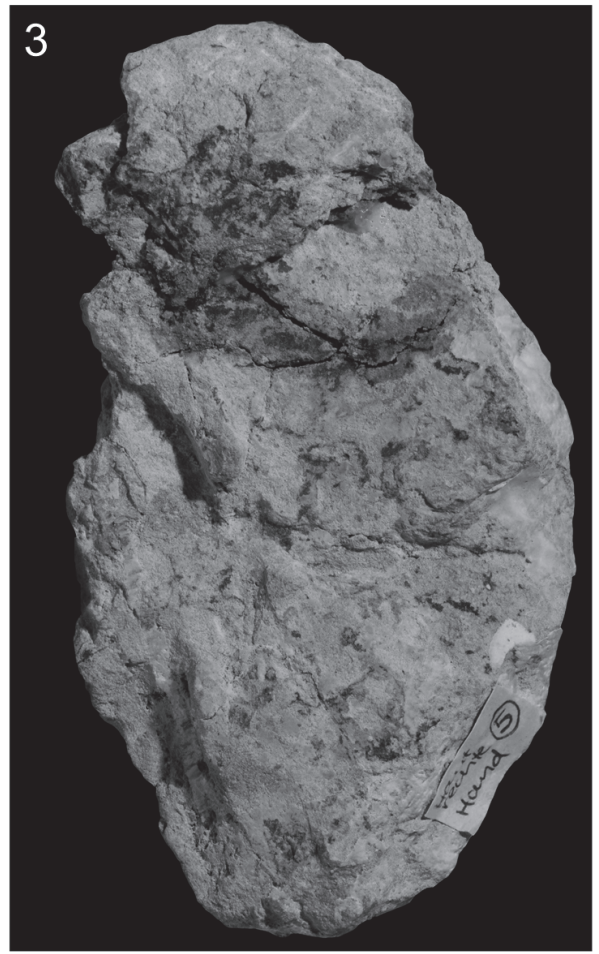

FIGURE 32. Photographs of the manual skin impression preserving also the negatives of the distal tips of the phalanges in proximal (1), lateral (2), and distal views (3). Photographs taken by Rosemarie Roth.

Except for its rough proximoposterior portion, the face is almost smooth. The posterior side is very similar to the corresponding faces of php I-2 and II3 , with the exception that the posterior face of php III-4 appears to be stouter at its distal end. There, the posterior surface passes into the blunt and less pitted tip of the bone, compared to php II-3.

The proximal articular surface of the pedal phalanx IV-1 is expanded mediolaterally and anteroposteriorly. It has an ovoid outline with its greatest anteroposterior diameter being located medial to its center. The face itself is slightly rugose and concave, having its deepest point somewhat lateral to the center. Unlike the previous proximal phalanges, the anterior surface of the left php IV-1 has subequally long medial and lateral borders, and in the right element the latter is even longer than the former. Both these margins are concave and in the left php IV-1, the distal end of the lateral rim exhibits a large, rounded knob, which is not present in the right specimen, and was interpreted as a bone tumor by Tschopp et al. (in press). This knob passes into the lateral condyle of the distal articular surface, which in anterior view is separated from the medial one by a deep intercondylar groove. The lateral surface is smooth, and as in php III-1, there is no depression at its distal end. The posterior surface of php IV-1 as well is mostly smooth. Its proximomedial and laterodistal ends are greatly expanded. Given that the proximal margin also projects laterally, the lateral border is more concave than the medial one, whose distal edge is weakly accentuated. Unlike in the other phalanges, there is a sudden step-like depression at the center of the lower end of the posterior face. The medial and the lateral surface are gently rounded and anteroposteriorly convex. The distal rim of the medial face is more accentuated, but less expanded transversely than the one of the lateral side. The lateral condyle of the slightly roughened distal articular surface is larger than the medial one. The anterior border of the lower articular surface is only weakly concave mediolaterally, because there is almost no central depression in the corresponding face of the element. Because of the step-like posterior depression mentioned above, the posterior rim of the distal articular surface is much more concave than the anterior one.

The pedal phalanx IV-2 is only preserved in the left pes of SMA 0002. It is heavily damaged 

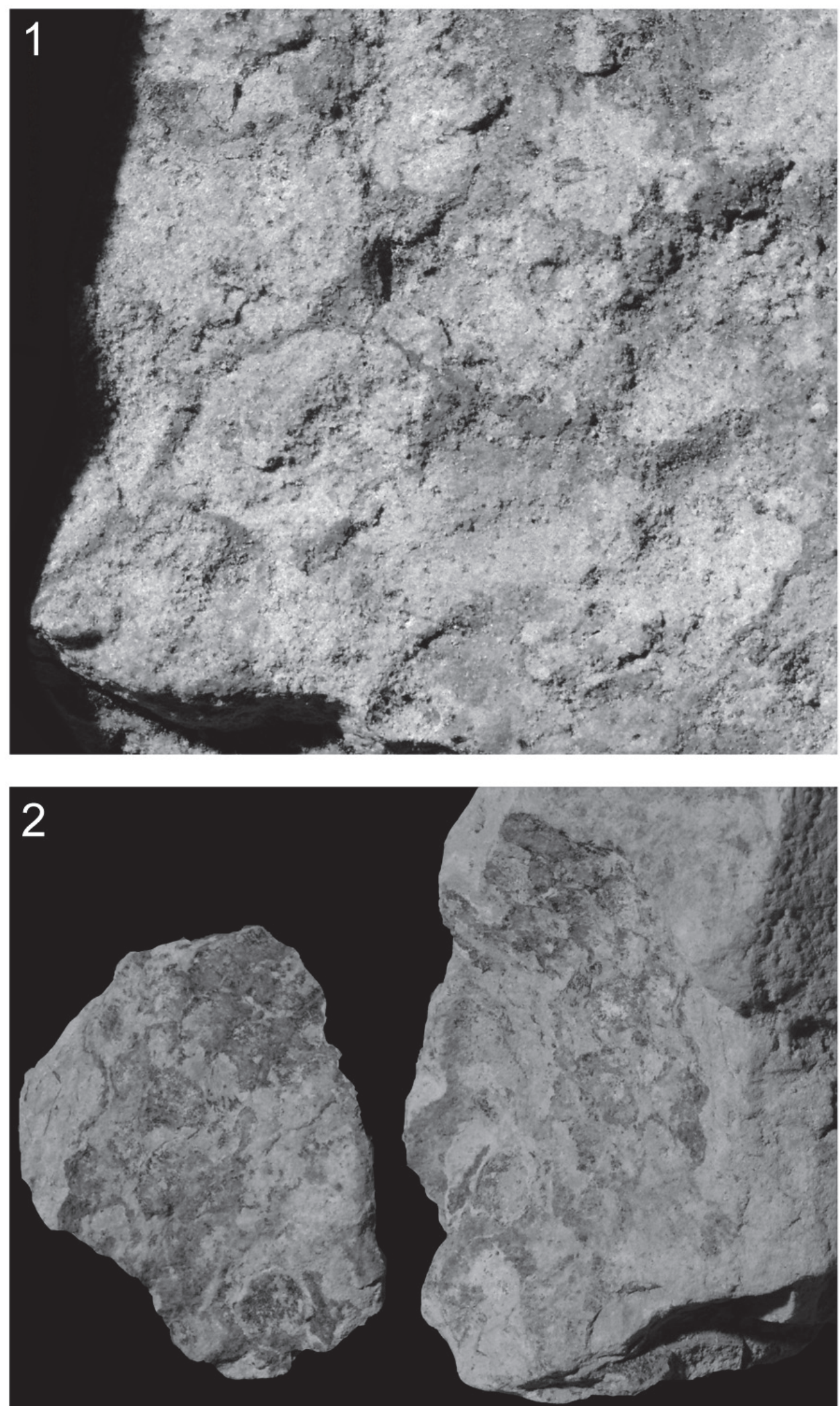

FIGURE 33. Photographs of the two different skin structures found in the region of the hindlimb and the pes of Camarasaurus sp. SMA 0002: (1) shows the large polygonal structure, (2) the positive and negative impressions of the smaller texture. Scale bars equal $5 \mathrm{~cm}$. Photographs taken by Rosemarie Roth. 
and still embedded in matrix. We can therefore only conclude that digit IV bore a small terminal phalanx, which appears to have been more or less rugose.

\section{Skin Impressions}

Skin impressions are present in various regions of specimen SMA 0002, including the manus and pedes (Figure 3). The manual impression is from the palmar side of the phalanges of the second and the third digit and shows no distinct characteristics concerning squamation of the integument. It is preserved on a small slab that also exhibits the negatives of the phm II-1 and phm III-1 (Figure 32). A light to dark gray layer is covering the area of the impression. The minimum distance between this layer and the negatives of the bones is only $6 \mathrm{~mm}$.

The skin impressions of the pes and the adjacent parts of the hind legs exhibit two different patterns. Both patterns are polygonal, mostly hexagonal structures but they vary in size of their polygons: the first texture consists of relatively large fields with a flat surface measuring 15 to 18 $\mathrm{mm}$ in diameter, being arranged in rows. Their borders are preserved as light gray lines (Figure 33.1). The second pattern shows smaller tuberculate structures with diameters of 6 to $10 \mathrm{~mm}$, which are not as obviously arranged in rows as in the one above. The elements of the second texture are available as positive and negative (Figure 33.2). They have gently convex surfaces and are covered by a very thin, dark, probably carbonaceous layer.

\section{DISCUSSION}

\section{Manus}

The sauropod manus was initially reconstructed in a similar way as the pes, being interpreted as having an elephantine structure (e.g., Osborn, 1899; Osborn and Granger, 1901). However, since the discovery of the first articulated manus (Osborn, 1904; Hatcher, 1902), it is known to have evolved a tubular arrangement in eusauropods, with an almost vertically oriented and only distally slightly spreading metacarpus (Mclntosh, 1990a; Upchurch, 1998; Wilson and Sereno, 1998; Wilson, 2002, 2005a; Upchurch et al., 2004a; Harris, 2006; Carballido et al., 2012b). As Coombs (1975) and Thulborn (1990) stated, such a manual shape bears more affinities to hippo or rhino forefeet than to the ones of elephants, but with their reduced carpus and phalanges, they remain without exact modern analog, which makes them diffi- cult to understand and reconstruct. Recently, Senter $(2010,2011)$ suggested that also thyreophorans might exhibit similar metacarpal configurations. However, the articulated states preserved in the right and the left manus of Camarasaurus SMA 0002 show much more bound metacarpals compared to thyreophorans.

Carpus. When compared to closely related taxa, the medial Camarasaurus carpal is more anteroposteriorly compressed than its corresponding element of Aragosaurus, Turiasaurus, and Losillasaurus (Royo-Torres et al., 2014, figure 10). Aragosaurus in particular has a nearly subquadrangular medial carpal, whereas the elements of Turiasaurus and Losillasaurus are more rounded. Only one left and one right carpal were reported from the brachiosaurid Giraffatitan, which are both lost now (Janensch, 1961). They were flat elements with a subtriangular outline in proximal view and rugose surfaces (Janensch, 1922), and thus also easily distinguishable from the subrectangular medial carpal of SMA 0002. The carpal most similar to the medial carpal of Camarasaurus is one referred to Janenschia robusta (MB.R.2095.10; Janensch, 1961, plate XXIII, figure 5), but this element appears more wedge-shaped in anterior view compared to the elements of SMA 0002, where the anteroposteriorly longest dimension is located centrally (Figure $8.1,8.6$ ). Within Camarasaurus, the herein described medial carpal differs from its homologues mentioned by McIntosh et al. (1996b) and Bonnan (2003) in being proximally concave instead of flat. However, Bonnan (2003) describes a shallow concavity on the upper surface of a medial carpal, a feature that could have become overemphasized by diagenetic deformation and anteroposterior compression in SMA 0002. Lateral carpals are rarely described, probably due to rare preservation or misidentification of disarticulated elements.

Ostrom and Mclntosh (1966, plate 79) show two probable carpals: whereas one bone (their figures 1-5) exhibits similar features as the lateral carpal of SMA 0002, the other one (their figures 6-10) is much smoother than the herein described elements. Smooth surfaces are typical for the articular ends of long bones of young sauropods (Ikejiri, 2004; Ikejiri et al., 2005; Schwarz et al., 2007a), because they grow continuously, but irregularly into a covering of hyaline cartilage. This results in increasingly rugose surfaces as the animals get older (Halstead, 1974; Caplan, 1984; Bonnan, 2003). However, compared to the immature Camarasaurus lentus CM 11338 and the young 
juvenile neosauropod SMA 0009 (Schwarz et al., 2007a), the smoothness of the element figured by Ostrom and McIntosh (1966, plate 79, figures 6-10) appears to be too distinct for it to be a carpal.

The carpus of Camarasaurus and other basal macronarians consists of two unequally large, block-like elements (Osborn, 1904; Madsen et al., 1995; Bonnan, 2001; Upchurch et al., 2004a; Ikejiri, 2005). On the contrary, only single carpals have yet been reported in the diplodocid carpus (Hatcher, 1902; Gilmore, 1936; Bedell and Trexler, 2005). Carpal shape varies considerably between diplodocine and apatosaurine elements (Tschopp et al., 2015): they are box- to wedge-shaped in diplodocines (Bedell and Trexler, 2005), and platelike, with a central ridge marking the proximal articular surface in apatosaurines (Hatcher, 1902; Gilmore, 1936). The known diplodocine carpal clearly covers the medial-most metacarpals (Bedell and Trexler, 2005). Its proximodistally thickened shape results in a relatively large distance between epipodium and metacarpus, and thus implies the presence of a second element, although such a bone has not been reported yet in any diplodocine manus. The single, plate-like apatosaurine carpal, on the other hand, is located centrally above the metacarpus, and articulates with both the ulna and the radius (Hatcher, 1902; Gilmore, 1936), thus indicating that the apatosaurine carpus consisted of a single ossified element (Bonnan, 2003).

Historically, the carpals of Camarasaurus were interpreted as being homologous to the proximal elements of the carpus, the radiale and the ulnare (Osborn and Granger, 1901; Riggs, 1901; Gilmore, 1925; Ostrom and McIntosh, 1966; Ikejiri, 2005). In the articulated SMA 0002, however, there is much more space between the two carpals and the radius or the ulna than between the carpal bones and the metapodials (Figures 5.2, 7). Additionally, the distal surfaces of the two elements fit more closely to the metacarpals than do their proximal faces to the radius or the ulna. This is especially visible by the proximally projecting anterolateral portion of the upper articular surface of $\mathrm{mcl}$, which fits very well into the central anterior cavity of the distal articular face of the medial carpal. The fact that the medial carpal covers metacarpals I, II, and (in parts) III, supports the suggestion of Osborn (1904), Bonnan (2001), McIntosh (2005) and Apesteguía (2005) that the medial specimen of the two bones represents either the first carpal or the fused first two or three carpals of the distal row. The lateral carpal would then be a distal carpal as well, derived from one bone or from two primarily separated elements. This arrangement also corroborates Osborn's (1904) and Wilson's (2005b) statement that the wrist axis in Camarasaurus was situated between the carpus and the epipodium.

The evolution of the sauropod carpus and homology of the carpal elements is poorly understood. Generally, the number of elements in the sauropod carpus decreases and appears to culminate in complete absence of ossified elements in titanosaurs (Borsuk-Bialynicka, 1977; Poropat et al., 2015a). Proximal carpals appear to be unossified in early sauropodomorphs and in the basal eusauropod Shunosaurus (Zhang, 1988; Benton et al., 2000; Remes, 2008; Sertich and Loewen, 2010), with the possible exception of the intermedium (e.g., in Jingshanosaurus xinwaensis and Seitaad ruessi; Remes, 2008; Sertich and Loewen, 2010). However, a completely preserved carpus of a more derived eusauropod from Madagascar shows a different pattern: MNHN MAJ 289, a derived non-neosauropod eusauropod or early macronarian referred to "Bothriospondylus" madagascariensis Lydekker, 1895, has five carpals (Läng and Goussard, 2007). Läng and Goussard (2007) suggested that the carpals of MNHN MAJ 289 represent: 1) a radiale; 2) a fused intermedium, centrale, and distal carpal I; 3) the distal carpal II; 4) the distal carpal III; and 5) the distal carpal IV, possibly fused with the distal carpal V. If correct, this would imply that some (mostly proximal) elements were retained cartilaginous in more basal forms, and are thus not preserved in the fossil record. Support for the retention of proximal carpals also comes from apatosaurines, which have a single ossified element that covers mc II to IV and bears two depressions on its proximal surface for the reception of the ulna and the radius, indicating that it represents fused proximal elements (Gilmore, 1936; Bonnan, 2001, 2003; Upchurch et al., 2004a). Given that the few preserved diplodocine carpals (e.g., WDC-FS001A, Bedell and Trexler, 2005) rather resemble the medial elements of Camarasaurus than the centrally located elements of apatosaurines, the early diplodocoid carpus must have consisted of both proximal and distal elements, at least in cartilaginous forms.

It has often been hypothesized that the reduction of the sauropod carpus did not lead to only two ossified carpals in Camarasaurus or to the complete absence of carpal elements in certain titanosaurs, but that some of the primordially eleven elements remained cartilaginous during lifetime (Romer, 1956; Janensch, 1961; Borsuk-Bialynicka, 
TABLE 3. Length ratios between metacarpals of one single manus. Data are obtained from Gilmore (1925: CM 11338), Mclntosh et al. (1996b: BYU 9047), and Ostrom and Mclntosh (1966: YPM 4633). Note that mc II is not always the longest, and mc I not always the shortest of the series.

\begin{tabular}{|l|c|c|c|c|c|}
\hline \multirow{2}{*}{} & \multicolumn{2}{|c|}{ SMA 0002 } & CM 11338 & BYU 9047 & YPM 4633 \\
\cline { 2 - 6 } & right & left & right & right & 0.9 \\
\hline I to II & 0.77 & 0.83 & 0.76 & 0.87 & 0.85 \\
\hline I to III & 0.8 & 0.86 & 0.79 & 0.97 & 0.83 \\
\hline I to IV & 0.86 & 0.87 & 0.89 & 1.04 & 0.96 \\
\hline I to V & 0.98 & 1.02 & 0.98 & 0.96 & 0.96 \\
\hline II to III & 1.04 & 1.04 & 1.04 & 1.07 & 0.98 \\
\hline II to IV & 1.13 & 1.05 & 1.17 & 1.15 & 1.13 \\
\hline II to V & 1.28 & 1.23 & 1.28 & 1.12 & 1.02 \\
\hline III to V & 1.08 & 1.01 & 1.13 & 1.2 & 1.18 \\
\hline IV to V & 1.23 & 1.18 & 1.24 & 1.08 & 1.16 \\
\hline
\end{tabular}

1977; Bonnan, 2003; Apesteguía, 2005; Poropat et al., 2015a). Other authors proposed that a thick layer of hyaline cartilage was enclosing the two bony carpals (Jensen, 1988; Wilson and Sereno, 1998). Both of these assumptions are advantageous in distributing the weight evenly to all five digits, because cartilage is more flexible than bone (Knese and Biermann, 1958; Wilson and Sereno, 1998; McGowan, 1999). However, the packing of the bony carpals into thick layers of hyaline cartilage has been rejected by several authors, because this sort of cartilage was argued to be insufficiently vascularized to maintain its functionality under such heavy loads (Bunim, 1956; Larson, 1962; Coombs, 1975; Currey, 1984; Bonnan, 2000, 2003; Apesteguía, 2005). Therefore, Christiansen (1997c) proposed that cartilaginous elements in the sauropod carpus, if present, rather consisted of fibrocartilage, which is less susceptible to stresses but still enough compliant, and thus even better suited to disperse the weight more effectively than bone (Jaffe, 1972). Such sesamoid fibrocartilage is also present in human feet, reducing stress concentrations (Shaw and Benjamin, 2007). Furthermore, recent studies of extant archosaur long bones show that these can be capped with a significant layer of cartilage, adding up to approximately $10 \%$ of total bone length in certain cases (Bonnan et al., 2010; Holliday et al., 2010). This implies that also the corresponding elements in dinosaurs probably exhibited thick layers of articular cartilage, as was previously shown in a sauropod humerus (Schwarz et al., 2007b).
In SMA 0002, metacarpal III is in both manus slightly separated from both the medial and the lateral carpals, as is the case in the majority of manual remains of Camarasaurus (Bonnan, 2001). This would leave some space for a possible cartilaginous carpal, which - if present - would most probably represent the unossified distal carpal three, which occurs as a bone in " $B$." madagascariensis (Läng and Goussard, 2007). The distal displacement also occurs in an articulated manus of Opisthocoelicaudia skarzynskii Borsuk-Bialynicka, 1977 (specimen ZPAL MgD-I/48). Although there are no ossified carpals preserved, Borsuk-Bialynicka (1977) interpreted the displacement to be a hint for the presence of a cartilaginous carpal. It therefore seems that not all carpal bones were fused or lost during the evolution of the sauropod carpus, but that there might have been some unossified and thus not fossilized elements. Additional support for the existence of cartilaginous elements in the sauropod carpus comes from two nearly completely articulated juvenile sauropod specimens (Brachiosauridae indet. SMA 0009 and Camarasaurus lentus CM 11338). Both CM 11338 and SMA 0009 do not preserve lateral carpals (Gilmore, 1925; Schwarz et al., 2007a; Carballido et al., 2012a). The lack of these small carpal elements in otherwise nicely articulated forelimbs, indicates that ossification of these elements occurred late in ontogeny, and implies that cartilaginous elements must have been present in the sauropod wrist. Also, at least two cases of juvenile to subadult non-sauropod sauropodomorphs are reported to lack ossified carpals although adult 
specimens of the same taxon have them (Massospondylus and Melanorosaurus; Bonnan and Yates, 2007). Given that the carpus of many extant reptiles consists of a combination of bony and cartilaginous elements (Heidsieck, 1928), it is plausible that this was also the case in sauropods.

Metacarpus. Camarasaurus metacarpals can easily be referred to Macronaria due to their slender, elongate shape (Wilson and Sereno, 1998). Both basal eusauropods and diplodocoids have rather stout metacarpals (e.g., Mamenchisaurus youngi and Apatosaurus louisae; Gilmore, 1936; Ouyang and Ye, 2002). Within Macronaria, the strongly developed distal condyles of Camarasaurus metacarpals differ from titanosauriform elements with their flat distal ends (Wilson and Sereno, 1998). Turiasaurian metacarpals have subtrapezoid rather than subtriangular proximal articular surfaces (e.g., Zby atlanticus ML 368; Mateus et al., 2014), and $\mathrm{mc}$ II with flat distal articular surfaces (Royo-Torres et al., 2014). The metacarpals referred to the probable non-titanosauriform macronarian Janenschia robusta are much more robust compared to Camarasaurus elements (Janensch, 1922). Aragosaurus metacarpals appear to be the most similar to Camarasaurus within Sauropoda, but only a mc I and a partial mc II are known from this taxon (Royo-Torres et al., 2014). The metacarpal II of Aragosaurus has a similar robustness as the corresponding element in Camarasaurus, and is also marked by a distinct distal concavity on its posterior side, which leads into the intercondylar groove (Royo-Torres et al., 2014). However, mc I of Aragosaurus has a more D-shaped proximal articular surface, compared to Camarasaurus (Royo-Torres et al., 2014), and mc II of Aragosaurus bears a distinct tubercle on the distomedial ridge on the posterior surface, just proximal to the rugose articular facet (Royo-Torres et al., 2014, figure 12), which is absent in Camarasaurus.

The length ratio between the metacarpals of a single manus is highly variable among genera (Poropat et al., 2015a), but also among different Camarasaurus specimens (Table 3 ). Whereas in SMA 0002, mc II is the longest and mc I the shortest of the series, other specimens exhibit a mc III that is longer than mc II (Ostrom and Mclntosh, 1966; Mclntosh, 2005), or a shorter or equally long $\mathrm{mc} \mathrm{V}$ as mc I (Riggs, 1901; Mclntosh, 2005). Wilson and Sereno (1998) stated that $\mathrm{mcl}$ is subequal in length to mc IV in Camarasaurus and Titanosauriformes. However, all the reported differences are relatively small, and until a comprehensive review of all manual bones is published, an accurate com- parison of the metacarpal lengths in various individuals as well as the use of this feature in phylogenetic analyses remains problematic. Nevertheless, comparing the average ratio of metacarpal length to radius length in Camarasaurus, the metacarpals of SMA 0002 show considerably higher values than other congeneric specimens: for $\mathrm{mc} \mathrm{III,} \mathrm{the} \mathrm{average} \mathrm{is} \mathrm{given} \mathrm{as} 0.46$ (Mclntosh, 1990b) or 0.47 (Gilmore, 1925; Apesteguía, 2005), and is 0.55 in the present specimen. SMA 0002 thus groups among derived somphospondylian taxa for this ratio (Poropat et al., 2015a, table 13). To a lesser degree, the same is the case when comparing metacarpal length to humerus length: in SMA 0002, the ratio is 0.36 for mc III (Table 2), whereas the average calculated by Madsen et al. (1995) is of 0.33. There are several possible reasons for this substantial discrepancy, but some of them are probably not testable in the near future, due to the small sample size of well-preserved manual remains. First, the growth of the metacarpals might have stopped later in lifetime compared to the growth stop of more proximal leg bones, or metacarpals might have grown faster than upper leg bones. In older animals as SMA 0002 (Klein and Sander, 2008; Waskow and Sander, 2014), metacarpals would therefore be relatively longer than the upper leg bones. Second, the humerus and the metacarpal lengths might have been diagenetically deformed. However, the quarry maps show that only the metacarpals were found in an oblique position, indicating that they would have become more shortened than the humerus, thus leading to an even greater relative length. Finally, these values might be diagnostic for a new, small Camarasaurus species, proposed by Klein and Sander (2008) and Waskow and Sander (2014) based on histological samples of SMA 0002.

The metacarpals of neosauropods are arranged in a tubular structure, which results from the subtriangular proximal surfaces of $\mathrm{mc}$ II to IV (Mclntosh, 1990a; Wilson and Sereno, 1998; Upchurch, 1998; Wilson, 2002, 2005a; Upchurch et al., 2004a; Senter, 2010, 2011). The rugose areas on the upper parts of the medial and lateral sides, and the proximodistally extending, roughened ridges on the posterior surfaces of the bones, which reach as far as midshaft in most elements, show that these bones were bound to each other very tightly (Wilson, 2002, 2005a; Milàn et al., 2005), and that there were strong musculi intermetacarpales and a powerful palmar aponeurosis keeping the metacarpals closely together (Borsuk- 

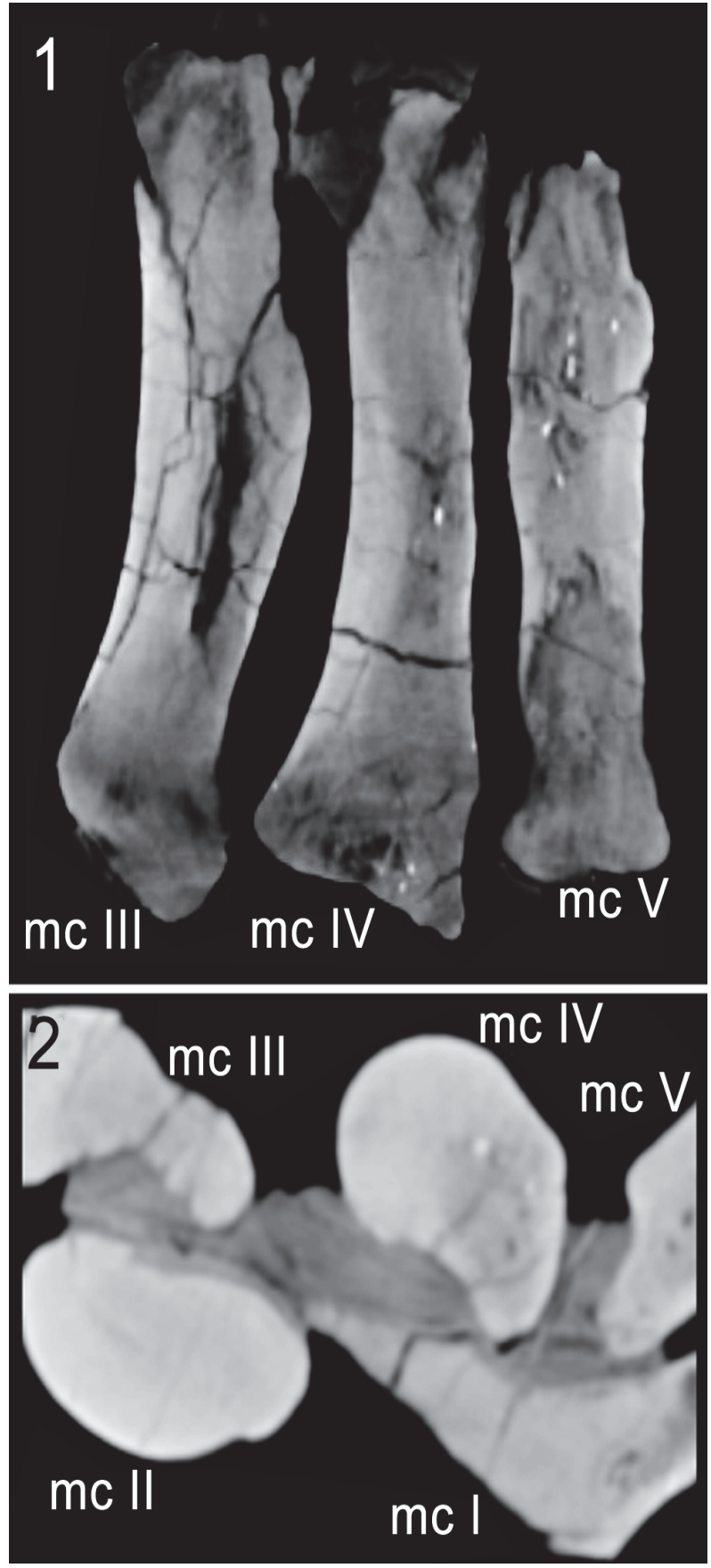

FIGURE 34. X-ray CT images of the left metacarpals in longitudinal (1) and transverse (2) cross section. Note the absence of hollow medullary cavities.

Bialynicka, 1977; Wilson and Sereno, 1998; Upchurch et al., 2004a).

The articulated left and right manus of SMA 0002 not only confirm these interpretations, they give even more insights into the proper arrangement of the metacarpus: the distally slightly splayed right manus indicates that this tight binding was mostly restricted to the proximal part. However, with the rugose ridges extending as far as midshaft, the binding of the proximal portion of the metacarpals into soft tissue should have been strong enough to restrict individual movements of their distal ends to a minimum or to inhibit them completely (Bonnan, 2003). The entire metacarpus did thus not spread distally in life, but formed a single tubular structure. This fact has also been recognized in the articulated manus of " $B$." madagascariensis (Läng and Goussard, 2007). Given the block-like shape of the carpals with their parallel proximal and distal articular surfaces, it is evident that the metacarpus of Camarasaurus was held vertically beneath the carpus (Janensch, 1961; Thulborn, 1990; Bonnan, 2003). The only feasible motion to adjust the manus to irregular terrain must therefore have been in the metacarpophalangeal joint. According to Biewener (1983) and McGowan (1999), such a position is typical for legs of large, heavy animals, and it is therefore commonly interpreted as an adaptation to graviportalism (e.g., Gilmore, 1936; Bonnan, 2003; Upchurch et al., 2004a), although extant graviportal animals and large ornithischians have a broad and short metacarpus, which they hold in an oblique angle to the ground. However, none of them reached the size of sauropods, and it is plausible that this vertical arrangement of the metacarpus was one of the anatomical adaptations that allowed sauropods their gigantic body size. Another adaptation to graviportalism is the very massive condition of the leg bones, which have a medullary cavity filled with relatively dense, spongy bone (McGowan, 1999; Carrano, 2005), a feature that is also recognized in the metacarpals of SMA 0002 (Figure 34), thereby emphasizing their contribution in weight-bearing.

The distal articular surfaces of the metacarpals have a curvature that is more prominent at their posterior than at their anterior ends. This implies a more restricted mobility of the proximal phalanges toward the front than toward the back, and thus contradicts a digitigrade reconstruction of the manus, where the distal ends of the metacarpals would touch the ground, as proposed by several authors (e.g., Thulborn, 1990; Upchurch, 1994; Bonnan, 2003; Upchurch et al., 2004a; Wilson, 2005a, Senter, 2010, 2011). Instead, the articulated manus of SMA 0002 supports the opinion of Christiansen (1997a) and Milàn et al. (2005) that at least the camarasaurid manus was unguligrade. Together with the immobility of the wrist, it implies that the forefeet did not contribute much to the propulsion but that their main function was weight- 
bearing (Janensch, 1922; Christiansen, 1997a; Upchurch et al., 2004a; Carrano, 2005; Milàn et al., 2005). The possible movements of the phalanges might have helped in adjusting the manus to uneven terrain in order to attain a secure stand. The distal articular surface of $\mathrm{mc} \mathrm{I}$ is different from the others in facing obliquely mediodistally. Therefore, taking the tubular arrangement of the metacarpus into account, the corresponding phalanx I-1 was directed slightly posteromedially.

Manual phalanges. Phalanx morphology is very similar among most sauropod taxa. With the exception of phm I-1, they are short and broad with flat proximal articular surfaces, which contribute to the restriction of movements against their corresponding metacarpals (Janensch, 1922; Thulborn, 1990; Farlow, 1992; Upchurch, 1994; Wilson and Sereno, 1998; Wilson, 2002; Bonnan, 2003; Upchurch et al., 2004a; Milàn et al., 2005). Apatosaurine manual phalanges are generally slightly shorter proximodistally and the diplodocid phm I-1 is much more wedge-shaped compared to Camarasaurus (e.g., Brontosaurus parvus UW 15556 or the indeterminate apatosaurine NSMT-PV 20375; Hatcher, 1902; Gilmore, 1936; Upchurch et al., 2004b). Manual phalanges of Giraffatitan brancai have rather circular proximal articular surfaces, in contrast to the transversely long, ellipsoid facets of Camarasaurus (e.g., MB.R.2249; ET, pers. obs. 2014). Janenschia resembles diplodocids more than Camarasaurus in having a wedge-shaped phm I-1 (Janensch, 1961). Within Camarasaurus, the manual phalanges of SMA 0002 are distinctive due to their bony overgrowths described as symptoms of osteoarthritis by Tschopp et al. (in press), which is thus not considered taxonomically significant.

Based on the observations in SMA 0002, some of the disarticulated elements figured by Ostrom and McIntosh (1966, plates 62 and 63) can be reconsidered. The questioned first phalanx (Ostrom and Mclntosh, 1966, plate 62, figures 1-6) appears to be accurately identified as phm l-1. However, the captions of some of the figures are inverted: in our opinion, figures 1-4 on plate 62 of Ostrom and McIntosh (1966) illustrate the anterior, medial, posterior, and lateral surface, respectively. This would indicate that it is a right element, due to the elongated outer condyle. The second questioned manual phalanx (Ostrom and Mclntosh, 1966, plate 62, figures 7-12) does not show such a distinct proximal convexity on its posterior side, as occurs in phm III-1 and phm IV-1 of SMA 0002. The lack of this feature, but also the slightly elongated shape of this element rather implies that it is a pedal phalanx, most probably php III-1, although there is no nutrient foramen visible in posterior view. The unidentified phalanx on plate 63 of Ostrom and Mclntosh (1966) most closely resembles phm V-1 in having an irregular shape, flattened medial and lateral ends, and roughened surfaces.

Manual phalangeal reduction is one of the most distinctive evolutionary trends from basal sauropodomorphs to derived titanosaurs, and strongly correlated with the obligatory quadrupedal stance, and thus graviportal function of the manus (Bonnan, 2003; Upchurch et al., 2004a; Bonnan and Yates, 2007). Phalangeal reduction apparently affected both size and number of elements: whereas the non-sauropod sauropodomorph Melanorosaurus has a preserved phalangeal formula of 2-3-4-1-1, with longer-than-wide proximal phalanges and distinct claws on the first three digits (Bonnan and Yates, 2007), this was reduced to 2-2-2-22 (Wilson and Sereno, 1998; Wilson, 2002) or 2-22-2-1 (Upchurch, 1998; Upchurch et al., 2004a) in eusauropods and further to 2-2-1-1-1 (Upchurch, 1998) or 2-1-1-1-1 (Upchurch et al., 2004a) in neosauropods. Early sauropods reduced the length of proximal manual phalanges, such that they became subequal in length and width (Upchurch et al., 2007), and eusauropods are even characterized by wider than long proximal manual phalanges (Wilson, 2002). Sauropod manual unguals are only known in the first digit, but no articulated manus of a non-eusauropod sauropod has yet been reported (Wilson, 2005b). Non-ungual, second phalanges, if present, are vestigial, button-like ossifications that can easily get lost or remain unrecognized, especially when found disarticulated (Wilson and Sereno, 1998). Nevertheless, such bones were found associated with phm II-1 in Apatosaurus louisae (CM 3018; Carrano, 2005) and Janenschia robusta (MB.R.2093; Janensch, 1961; Carrano, 2005). Since these two species enclose Camarasaurus into a phylogenetic bracket, Carrano (2005, table 8.3) assumed that also the latter genus should have a second phalanx in the second digit, although no clear morphological evidence for that existed until the finding of SMA 0002 (e.g., Osborn, 1904; Gilmore, 1925; Wilson, 2005b). Mclntosh et al. (1996b) reported vestigial bones from the manus of the two Camarasaurus specimens USNM 13786 (articulated with phalanx V-1) and YPM 1910 (disarticulated), and therefore proposed a phalangeal formula of 2-2-1-1-1 or 2-1$1-1-2$ in this genus. Bonnan (2003, figure 2) figured 


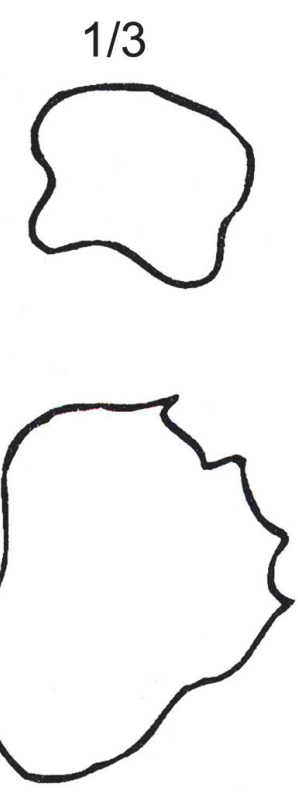

Texas
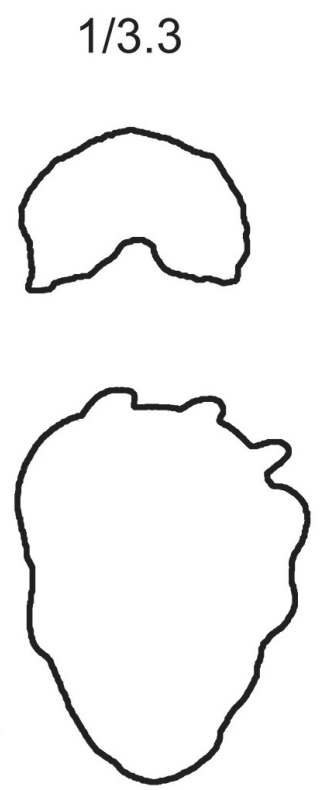

Spain

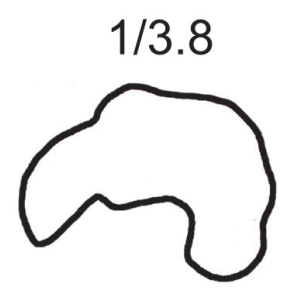

$1 / 5$
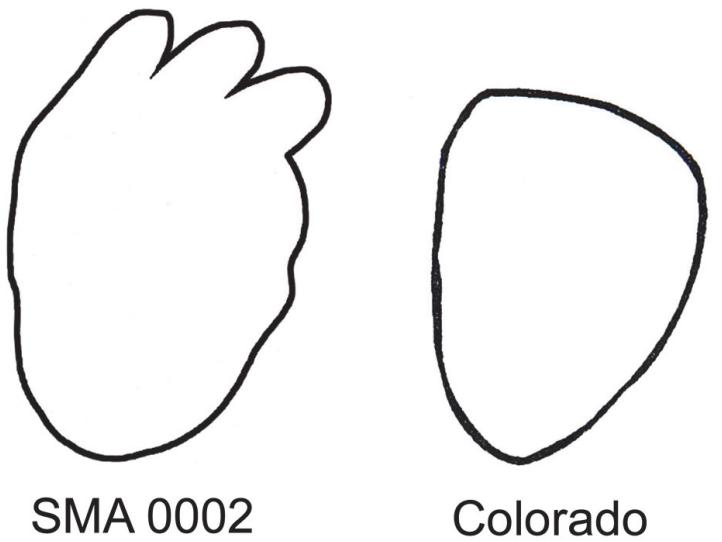

Colorado

FIGURE 35. Comparison of the supposed footprint of SMA 0002 with published tracks from different locations. Reported (Texas, Colorado) or calculated (Spain, SMA 0002) heteropody rate is indicated on top. Modified from Lockley and Meyer (2000; Texas, Colorado), Castanera et al. (2012; Spain, left print reversed).

a Camarasaurus manus with a hypothetical second vestigial phalanx in the third digit, but without referring to actual specimens. SMA 0002 is therefore the first Camarasaurus skeleton with a vestigial phalanx that is clearly articulated with phm II-1. The reduction of the phalanges culminates in derived titanosaurs, where all phalanges are vestigial or entirely absent (Borsuk-Bialynicka, 1977; Martínez et al., 2004; Hocknull et al., 2009; Poropat et al., 2015b). The shape of the phalanges yields insight into the sequence of their reduction. The reduction in length and the gradual loss of distinct distal condyles as seen throughout sauropod phylogeny is also represented in the series from medial-most to lateral-most phalanges. In diplodocids, camarasaurids, and early titanosauriforms, the distal articular surface of the proximal manual phalanges changes from being distinctly transversely concave in phm I-1 and II-1, to flat in phm III-1 and IV-1, to convex in phm V-1 (Gilmore, 1936; Janensch, 1961; Upchurch et al., 2004b; this study). The occurrence of vestigial elements that are directly articulated or even fused with the metacarpals in the derived titanosaurs Opisthocoelicaudia and Epachthosaurus (Borsuk-Bialynicka, 1977; Martínez et al., 2004; Poropat et al., 2015b) implies that the loss of distal condyles was followed by a significant reduction in both proximodistal length and transverse width (Carrano, 2005). Such a development must first have happened in the distal rows, and potentially initiated with the change of the function of the manus from grasping to weightbearing, which was probably the selection pressure favoring the loss of interphalangeal joints and manual unguals (Carrano, 2005). The sequence of manual phalangeal reduction thus appears to have been as follows: 1) reduction of terminal unguals, resulting in the inutility of distal articular surfaces of non-terminal phalanges; 2) flattening of distal surfaces of elements that have recently become terminal, non-ungual phalanges; 3 ) complete loss of distal condyles in terminal non-ungual phalanges; 4) significant reduction in size of terminal phalanges; 5) loss of vestigial terminal phalanges, or fusion with a more proximal element. A slightly different pattern of phalangeal reduction was proposed by Nair and Salisbury (2012), including an asymmetric phase and medial dislocation of the vestigial phalanges, which, however, are often not terminal elements. The fact that digit I retains a distinct ungual in all non-somphospondylian sauropods implies that this digit did not have an important role in weight-bearing, although its actual function is still debated (Upchurch, 1994; Wright, 
2005). A function in feeding, as a weapon or as anti slipping device was discussed by Upchurch (1994). Although the use as a weapon seemed the least possible, Upchurch (1994) was unable to reject this hypothesis entirely, even though he analyzed several fairly complete sauropod manus skeletons. Because the articulated pollex elements of SMA 0002 do not vary decisively from the bones described by Upchurch (1994), they provide little new information on their function.

Function of the manual ungual is influenced by its orientation. Due to its slightly oblique metacarpo-phalangeal joint, phm I-1 points mediodistally and therefore away from the other digits. The fact that its lateral side is longer than its medial one (mostly because the lateral distal condyle is more pronounced than the medial one) and that also the proximal articular face of the claw is oblique results in an ungual that points posteriorly and nearly touches the ground with the distal end of its lateral side (Figure 6; see also Wright, 2005). Trackways showing manual claw imprints (e.g., Bilbey et al., 2005; Pascual Arribas et al., 2008) are consistent with the herein proposed articulation of the ungual (Figure 35). The hypothesis of Thulborn (1989, 1990) that the claw is usually held in dorsolateral hyperextension is therefore rejected for Camarasaurus, also because both the distal articular surface of $\mathrm{mc} \mathrm{I}$ and the one of phm I-1 curve further proximally on its palmar side than anteriorly, implying that the mobility was less restricted posteriorly than towards the front (see Farlow et al., 1989 for other objections). Anteroposterior movements of the pollex also appear to have been less constricted than the ones in the other fingers (Upchurch, 1994; Bonnan, 2003; Upchurch et al., 2004a), but the orientation of the joints in digit I indicates that motion mainly occurred in a more transversal plane, because of the oblique distal faces of the precedent elements (Upchurch, 1994). This leads to the conclusion that the pollex although it was probably not separate as a whole (Paul, 1987) - was not as tightly incorporated into connective tissue as the other digits were. The absence of claw marks in some tracks might thus indicate that the ungual was habitually flexed posterolaterally during walking.

\section{Pes}

The sauropod pes is known from more individuals and better understood than the manus (Thulborn, 1990). It has a fairly uniform shape (Carrano and Wilson, 2001), and was much more elephantine than the forefeet in having a cushioning pad and a semidigitigrade stance (Osborn, 1899; Sikes, 1971; Thulborn, 1990; Christiansen, 1997c; Upchurch et al., 2004a; Milàn et al., 2005; Wilson, 2005a, 2005b; Miller et al., 2008). Unlike the condition present in elephants, eusauropod hind feet are asymmetrical and generally exhibit three large claws on digits one to three, which point somewhat laterally and are often interpreted as anti-slipping devices (Coombs, 1975; Farlow, 1992; Wilson, 2002, 2005a, 2005b; Upchurch et al., 2004a; Bonnan, 2005), or to have been used for scratch-digging (Gallup, 1989; Fowler and Hall, 2011; Tschopp et al., in press). The pedes of SMA 0002 confirm these previous interpretations.

Tarsus. The sauropod tarsus consists of two ossified elements of unequal size, which are consistently recognized as the proximal tarsal elements astragalus and calcaneum (Marsh, 1882; Bonnan, $2000,2005)$. With its ascending process, the astragalus tightly interlocks with a corresponding fossa at the distal end of the tibia in all sauropods (Gilmore, 1936; Romer, 1956; Janensch, 1961; Salgado et al., 1997; Holtz and Osmólska, 2004). Astragalus and tibia are therefore often found in articulation, as was the case in both hind legs of SMA 0002. The calcaneum is often not preserved or recognized, but was probably present in most sauropods (Gilmore, 1925; Bonnan, 2000, 2005).

The astragalus of Camarasaurus is transversely wide, subtriangular in both posterior and distal view, with a tapering medial end. Its ascending process is reaching the posterior margin of the bone in proximal view. As such, it is different from basal sauropods, where the ascending process is restricted to the anterior portion (Wilson, 2002), and from diplodocines and derived titanosaurs, which have a reduced medial end, resulting in a rather trapezoidal outline in posterior view (Poropat et al., 2015b; Tschopp et al., 2015). Diplodocoids in general have posterolaterally facing fibular facets (Tschopp et al., 2015), instead of being strictly laterally oriented as in Camarasaurus. Within nonsomphospondylan macronarians, Camarasaurus is different from the brachiosaurids Giraffatitan and Lusotitan in that these genera have a shortened medial end similar to derived titanosaurs (Janensch, 1961; Mannion et al., 2013). Janenschia has a potentially autapomorphic process on the posterodistal edge (Bonaparte et al., 2000; Mannion et al., 2013). Within Camarasaurus there is some variation in relative transverse width and proximodistal length (compare AMNH 5761 and YPM 1901 or 1905; Osborn and Mook, 1921; 
Ostrom and Mclntosh, 1966), but this might be partially due to deformation.

With its proximodistally flattened shape, the calcaneum of Camarasaurus is different from the more globular element of Suuwassea (Harris, 2007) or Haplocanthosaurus (Erickson, 2014). Camarasaurus calcanea can be distinguished from the elements of diplodocids and Jobaria by their subrectangular instead of subcircular outline in proximal view (Bonnan, 2000; ET, pers. obs. 2011, 2014). The most similar reported calcaneum belongs to Tastavinsaurus (Royo-Torres et al., 2012), from which Camarasaurus elements are virtually indistinguishable. Other titanosauriform calcanea are similar to diplodocid elements in having a subcircular shape (e.g., Neuquensaurus, Euhelopus, and Elaltitan; Huene, 1929; Wilson and Upchurch, 2009; Mannion and Otero, 2012).

As the reduction of the carpus, also the reduction of the tarsus was interpreted as an adaptation to graviportalism (Carrano, 2005; Wilson, 2005b). Whereas basal sauropods like Gongxianosaurus and Blikanasaurus still possessed ossified distal tarsals (He et al., 1998; Upchurch et al., 2004a), no eusauropod is known to have such elements (Upchurch et al., 2004a; Bonnan, 2005). Due to the rare findings of calcanea, some researchers also proposed that this bone is lost in certain taxa (Borsuk-Bialynicka, 1977; Mclntosh, 1990a, 1990b), but subsequent findings of these elements revealed that their absence was most probably due to preservational bias (Bonnan, 2000; Mannion and Otero, 2012).

The heavily rugose surfaces of both sauropod tarsals provoke the same questions concerning cartilage covering or additional cartilaginous elements as in the carpus. However, it is more widely accepted that some elements might have remained unossified in the tarsus (Raath, 1972; Upchurch, 1995, 1998; Wilson and Sereno, 1998; Wilson, 2002). The diagenetically rotated left calcaneum of SMA 0002 provides more information on cartilage covering: because it is still in close contact with the astragalus at its medial edge, its connection to the latter appears to have been stronger than the one to the fibula. This indicates that the two ossified tarsal elements were packed into stout connective tissue to minimize movements between them and to obtain a functional unit in order to distribute the weight more evenly through the pes.

If weight-bearing was the main function of the manus, the pedes must have been chiefly responsible for propulsion (Janensch, 1961; Christiansen, 1997c). In addition to the distribution of the high load to the metatarsals, the ankle must therefore have been less restricting for movements than the wrist. The rounded, continuously merging anterior and distal surfaces of the astragalus, producing the so-called distal roller, allow extensive anteroposterior movements of the metatarsus against the tarsus (maybe together with some cartilaginous distal tarsals; Christiansen, 1997b, 1997c; Bonnan, 2005). Because the distal roller is straight mediolaterally, the motions in these directions are limited, eliminating a transversal pulling and thereby supporting the weight-bearing capabilities of the pes (Bonnan, 2000).

Metatarsus. In contrast to the metacarpals, which exhibit rather diverse morphologies in the various groups of sauropod dinosaurs, the metatarsals have a more uniform shape (Farlow, 1992; Carrano and Wilson, 2001). This is reflected in phylogenetic analyses, which only recently included characters describing varying morphologies within macronarian metatarsals: Carballido et al. (2012b) and D'Emic (2012) each included two characters that are variable within Macronaria, whereas Mannion et al. (2013) have eight, and Curry Rogers (2005) has nine. However, only one feature was found as a synapomorphy of a clade within Macronaria by more than one of these analyses: the medially beveled distal articular surface of $\mathrm{mt}$ IV in brachiosaurids (D'Emic, 2012; Mannion et al., 2013). Only flagellicaudatans with their pronounced rugosities on the distal portion of the anterolateral edges of metatarsals I to III can be readily distinguished from other neosauropod taxa (Whitlock, 2011; Tschopp et al., 2015). Within non-titanosauriform macronarians, the Camarasaurus metatarsal $\mathrm{V}$ is relatively longer than its counterpart in Janenschia, compared to proximal width (Fraas, 1908), and $\mathrm{mt}$ II and III of Janenschia appear to bear distinct concave areas lateral to the distal condyles (Fraas, 1908, plate XII, figures 4, 8).

Whereas Camarasaurus metacarpals and metatarsals are of similar width and height, the single elements of the metatarsus are approximately 0.54 to 0.57 of the length of the metacarpals in SMA 0002, and slightly more in CM 11338 (0.56 to 0.66 ) and GMNH-PV 101 (0.6 to 0.61). Compared to the ratio of 0.74 to 0.96 in the diplodocid Apatosaurus louisae CM 3018 and 0.51 to 0.77 in the derived macronarian Opisthocoelicaudia skarzynskii ZPAL MgD-I/48, the elongation of the macronarian metacarpals in contrast to diplodocid elements becomes obvious (Table 4).

The proximal articular surfaces of the first three metatarsals have a rectangular to trapezoidal 
TABLE 4. Ratios between metacarpals and metatarsals in Neosauropods. All measurements in mm. Data of the other individuals obtained from Gilmore (1925: CM 11338; 1936: CM 3018), Mclntosh et al. (1996a: GMNH-PV 101), and Borsuk-Bialynicka (1977: ZPAL MgD-I/48). Metacarpals of SMA 0002 are more elongated compared to metatarsals than the metacarpals of Apatosaurus or other Camarasaurus specimens.

\begin{tabular}{|c|c|c|c|c|c|c|c|c|}
\hline & \multicolumn{3}{|c|}{ manus } & \multicolumn{3}{|c|}{ pes } & \multirow[t]{2}{*}{ ratios } \\
\hline & & right & left & mean & right & left & mean & \\
\hline \multicolumn{9}{|l|}{ Camarasaurus } \\
\hline \multirow[t]{5}{*}{ SMA 0002} & I & 204 & 196 & 200 & 113 & & 113 & 0.57 \\
\hline & II & 266 & 236 & 251.15 & 134 & 140 & 137 & 0.55 \\
\hline & III & 255 & 228 & 241.65 & 133 & 145 & 139 & 0.58 \\
\hline & IV & 236 & 225 & 230.55 & 112 & 140 & 126 & 0.55 \\
\hline & V & 208 & 193 & 200.35 & 108 & 107 & 107.5 & 0.54 \\
\hline \multirow[t]{5}{*}{ CM 11338} & I & 107 & 104 & 105.5 & 70 & 70 & 70 & 0.66 \\
\hline & II & 140 & & 140 & & 90 & 90 & 0.64 \\
\hline & III & 135 & 134 & 134.5 & & 88 & 88 & 0.65 \\
\hline & IV & 120 & 122 & 121 & & 80 & 80 & 0.66 \\
\hline & $\mathrm{V}$ & 109 & 107 & 108 & & 60 & 60 & 0.56 \\
\hline \multirow[t]{5}{*}{ GMNH-PV 101} & I & & 280 & 280 & 172 & & 172 & 0.61 \\
\hline & II & & 324 & 324 & 193 & & 193 & 0.60 \\
\hline & III & & & & 223 & & 223 & \\
\hline & IV & & & & 204 & 208 & 206 & \\
\hline & $\mathrm{V}$ & & & & 166 & & 166 & \\
\hline
\end{tabular}

Apatosaurus louisae

\begin{tabular}{|c|c|c|c|c|c|c|c|c|}
\hline CM 3018 & I & & 265 & 265 & & 195 & 195 & 0.74 \\
\cline { 2 - 9 } & II & & 285 & 285 & & 213 & 213 & 0.75 \\
\cline { 2 - 9 } & III & & 293 & 293 & & 236 & 236 & 0.81 \\
\cline { 2 - 9 } & IV & & 245 & 245 & & 236 & 236 & 0.96 \\
\cline { 2 - 9 } & V & & 235 & 235 & & & &
\end{tabular}

Opisthocoelicaudia skarzynskii

\begin{tabular}{|c|c|c|c|c|c|c|c|c|}
\hline ZPAL MgD-I/48 & I & 295 & 290 & 292.5 & 150 & & 150 & 0.51 \\
\cline { 2 - 9 } & II & 280 & 290 & 285 & 180 & & 180 & 0.63 \\
\cline { 2 - 9 } & III & & 275 & 275 & 200 & & 200 & 0.73 \\
\cline { 2 - 9 } & IV & & 235 & 235 & 180 & & 180 & 0.77 \\
\cline { 2 - 9 } & V & & 245 & 245 & 140 & & 140 & 0.57 \\
\hline
\end{tabular}

shape. As in the metacarpals, the metatarsals exhibit large rugose areas in the proximal parts of their medial and lateral sides, where they contact each other (Bonnan, 2005). The tightest association is between $\mathrm{mt} \mathrm{IV}$ and $\mathrm{mt} \mathrm{V}$, where the medially greatly expanded end of the latter reaches far into the opening of the $\mathrm{V}$-shaped proximal face of the former, implying a very close connection of the two elements so that they possibly even functioned as one single unit (Bonnan, 2005). Contrary to the metacarpals, sauropod metatarsals lack distinct ridges on their posterior sides, arguing against strong plantar soft tissue insertions. It therefore appears that the proximal articular surfaces of the metatarsals were only interconnected with soft tissue between their proximomedial and proximolateral portions, resulting in the distally spreading metatarsus typical for all sauropods (e.g., Janensch, 1922; Cooper, 1984; Mclntosh, 1990a; Upchurch et al., 2004a) or at least eusauropods (Wilson and Sereno, 1998; Wilson, 2002, 2005a, 2005b; Yates and Kitching, 2003). The morphologies of the proximal articular surfaces lead to an arrangement of the articulated sauropod metatarsus as a gentle arch (e.g., Borsuk-Bialynicka, 1977; Mclntosh et al., 1996a; Bonnan, 2005). 
Together with the distal spreading of the metatarsals, this leaves space for a cushioning pad beneath them and the tarsus (Paul, 1987).

The decreasing stoutness of the single metatarsals from the first to the last element implies that the weight was mainly carried by the medial portion of the pes (Gilmore, 1936; Wilson and Sereno, 1998; Upchurch et al., 2004a; Carrano, 2005). Tracks confirm this assumption, but also show a very deep impression at their posterior parts, where the pes is supported by the heel pad (Farlow et al., 1989; Farlow, 1992; Bonnan, 2005; Wilson, $2005 b)$. Because movements in both anterior and posterior directions must be performed during locomotion to produce propulsion, the metatarsals probably articulated somewhere in the center of the distal roller of the astragalus when standing. This results in a slightly oblique position of the metatarsus relative to the substrate, retaining the possibilities to move the pes both back and forth. Such a position is commonly described as a semidigitigrade (Thulborn, 1990; Upchurch et al., 2004a; Wilson, 2005a, 2005b) or semiplantigrade (Mclntosh et al., 1996a) foot posture.

Pedal phalanges. As in the manus, pedal phalangeal morphology does not vary decisively among sauropod taxa. The proximalmost elements resemble the manual phalanges, but are often slightly more elongate. The more distal nonungual elements continuously decrease in size, culminating in vestigial phalanges similar to the left phm II-2 of SMA 0002 (Thulborn, 1990; Wilson and Sereno, 1998; Wilson, 2002; Upchurch et al., 2004a). Camarasaurus pedal phalanges can be distinguished from flagellicaudatan elements and from Cetiosauriscus stewarti by the shape of php I-1, which is much deeper anteroposteriorly in these taxa than in Camarasaurus (Tschopp et al., 2015), and have a distinct proximoventral lip that projects below the metatarsal I (Upchurch et al., 2004b; Tschopp et al., 2015). Giraffatitan has an anteroposteriorly concave distal end of the lateral surface of php I-1 (Janensch, 1961), whereas this side is convex in Camarasaurus SMA 0002. Also, php I-1 of Giraffatitan has a subcircular proximal articular surface (Janensch, 1961), in contrast to the transversely expanded one in Camarasaurus SMA 0002. The proximodistal length of php $\mathrm{II}-1$ is shorter relative to transverse width in Camarasaurus, compared to Giraffatitan (Janensch, 1961). The distal condyles of php III-1 are better developed in anterior view in Camarasaurus than in Giraffatitan (Janensch, 1961). Pedal unguals of Giraffatitan are different from Camarasaurus in being less curved, and having the lateral groove located close to the dorsal edge (Janensch, 1961), instead of more plantarly as in SMA 0002. The medial condyle of php II-1 of Janenschia is similarly expanded distally as in SMA 0002, but its posterior surface is not marked by such a distinct foramen as in SMA 0002 (SMNS 12144; J. Nair, personal commun., 2014). Pedal unguals of Janenschia have an anterior portion of the proximal surface that is of subequal transverse width as the posterior portion (SMNS 12144; J. Nair, personal commun., 2014), whereas the proximal surface of the pedal unguals of SMA 0002 tapers anteriorly. There is no significant variation in pedal phalanx and ungual morphology among specimens of Camarasaurus.

The fact that claws are only preserved in the first three digits of SMA 0002 is consistent with all but one description of a Camarasaurus pes, where a very reduced fourth ungual is mentioned (Jensen, 1988). This underlines that the exact pedal phalangeal formula is still in question in many genera, and that this formula might be inter- or even intraspecifically variable. Upchurch $(1995,1998)$ and Upchurch et al. (2004a) assumed the phalangeal formula to be 2-3-4-2-1 in neosauropods, which was further reduced in derived titanosaurs to 2-2-2-1-0 (Borsuk-Bialynicka, 1977; González Riga et al., 2008; Nair and Salisbury, 2012). The exact phalangeal formula of Camarasaurus is unknown, because no complete pes has been described up to now (Mclntosh et al., 1996a; ET, pers. obs., 2014). Whereas Thulborn (1990) proposed the formula to be 2-2-2-1-1 (which can be rejected based on SMA 0002 and other Camarasaurus specimens), Wilson (2005b) and González Riga et al., (2008) left a question mark at the number of phalanges in the fifth digit of this genus (2-3-4-2-?). In SMA 0002, the preserved count is 2-3-4-2-0. Other articulated specimens of Camarasaurus show formulas like 2-3-4-1-0 (CM 11338; Gilmore, 1925; Mclntosh et al., 1996a), 2-3-3-2-1 (USNM 13786; Mclntosh et al., 1996a), and 2-3-4-2-1 or 2-3-4-3-1 in a pes figured by Jensen (1988; it is difficult to decide if a supposed fourth claw is the second or the third phalanx, after his figures $7 b$ and 7c), a fact that might imply individual variation as already discussed for the manual phalanges (see above). However, the questionable elements are all small rounded lumps of bone, which could easily have been overlooked during the excavation of the specimens. This might also have been the case in SMA 0002, since the right php IV-2 is missing and the corresponding element of the left pes was dam- 
aged during excavation. It is plausible that both php V-1 of SMA 0002 got lost pre- or post-mortem - especially when considering their vestigial shape (Jensen, 1988; McIntosh et al., 1996a, 1996b). Taking all this into account, the actual phalangeal formula in Camarasaurus appears to have been 23-4-2-1.

As the metatarsals, the phalanges continuously decrease in stoutness from the first to the fifth digit (Farlow, 1992). The proximal elements of the claw-bearing digits retain fairly distinct condyles at their distal ends, indicating that motion between them and their following bones were still of importance for locomotion or possibly scratchdigging behavior (Gallup, 1989; Christiansen, 1997b; Bonnan, 2005; Fowler and Hall, 2011; Tschopp et al., in press). In all the phalanges the medial condyle projects further distally than the lateral one, except for php IV-1 where the opposite condition is present. The succeeding elements conserve this trend, which was also reported in most other sauropod taxa (Gilmore, 1936; BorsukBialynicka, 1977; Yates and Kitching, 2003; Upchurch et al., 2004a; Harris, 2007; González Riga et al., 2008). The oblique articular surfaces of the claws enhance this trend, so that their tips point distinctly laterally, a trait that is considered a synapomorphy of Eusauropoda (Wilson, 2002, 2005b). This outwards rotation increases from the first to the third digit, which is influenced by higher numbers of precedent phalanges with unequally long sides in digits II and III. The fact that the development of the distal condyles is opposite in php IV-1 has also been recognized by Gilmore (1936) in Apatosaurus louisae CM 3018, and was considered by him an important feature to distinguish this element from the other phalanges. It might also be an indication that this digit did not bear an ungual. Moreover, taking the arched condition of the metatarsus into account, it appears that the elongated lateral side of php IV-1 touched the substrate at its distal end, thereby providing lateral support for the pes. This would not be possible with the same dimensions as the other phalanges.

\section{Pathologies}

Many of the manual and pedal proximal phalanges and the pedal unguals of SMA 0002 show osteological features, in particular different types of bone overgrowths, which were described in detail by Tschopp et al. (in press). The bone overgrowths and other anomalies comprise symptoms of osteoarthritis, osteochondrosis, enthesophytes, bone fractures, and bone tumors (Tschopp et al., in press). This accumulation of various pathologies provides additional support for a senescent age of SMA 0002, as already recognized by bone histology (Klein and Sander, 2008; Waskow and Sander, 2014; Tschopp et al., in press).

\section{Taphonomy}

Manual and pedal remains are rarely found in sauropods, and when found, they are mostly incomplete and the bones scattered (Wilson, 2005a). This results from an earlier disarticulation of distal compared to proximal body parts, or of scavenging (Dodson, 1990; Harris, 2007). The presence of all four autopodia in articulation therefore implies a rapid burial and thus supports the view of Ayer (2000) that at least SMA 0002 died in a flood event, was washed into a river or an oxbow lake, and covered by sediment soon after. The quick burial is also indicated by the missing tooth marks of theropods on autopodial elements of SMA 0002 and by the presence of skin impressions. The latter can only be preserved after a rapid burial, mostly due to high sedimentation rates or a very soft substrate (Martill, 1991; Benton, 1998). Moreover, a thin, dark, organic-rich layer covering skin impressions is also known from ichthyosaurs of Great Britain (Martill, 1991 and references therein) or Germany (Keller, 1992), from a theropod of Brazil (Kellner, 1996; Benton, 1998), from a Pelecanimimus of Spain (Briggs et al., 1997), and a Hesperosaurus mjosi from the same quarry as SMA 0002 (Christiansen and Tschopp, 2010). They are usually interpreted as replications by lithified bacterial mats.

\section{D Reconstruction}

The preserved skin impressions and the perfect articulation of the autopodia give more information as hitherto known on the morphology of the manus and pes of Camarasaurus. Furthermore, the produced 3D models provide insights into Alexander"s (1976) and Thulborn's (1990) formula on hip height, and comparisons with published drawings and photographs of footprints help reconstructing the shape of Camarasaurus trackways.

Skin impressions. The macroscopic polygonal patterns of the skin impressions found in the regions of the manus and the distal hind legs are consistent with earlier described sauropod soft tissue preservations of this kind (e.g., Czerkas, 1992, 1997; Upchurch et al., 2004a; Platt and Hasiotis, 2006; Coria and Chiappe, 2007; Foster and HuntFoster, 2011). Such a structure was also reported from various ornithischians (e.g., Osborn, 1912; 
Brown, 1916; Sternberg, 1925; Czerkas, 1997; Christiansen and Tschopp, 2010).

Several studies on thin dark layers covering preserved soft-tissue have been published (e.g., Brown, 1935; Martill, 1991; Czerkas, 1992; Keller, 1992; Briggs et al., 1997), with varying results: whereas Brown (1935) and Czerkas (1992) in their publications on material of the Howe Quarry, and Martill (1991) on a thyreophoran specimen proposed the layer to represent parts of the original skin, the majority of the authors interpreted it as remnants of microbial mats that decomposed the soft-tissue, thereby reproducing the skin pattern (e.g., Keller, 1992; Briggs et al., 1997). A detailed geochemical analysis could possibly help solving this question, but is outside the scope of this publication.

The skin impression preserved near the posterior side of the right manual phalanges provides additional information concerning external sauropod manus morphology. The very short distance between the phalangeal imprints on one side and the skin impression on the other side of the slab (Figure 32) argues against the presence of a palmar pad of soft tissue in the manus. It is difficult to explain the absence of any impression of such a pad as the result of diagenetic compression of a tissue that supported the weight of a sauropod, while the manus is preserved in three dimensions and even with skin impressions partially wrapped around it. At least the phalanges of the second to the fourth digit thus appear to have been tightly packed into connective tissue, so that the single "fingers" were probably not visible in vivo (Janensch, 1922). Furthermore, the skin impressions around the manual phalanges do not show the striated pattern as the impressions of the keratinous sheat covering stegosaur dorsal plates (Christiansen and Tschopp, 2010). The fact that the manus of SMA 0002 does not have any bones similar to the hoof-shaped terminal phalanges known from ornithischians (e.g., Currie et al., 2011), indicates that no hoofs were present. These interpretations confirm earlier findings based on sauropod manus prints (Bird, 1944; Farlow, 1992; Christiansen, 1997a).

Footprints. Sauropod footprints were found all around the world, and several different ichnotaxa were described (Wright, 2005; Kim and Lockley, 2012; and references therein). However, due to the very similarly shaped manus and pedes among members of this clade, most of the tracks can only be identified as belonging to one of the main groups of the Sauropoda (Farlow, 1992; Carrano and Wilson, 2001; Day et al., 2004; Wright, 2005). Since SMA 0002 is one of very few reported sauropod skeletons exhibiting articulated manus and pedes of a single individual, accurate size relationships between manus and pes of SMA 0002 yield rare insights into the proportions of manual and pedal prints of Camarasaurus, which are supposed to be distinctive characteristics of ichnospecies by several track workers (e.g., Lockley and Meyer, 2000; Santos et al., 2009), and can thus be used to narrow down the possible tracks made by this genus. The "trackway" made by our 3D model shows a heteropody rate of 1:3.77, so that the pes print is nearly four times the size of the manus print (Figure 35). Additionally, the articulation of the pollex claw leads to the conclusion that an ungual imprint should be present in the tracks of Camarasaurus. However, due to the short first metacarpal, the corresponding claw might have touched the ground only at its distal end, if the animal was walking on hard substrate. In such a case, the ungual mark would be very shallow (Wright, 2005), and the heteropody rate would be lowered. The less restricting fifth metacarpo-phalangeal joint surface in SMA 0002, compared to the joints in digits II to $\mathrm{IV}$, indicates that digit $\mathrm{V}$ was slightly more mobile, and thus possibly more separate from the rest of the manus in a Camarasaurus manus track.

A recent comprehensive study on appendicular morphology (Wilhite, 2003) suggested that Camarasaurus was a wide gauge trackmaker (contra Carrano and Wilson, 2001). However, there appears to be some overlap of narrow and wide gauge tracks (Wright, 2005), and also reports of trackways with small changes in gauge exist (Marty et al., 2006; Castanera et al., 2012). Therefore, an intermediate gauge pattern was proposed for certain sauropod trackways (Lockley et al., 1994a; Meyer et al., 1994; Day et al., 2004). Such a pattern might very well have been produced by Camarasaurus (Wilhite, 2003; Foster, 2007). To sum up, Camarasaurus tracks should be intermediate- to wide-gauge with a heteropody rate of approximately $1: 3$ to $1: 4$. When well-preserved, they should have imprints of a single manual and three pedal claws, and possibly a distinct impression of digit $\mathrm{V}$ in the manus.

Intermediate- to wide-gauge trackways attributed to Sauropoda include the ichnospecies Brontopodus birdi and B. pentadactylus, Rotundichnus muenchehagensis, Sauropodichnus giganteus, Elephantopoides barkhausensis, Polyonyx gomesi, and Titanopodus mendozensis (Wright, 2005; González Riga and Calvo, 2009; 
Santos et al., 2009; Kim and Lockley, 2012). Of these, B. birdi, R. muenchehagensis, S. giganteus, E. barkhausensis, and T. mendozensis have a similar heteropody rate as the reconstructed footprints of SMA 0002. Manual claw imprints do not occur in any of these ichnospecies (Wright, 2005; González Riga and Calvo, 2009; Santos et al., 2009; Kim and Lockley, 2012), although this might in parts be due to poor preservation. A similar track to the hypothetical Camarasaurus track created herein was reported from Spain (LCU-I-37; Pascual Arribas et al., 2008; Castanera et al., 2012). Although initially classified as narrow-gauge (Pascual Arribas et al., 2008), Castanera et al. (2012) revised this interpretation and concluded that it should be referred to an intermediate-gauge ichnomorphotype. However, the trackway has not yet been assigned to any ichnotaxon. A manus print with claw impressions is also known from the Morrison Formation, but was found isolated and thus yields no information on heteropody rate or associated pes morphology (Bilbey et al., 2005, figure 10). It therefore seems that although some potential Camarasaurus prints exist, none of the described ichnospecies would fit the combined manual and pedal morphology of this genus. A more detailed study of potential camarasaurid tracks is thus needed, in particular of the occurrences in the Morrison Formation.

Three attempts were undertaken to calculate the hip height $(\mathrm{h})$ of sauropod dinosaurs based on their pedal footprint length (FL), proposing the equations $\mathrm{h}=4 \mathrm{FL}$ (Alexander, 1976), $\mathrm{h}=5.9 \mathrm{FL}$ (Thulborn, 1990), and h = 4.6 FL (González Riga, 2011). Only the study of González Riga (2011) is based on direct measurements of articulated hind limbs with complete pedes. The 3D model of the pes of SMA 0002 yields additional information on the exact formula in Camarasaurus. It was created assuming that the metatarsals were inclined in an angle of about $20^{\circ}$, and that the metatarso-phalangeal joint was touching the ground. The resulting $\mathrm{FL}$ including ungual imprints is approximately 60 $\mathrm{cm}$, whereas h (see Thulborn, 1990, figure 8.4 for the measuring method) is approximately $168 \mathrm{~cm}$. Hip height would then be roughly 2.8 FL. Taking FL without the claw imprints, h would increase to 3.6 FL. Although a large cartilage covering of the long bones as supposed by Holliday et al. (2010), Schwarz et al. (2007b), and Bonnan et al. (2010) might increase $\mathrm{h}$ by up to $10 \%$, it would still result around $3 \mathrm{FL}$. The ratio of metatarsal length to footprint length is also much lower in the 3D model than proposed by Thulborn $(1990 ; 24 \%$ in the model including claw prints, $46 \%$ in Thulborn). The formula of Thulborn (1990) therefore appears to be rather inaccurate and likely results in overestimated body sizes of the trackmakers. The use of Alexander's (1976) formula in various other studies on sauropod tracks (e.g., Lockley et al., 1994b; Mazzetta and Blanco, 2001; Castanera et al., 2012) is therefore supported by our data. Comparing our results with the ones reported by González Riga (2011), there seem to be significant differences among taxa as well, given that he based his calculations on an articulated titanosaurian pes (MUCPv-1533). However, González Riga (2011) reconstructed the metatarsals at a higher angle (40-50 instead of $20^{\circ}$ as proposed herein), which increases the relative hip height. Following González Riga's (2011) equation (2), hip height of SMA 0002 would only be marginally higher (171 $\mathrm{cm}$ ), and the $\mathrm{h} / \mathrm{FL}$ ratio therefore more or less equal to the one mentioned above. The smaller ratio in the titanosaur MUCPV-1533 might be partially caused by the reduction of the number of pedal phalanges, compared to Camarasaurus.

\section{CONCLUSION}

The manus and pedes of Camarasaurus SMA 0002 represent the first complete set of articulated autopodia known from a singular sauropod individual. This allowed to review the evolution of manual and pedal shape in more detail, and to produce an accurate reconstruction of the Camarasaurus manus and pes in $3 \mathrm{D}$. This reconstruction indicates that the relation of hip height to footprint length varies among sauropod taxa, and that the equations proposed in the past have to be used with care. Currently accepted ichnogenera do not fit the expected footprint shape of Camarasaurus. However, certain tracks from both the USA and from Spain are very similar to prints produced with the herein reconstructed 3D models. The completeness of the autopodia and the fact that they were preserved with skin impressions covering some areas, imply a rapid burial of the specimen.

\section{ACKNOWLEDGMENTS}

We are very grateful to $\mathrm{H}$.-J. Siber (director of the SMA) for making SMA 0002 available for study. Thanks to the great job of the field team of the SMA in excavating and preparing, which was mainly done by E. Premru, B. Pabst, H.-J. Siber, and $\mathrm{O}$. Gross, it has been possible to retain all the important scientific information provided by this well-preserved specimen. The X-ray Tomographies 
at USZ were possible thanks to $\mathrm{H}$. Alkadhi, and technical support was provided by C. Karlo. We thank R. Roth and E. Premru for photos of the bones, and B. Scheffold for the help with the drawings and the 3D model. J. Ayer kindly provided previously unpublished data of ongoing studies. T. Ikejiri, D. Brinkman, A. Henrici, and R. Simon shared unpublished pictures of manus and pedes of sauropod specimens. A special thank goes to $\mathrm{N}$. Christiansen (Milan, Italy), J. Nair (University of Queensland, Australia), L. Wilson (University of New South Wales, Australia), and A. Kopps (University of Groningen, Netherlands) for correcting the English and reviewing a previous version of this manuscript. Two anonymous referees provided crucial revisions. Finally, we want to thank the Executive Editor of Palaeontologia Electronica, Julien Louys, for the uncomplicated editorial handling and the technical editors for support. Financial support to E. Tschopp and O. Wings was provided by the "Europasaurus-Project", funded by the Volkswagen Foundation. E. Tschopp is currently funded by the European Union's Horizon 2020 research and innovation programme under the Marie Skłodowska-Curie grant agreement No 609402 - 2020 researchers: Train to Move (T2M).

\section{REFERENCES}

Alexander, R.M. 1976. Estimates of speeds of dinosaurs. Nature, 261:129-130.

Apesteguía, S. 2005. Evolution of the titanosaur metacarpus, p. 321-346. In Tidwell, V. and Carpenter, K. (eds.), Thunder-Lizards: The Sauropodomorph Dinosaurs. Indiana University Press, Bloomington.

Averianov, A.O., Voronkevich, A.V., Maschenko, E.N., Leshchinskiy, S.V., and Fayngertz, A.V. 2002. A sauropod foot from the Early Cretaceous of Western Siberia, Russia. Acta Palaeontologica Polonica, 47:117-124.

Ayer, J. 2000. The Howe Ranch Dinosaurs. Sauriermuseum Aathal, Aathal, Switzerland.

Bedell, M.W.J. and Trexler, D.L. 2005. First articulated manus of Diplodocus carnegii, p. 302-320. In Tidwell, V. and Carpenter, K. (eds.), Thunder-Lizards: The Sauropodomorph Dinosaurs. Indiana University Press, Bloomington.

Benton, M.J. 1998. Dinosaur fossils with soft parts. Trends in Ecology \& Evolution, 13:303-304. doi:10.1016/S0169-5347(98)01420-7

Benton, M.J., Juul, L., Storrs, G.W., and Galton, P.M. 2000. Anatomy and systematics of the prosauropod dinosaur Thecodontosaurus antiquus from the Upper Triassic of southwest England. Journal of Vertebrate Paleontology, 20:77-108. doi:10.1671/0272-4634

Biewener, A.A. 1983. Allometry of quadrupedal locomotion: the scaling of duty factor, bone curvature and limb orientation to body size. Journal of Experimental Biology, 105:147-171.

Bilbey, S.A., Mickelson, D.L., Hall, J.E., Kirkland, J.I., Madsen, S.K., Blackshear, B., and Todd, C. 2005. Vertebrate ichnofossils from the Upper Jurassic Stump to Morrison Transition-Flaming Gorge Reservoir, Utah. In Dehler, C.M., Pederson, J.L., Sprinkel, D.A., and Kowallis, B.J. (eds.), Uinta Mountain Geology, Utah Geological Association Publication, 33:111-123.

Bird, R.T. 1944. Did Brontosaurus ever walk on land? Natural History, 53:60-67.

Bonaparte, J.F., González Riga, B.J., and Apesteguía, S. 2006. Ligabuesaurus leanzai gen. et sp. nov. (Dinosauria, Sauropoda), a new titanosaur from the Lohan Cura Formation (Aptian, Lower Cretaceous) of Neuquén, Patagonia, Argentina. Cretaceous Research, 27:364-376.

Bonaparte, J.F., Heinrich, W.-D., and Wild, R. 2000. Review of Janenschia Wild, with the description of a new sauropod from the Tendaguru beds of Tanzania and a discussion on the systematic value of procoelous caudal vertebrae in the Sauropoda. Palaeontographica Abteilung A, 256:25-76.

Bonnan, M.F. 2000. The presence of a calcaneum in a diplodocid sauropod. Journal of Vertebrate Paleontology, 20:317-323.

Bonnan, M.F. 2001. The evolution and functional morphology of sauropod dinosaur locomotion. Unpublished PhD Thesis, Northern Illinois University, Dekalb, Illinois.

Bonnan, M.F. 2003. The evolution of manus shape in sauropod dinosaurs: implications for functional morphology, forelimb orientation, and phylogeny. Journal of Vertebrate Paleontology, 23:595-613.

Bonnan, M.F. 2005. Pes anatomy in sauropod dinosaurs: Implications for functional morphology, evolution, and phylogeny, p. 346-380. In Tidwell, V. and Carpenter, K. (eds.), Thunder-lizards: the Sauropodomorph dinosaurs. Indiana University Press, Bloomington.

Bonnan, M.F., Sandrik, J.L., Nishiwaki, T., Wilhite, D.R., Elsey, R.M., and Vittore, C. 2010. Calcified cartilage shape in archosaur long bones reflects overlying joint shape in stress-bearing elements: Implications for nonavian dinosaur locomotion. The Anatomical Record: Advances in Integrative Anatomy and Evolutionary Biology, 293:2044-2055. doi:10.1002/ ar.21266

Bonnan, M.F. and Yates, A.M. 2007. A new description of the forelimb of the basal sauropodomorph Melanorosaurus: implications for the evolution of pronation, manus shape and quadrupedalism in sauropod dinosaurs. Special Papers in Palaeontology, 77:157-168.

Borsuk-Bialynicka, M. 1977. A new camarasaurid sauropod Opisthocoelicaudia skarzynskii, gen. n., sp. n. from the Upper Cretaceous of Mongolia. Palaeontologia Polonica, 37:5-64.

Briggs, D.E.G., Wilby, P.R., Pérez-Moreno, B.P., Sanz, J.L., and Fregenal-Martínez, M. 1997. The mineral- 
ization of dinosaur soft tissue in the Lower Cretaceous of Las Hoyas, Spain. Journal of the Geological Society, 154:587-588. doi:10.1144/gsjgs.154.4.0587

Brown, B. 1916. Corythosaurus casuarius: skeleton, musculature and epidermis. Bulletin of the American Museum of Natural History, 35:709-716.

Brown, B. 1935. Sinclair dinosaur expedition, 1934. Natural History, 36:2-15.

Bunim, J.J. 1956. Arthritis in the elderly patient (osteoarthritis). Bulletin of the New York Academy of Medicine, 32:102-115.

Caplan, A.I. 1984. Cartilage. Scientific American, 251:82-90.

Carballido, J.L., Marpmann, J.S., Schwarz-Wings, D., and Pabst, B. 2012a. New information on a juvenile sauropod specimen from the Morrison Formation and the reassessment of its systematic position. Palaeontology, 55:567-582. doi:10.1111/j.14754983.2012.01139.x.

Carballido, J.L., Salgado, L., Pol, D., Canudo, J.I., and Garrido, A. 2012b. A new basal rebbachisaurid (Sauropoda, Diplodocoidea) from the Early Cretaceous of the Neuquén Basin; evolution and biogeography of the group. Historical Biology, 24:631-654. doi:10.1080/08912963.2012.672416

Carpenter, K., Chure, D.J., and Kirkland, J.I. (eds.) 1998. The Upper Jurassic Morrison Formation: an interdisciplinary study. Modern Geology, 22-23.

Carrano, M.T. 2005. The evolution of sauropod locomotion: morphological diversity of a secondarily quadrupedal radiation, p. 229-251. The Sauropods: Evolution and Paleobiology. University of California Press, Berkeley, California.

Carrano, M.T. and Wilson, J.A. 2001. Taxon distributions and the tetrapod track record. Paleobiology, 27:564582. doi:10.1666/0094-8373

Castanera, D., Pascual, C., Canudo, J.I., Hernández, N., and Barco, J.L. 2012. Ethological variations in gauge in sauropod trackways from the Berriasian of Spain. Lethaia, 45:476-489. doi:10.1111/j.15023931.2012.00304.x

Christiansen, N.A. and Tschopp, E. 2010. Exceptional stegosaur integument impressions from the Upper Jurassic Morrison Formation of Wyoming. Swiss Journal of Geosciences, 103:163-171. doi:10.1007/ s00015-010-0026-0

Christiansen, P. 1997a. Forelimbs and hands, p. 245253. In Currie, P.J. and Padian, K. (eds.), Encyclopedia of Dinosaurs. Academic Press, San Diego, California, USA.

Christiansen, P. 1997b. Hindlimbs and feet, p. 320-328. In Currie, P.J. and Padian, K. (eds.), The Encyclopedia of Dinosaurs. Academic Press, San Diego, California, USA.

Christiansen, P. 1997c. Locomotion in sauropod dinosaurs. Gaia, 14:45-75.

Coombs Jr, W.P. 1975. Sauropod habits and habitats. Palaeogeography, Palaeoclimatology, Palaeoecology, 17:1-33. doi:10.1016/0031-0182(75)90027-9
Cooper, M.R. 1984. A reassessment of Vulcanodon karibaensis Raath (Dinosauria: Saurischia) and the origin of the Sauropoda. Palaeontologia Africana, 25:203-231.

Cope, E.D. 1877. On a gigantic saurian from the Dakota epoch of Colorado. Paleontological Bulletin, 25:5-10.

Coria, R.A. and Chiappe, L.M. 2007. Embryonic skin from Late Cretaceous sauropods (Dinosauria) of Auca Mahuevo, Patagonia, Argentina. Journal of Paleontology, 81:1528-1532. doi:10.1666/05-150.1

Currey, J.D. 1984. The Mechanical Adaptations of Bones. Princeton University Press, New Jersey, USA.

Currie, P.J., Badamgarav, D., Koppelhus, E.B., Sissons, R., and Vickaryous, M.K. 2011. Hands, feet, and behaviour in Pinacosaurus (Dinosauria: Ankylosauridae). Acta Palaeontologica Polonica, 56:489-504. doi:10.4202/app.2010.0055

Curry Rogers, K.A. 2005. Titanosauria: a phylogenetic overview, p. 51-103. In Curry Rogers, K.A. and Wilson, J.A. (eds.), The Sauropods: Evolution and Paleobiology. University of California Press, Berkeley, California.

Curry Rogers, K.A. 2009. The postcranial osteology of Rapetosaurus krausei (Sauropoda: Titanosauria) from the Late Cretaceous of Madagascar. Journal of Vertebrate Paleontology, 29:1046-1086.

Czerkas, S.. 1997. Skin, p. 1100-1116. In Currie, P.J. and Padian, K. (eds.), Encyclopedia of Dinosaurs. Academic Press, San Diego, California.

Czerkas, S.A. 1992. Discovery of dermal spines reveals a new look for sauropod dinosaurs. Geology, 20:1068-1070.

Dantas, P., Sanz, J., Marques da Silva, C., Ortega, F., Santos, V., and Cachão, M. 1998. Lourinhasaurus n. gen. novo dinossáurio saurópode do Jurássico superior (Kimeridgiano superior-Titoniano inferior) de Portugal. Actas do V Congresso Nacional de Geologia, Comunicações do Instituto Geológico e Mineiro, 84:91-94.

Darton, N.H. 1906. Geology of the Bighorn Mountains. United States Geological Survey Professional Paper, 51:1-129.

Day, J.J., Norman, D.B., Gale, A.S., Upchurch, P., and Powell, H.P. 2004. A Middle Jurassic dinosaur trackway site from Oxfordshire, UK. Palaeontology, 47:319-348.

De Beaumont, G. and Demathieu, G.R. 1980. Remarques sur les extrémités anterieures des Sauropodes (Reptiles, Saurischiens). Compte rendu des séances de la Société de physique et d'histoire naturelle de Genève, 15:191-198.

D'Emic, M.D. 2012. The early evolution of titanosauriform sauropod dinosaurs. Zoological Journal of the Linnean Society, 166:624-671. doi:10.1111/j.10963642.2012.00853.x

D'Emic, M., Wilson, J.A., and Williamson, T.E. 2011. A sauropod dinosaur pes from the latest Cretaceous of North America and the validity of Alamosaurus san- 
juanensis (Sauropoda, Titanosauria). Journal of Vertebrate Paleontology, 31:1072-1079. doi:10.1080/ 02724634.2011 .595856

Dodson, P. 1990. Sauropod paleoecology, p. 402-407. In Weishampel, D.B., Dodson, P., and Osmólska, H. (eds.), The Dinosauria. University of California Press, Berkeley, California.

Dodson, P., Behrensmeyer, A.K., Bakker, R.T., and Mclntosh, J.S. 1980. Taphonomy and paleoecology of the dinosaur beds of the Jurassic Morrison Formation. Paleobiology, 6:208-232.

Erickson, B.R. 2014. History of the Poison Creek expeditions 1976 -1990 with description of Haplocanthosaurus post cranials and a subadult diplodocid skull. Science Museum of Minnesota Monograph, 8:1-33.

Falkingham, P. 2015. A rough guide to getting models out of CT scans using 3D Slicer (v4). Retrieved April 9, 2015, from https://pfalkingham.wordpress.com/ 2015/03/12/227/.

Farlow, J.O. 1992. Sauropod tracks and trackmakers integrating the ichnological and skeletal records. Zubia, 10:89-138.

Farlow, J.O., Pittman, J.G., and Hawthorne, M. 1989. Brontopodus birdi, Lower Cretaceous sauropod footprints from the US Gulf Coastal Plain, p. 371-394. In Gillette, D.D. and Lockley, M.G. (eds.), Dinosaur Tracks and Traces. Cambridge University Press, Cambridge, England, New York.

Faux, C.M. and Padian, K. 2007. The opisthotonic posture of vertebrate skeletons: postmortem contraction or death throes? Paleobiology, 33:201-226. doi:10.1666/06015.1

Foster, J.R. 2003. Paleoecological analysis of the vertebrate fauna of the Morrison Formation (Upper Jurassic), Rocky Mountain Region, USA. New Mexico Museum of Natural History and Science Bulletin, 23:2-100.

Foster, J.R. 2007. Jurassic West: The Dinosaurs of the Morrison Formation and Their World. Indiana University Press, Bloomington and Indianapolis, USA.

Foster, J.R. and Hunt-Foster, R.K. 2011. New occurrences of dinosaur skin of two types (Sauropoda? and Dinosauria indet.) from the Late Jurassic of North America (Mygatt-Moore Quarry, Morrison Formation). Journal of Vertebrate Paleontology, 31:717721. doi:10.1080/02724634.2011.557419

Fowler, D.W. and Hall, L.E. 2011. Scratch-digging sauropods, revisited. Historical Biology, 23:27-40. doi:10.1080/08912963.2010.504852

Fraas, E. 1908. Ostafrikanische Dinosaurier. Palaeontographica, 15:105-144.

Gallup, M.R. 1989. Functional morphology of the hindfoot of the Texas sauropod Pleurocoelus sp. indet. Paleobiology of the Dinosaurs. Geological Society of America Special Paper, 238:71-74.

Gilmore, C.W. 1925. A nearly complete articulated skeleton of Camarasaurus, a saurischian dinosaur from the Dinosaur National Monument, Utah. Memoirs of the Carnegie Museum, 10:347-384.
Gilmore, C.W. 1936. Osteology of Apatosaurus: with special reference to specimens in the Carnegie Museum. Memoirs of the Carnegie Museum, 11:175300.

González Riga, B.J. 2011. Speeds and stance of titanosaur sauropods: analysis of Titanopodus tracks from the Late Cretaceous of Mendoza, Argentina. Anais da Academia Brasileira de Ciências, 83:279-290. doi:10.1590/S0001-37652011005000002

González Riga, B.J. and Calvo, J.O. 2009. A new widegauge sauropod track site from the Late Cretaceous of Mendoza, Neuquén Basin, Argentina. Palaeontology, 52:631-640. doi:10.1111/j.14754983.2009.00869.x

González Riga, B.J., Calvo, J.O., and Porfiri, J. 2008. An articulated titanosaur from Patagonia (Argentina): new evidence of neosauropod pedal evolution. Palaeoworld, 17:33-40.

Halstead, L.B. 1974. Vertebrate Hard Tissues. Wykeham, London, UK.

Harris, J.D. 2006. The significance of Suuwassea emilieae (Dinosauria: Sauropoda) for flagellicaudatan intrarelationships and evolution. Journal of Systematic Palaeontology, 4:185-198.

Harris, J.D. 2007. The appendicular skeleton of Suuwassea emilieae (Sauropoda: Flagellicaudata) from the Upper Jurassic Morrison Formation of Montana (USA). Geobios, 40:501-522.

Hatcher, J.B. 1902. Structure of the forelimb and manus of Brontosaurus. Annals of the Carnegie Museum, 1:356-376.

Heidsieck, E. 1928. Der Bau der Skeletteile der freien Extremitäten bei den Reptilien: 1. Mitteilung: Gecconidae und Agamidae. Morphologisches Jahrbuch, 59:343-492.

He, X., Wang, C., Liu, S., Zhou, F., Liu, T., Cai, K., and Dai, B. 1998. A new species of sauropod from the Early Jurassic of Gongxian County, Sichuan. Acta Geologica Sichuan, 18:1-6.

Hocknull, S.A., White, M.A., Tischler, T.R., Cook, A.G., Calleja, N.D., Sloan, T., and Elliott, D.A. 2009. New Mid-Cretaceous (Latest Albian) Dinosaurs from Winton, Queensland, Australia. PLoS ONE 4:e6190. doi:10.1371/journal.pone.0006190

Holliday, C.M., Ridgely, R.C., Sedlmayr, J.C., and Witmer, L.M. 2010. Cartilaginous epiphyses in extant archosaurs and their implications for reconstructing limb function in dinosaurs. PLoS ONE, 5:e13120.

Holtz, T.R.J. and Osmólska, H. 2004. Basal Saurischia, p. 21-24. In Weishampel, D.B., Dodson, P., and Osmólska, H. (eds.), The Dinosauria. Second Edition. University of California Press, Berkeley, California.

Huene, F. 1929. Los Saurisquios y Ornithisquios de Cretaceo Argentine. Annales de Museo de La Plata, 3 (Series 2):1-196.

Ikejiri, T. 2004. Anatomy of Camarasaurus lentus (Dinosauria: Sauropoda) from the Morrison Formation (Late Jurassic), Thermopolis, central Wyoming, with 
determination and interpretation of ontogenetic, sexual dimorphic, and individual variation in the genus. Unpublished Masters Thesis, Fort Hays State University, Kansas, UMI.

Ikejiri, T. 2005. Distribution and biochronology of Camarasaurus (Dinosauria, Sauropoda) from the Jurassic Morrison Formation of the Rocky Mountain Region. New Mexico Geological Society Field Conference Guidebook, Geology of the Chama Basin, 56:367379.

Ikejiri, T., Tidwell, V., and Trexler, D.L. 2005. New adult specimens of Camarasaurus lentus highlight ontogenetic variation within the species, p. 154-179. Thunder-lizards: the Sauropodomorph Dinosaurs. Indiana University Press, Bloomington.

Jaffe, H.L. 1972. Metabolic, Degenerative, and Inflammatory Diseases of Bones and Joints. Lea \& Febiger, Philadelphia, USA.

Janensch, W. 1922. Das Handskelett von Gigantosaurus robustus und Brachiosaurus brancai aus den Tendaguru-Schichten Deutsch-Ostafrikas. Centralblatt für Mineralogie, Geologie und Paläontologie, 15:464480.

Janensch, W. 1961. Die Gliedmassen und Gliedmassengürtel der Sauropoden der Tendaguru-Schichten. Palaeontographica-Supplementbände, 4:177-235.

Jensen, J.A. 1988. A fourth new sauropod dinosaur from the Upper Jurassic pf the Colorado Plateau and sauropod bipedalism. Western North American Naturalist, 48:121-145.

Keller, T. 1992. "Weichteil-Erhaltung" bei grossen Vertebraten (Ichthyosauriern) des Posidonienschiefers Holzmadens (Oberer Lias, Mesozoikum Süddeutschlands). Kaupia, 1:23-62.

Kellner, A.W.A. 1996. Fossilized theropod soft tissue. Nature, 379:32-32. doi:10.1038/379032a0

Kim, J.Y. and Lockley, M.G. 2012. New sauropod tracks (Brontopodus pentadactylus ichnosp. nov.) from the Early Cretaceous Haman Formation of Jinju Area, Korea: implications for sauropods manus morphology. Ichnos, 19:84-92. doi:10.1080/ 10420940.2012.664056

Klein, N. and Sander, P.M. 2008. Ontogenetic stages in the long bone histology of sauropod dinosaurs. Paleobiology, 34:247-263.

Knese, K.-H. and Biermann, H. 1958. Die Knochenbildung an Sehnen- und Bandansätzen im Bereich ursprünglich chondraler Apophysen. Zeitschrift für Zellforschung und Mikroskopische Anatomie, 49:142-187. doi:10.1007/BF00324425

Kvale, E.P., Johnson, A.D., Mickelson, D.L., Keller, K., Furer, L.C., and Archer, A.W. 2001. Middle Jurassic (Bajocian and Bathonian) dinosaur megatracksites, Bighorn Basin, Wyoming, USA. Palaios, 16:233-254.

Läng, É. and Goussard, F. 2007. Redescription of the wrist and manus of ?Bothriospondylus madagascariensis: new data on carpus morphology in Sauropoda. Geodiversitas, 29:549-560.
Larson, C.B. 1962. The wearing-out of joints. Journal of the American Geriatrics Society, 10:558-566.

Lockley, M.G., Farlow, J.O., and Meyer, C. 1994a. Brontopodus and Parabrontopodus ichnogen. nov. and the significance of wide and narrow gauge sauropod trackways. Gaia, 10:135-146.

Lockley, M.G. and Meyer, C. 2000. Dinosaur Tracks and Other Fossil Footprints of Europe. Columbia University Press, New York, USA.

Lockley, M.G., Meyer, C.A., and Santos, V.F. 1994b. Trackway evidence for a herd of juvenile sauropods from the Late Jurassic of Portugal. Gaia, 10:27-35.

Madsen, J.H., Mclntosh, J.S., and Berman, D.S. 1995. Skull and atlas-axis complex of the Upper Jurassic sauropod Camarasaurus Cope (Reptilia: Saurischia). Bulletin of Carnegie Museum of Natural History, 31:1115.

Mallison, H. and Wings, O. 2014. Photogrammetry in paleontology - a practical guide. Journal of Paleontological Techniques, 12:1-31.

Mannion, P.D. and Otero, A. 2012. A reappraisal of the Late Cretaceous Argentinean sauropod dinosaur Argyrosaurus superbus, with a description of a new titanosaur genus. Journal of Vertebrate Paleontology, 32:614-638.

Mannion, P.D., Upchurch, P., Barnes, R.N., and Mateus, O. 2013. Osteology of the Late Jurassic Portuguese sauropod dinosaur Lusotitan atalaiensis (Macronaria) and the evolutionary history of basal titanosauriforms. Zoological Journal of the Linnean Society, 168:98-206. doi:10.1111/zoj.12029

Marsh, O.C. 1877. Notice of a new and gigantic dinosaur. American Journal of Science, s3-14:87-88. doi:10.2475/ajs.s3-14.79.87.

Marsh, O.C. 1882. Classification of the Dinosauria. American Journal of Science (Series 3), 23:81-86.

Marsh, O.C. 1889. Notice of new American Dinosauria. American Journal of Science, 331-336.

Martill, D.M. 1991. Organically preserved dinosaur skin: taphonomic and biological implications. Modern Geology, 16:61-68.

Martínez, R.D., Giménez, O., Rodríguez, J., Luna, M., and Lamanna, M.C. 2004. An articulated specimen of the basal titanosaurian (Dinosauria: Sauropoda) Epachthosaurus sciuttoi from the early Late Cretaceous Bajo Barreal Formation of Chubut Province, Argentina. Journal of Vertebrate Paleontology, 24:107-120.

Marty, D., Paratte, G., Meyer, C., Billon-Bruyat, J.-P., and Ayer, J. 2006. New multiple Late Jurassic dinosaur ichnocoenoses of Switzerland: evidence for enduring dinosaur communities on the northern tethys platform. Journal of Vertebrate Paleontology, 26:96A.

Mateus, O., Mannion, P.D., and Upchurch, P. 2014. Zby atlanticus, a new turiasaurian sauropod (Dinosauria, Eusauropoda) from the Late Jurassic of Portugal. Journal of Vertebrate Paleontology, 34:618-634. doi:10.1080/02724634.2013.822875 
Mazzetta, G.V. and Blanco, R.E. 2001. Speeds of dinosaurs from the Albian-Cenomanian of Patagonia and sauropod stance and gait. Acta Palaeontologica Polonica, 46:235-246.

McGowan, C. 1999. A Practical Guide to Vertebrate Mechanics. Cambridge University Press, Cambridge, UK.

Mclntosh, J.S. 1990a. Sauropoda, p. 345-401. In Weishampel, D.B., Dodson, P., and Osmólska, H., (eds.), The Dinosauria. University of California Press, Berkeley, CA.

Mclntosh, J.S. 1990b. Species determination in sauropod dinosaurs with tentative suggestions for their classification, p. 53-69. In Carpenter, K. and Currie, P.J. (eds.), Dinosaur Systematics: Perspectives and Approaches. Cambridge University Press, New York.

Mclntosh, J.S. 2005. The genus Barosaurus Marsh (Sauropoda, Diplodocidae), p. 38-77. In Tidwell, V. and Carpenter, K. (eds.), Thunder-lizards: the Sauropodomorph Dinosaurs. Indiana University Press, Bloomington.

Mclntosh, J.S., Coombs, W.P., and Russell, D.A. 1992. A new diplodocid sauropod (Dinosauria) from Wyoming, USA. Journal of Vertebrate Paleontology, 12:158-167.

Mclntosh, J.S., Miles, C.A., Cloward, K.A., and Parker, J.R. 1996a. A new nearly complete skeleton of Camarasaurus. Bulletin of the Gunma Museum of Natural History, 1:1-87.

McIntosh, J.S., Miller, W.E., Stadtman, K.L., and Gillette, D.D. 1996b. The osteology of Camarasaurus lewisi (Jensen, 1988). Brigham Young University Geology Studies, 41:73-116.

Meyer, C.A., Lockley, M.G., Robinson, J., and Santos, V.F. 1994. A comparison of well-preserved sauropod tracks from the Late Jurassic of Portugal and the Western United States: evidence and implications. Gaia, 10:57-64.

Michelis, I. 2004. Taphonomie des Howe Quarry's (Morrison-Formation, Oberer Jura), Bighorn County, Wyoming, USA. Unpublished PhD Thesis, Institute of Palaeontology, University of Bonn, Bonn, Germany.

Milàn, J., Christiansen, P., and Mateus, O. 2005. A threedimensionally preserved sauropod manus impression from the Upper Jurassic of Portugal: implications for sauropod manus shape and locomotor mechanics. Kaupia, 14:47-52.

Miller, C.E., Basu, C., Fritsch, G., Hildebrandt, T., and Hutchinson, J.R. 2008. Ontogenetic scaling of foot musculoskeletal anatomy in elephants. Journal of The Royal Society Interface, 5:465-475. doi:10.1098/ rsif.2007.1220

Mirsky, A. 1962. Stratigraphy of non-marine Upper Jurassic and Lower Cretaceous rocks, Southern Big Horn Mountains, Wyoming. American Association of Petroleum Geologists Bulletin, 46:1653-1680.

Moberly, R. 1960. Morrison, Cloverly, and Sykes Mountain Formations, Northern Bighorn Basin, Wyoming and Montana. Geological Society of America Bulletin,
71:1137-1176. doi:10.1130/00167606(1960)71[1137:MCASMF]2.0.CO;2

Mook, C.C. 1918. The habitat of the sauropod dinosaurs. The Journal of Geology, 26:459-470.

Nair, J.P. and Salisbury, S.W. 2012. New anatomical information on Rhoetosaurus brownei Longman, 1926, a gravisaurian sauropodomorph dinosaur from the Middle Jurassic of Queensland, Australia. Journal of Vertebrate Paleontology, 32:369-394. doi:10.1080/02724634.2012.622324

Osborn, H.F. 1899. Fore and hind limbs of carnivorous and herbivorous dinosaurs from the Jurassic of Wyoming. Bulletin of the American Museum of Natural History, 12:161-172.

Osborn, H.F. 1904. Manus, sacrum, and caudals of Sauropoda. Bulletin of the American Museum of Natural History, 20:181-190.

Osborn, H.F. 1912. Integument of the iguanodont dinosaur Trachodon. Memoirs of the American Museum of Natural History, 1:33-54.

Osborn, H.F. and Granger, W. 1901. Fore and hind limbs of Sauropoda from the Bone Cabin Quarry. Bulletin of the American Museum of Natural History, 14:199208.

Osborn, H.F. and Mook, C.C. 1921. Camarasaurus, Amphicoelias, and other sauropods of Cope. Memoirs of the American Museum of Natural History, New Series, 3:249-387.

Ostrom, J.O. and Mclntosh, J.S. 1966. Marsh's Dinosaurs: The Collection from Como Bluff. Vol. 1. Yale University Press, New Haven.

Ouyang, H. and Ye, Y. 2002. The First Mamenchisaurian Skeleton with Complete Skull, Mamenchisaurus youngi. Sichuan Publishing House of Science and Technology, Chengdu, China.

Pascual Arribas, C., Hernández Medrano, N., Latorre Macarrón, P., and Sanz Pérez, E. 2008. Estudio de un rastro de huellas de saurópodo del yacimiento de las Cuestas I (Santa Cruz de Yanguas, Soria, España). Implicaciones taxonómicas. Studia Geologica Salmanticensia, 44:13-40.

Paul, G.S. 1987. The science and art of restoring the life appearance of dinosaurs and their relatives: a rigorous how-to guide, p. 2, 4-49. In Czerkas, S.A. and Olson, E.C. (eds.), Dinosaurs Past and Present. University of Washington Press, Seattle, USA.

Platt, B.F. and Hasiotis, S.T. 2006. Newly discovered sauropod dinosaur tracks with skin and foot-pad impressions from the Upper Jurassic Morrison Formation, Bighorn Basin, Wyoming, USA. PALAIOS, 21:249-261. doi:10.2110/palo.2004.p04-69

Poropat, S.F., Mannion, P.D., Upchurch, P., Hocknull, S.A., Kear, B.P., and Elliott, D.A. 2015a. Reassessment of the non-titanosaurian somphospondylan Wintonotitan wattsi (Dinosauria: Sauropoda: Titanosauriformes) from the mid-Cretaceous Winton Formation, Queensland, Australia. Papers in Palaeontology, 1:59-106. doi:10.1002/spp2.1004 
Poropat, S.F., Upchurch, P., Mannion, P.D., Hocknull, S.A., Kear, B.P., Sloan, T., Sinapius, G.H.K., and Elliott, D.A. 2015b. Revision of the sauropod dinosaur Diamantinasaurus matildae Hocknull et al. 2009 from the mid-Cretaceous of Australia: Implications for Gondwanan titanosauriform dispersal. Gondwana Research, 27:995-1033. doi:10.1016/ j.gr.2014.03.014

Raath, M.A. 1972. Fossil vertebrate studies in Rhodesia: a new dinosaur (Reptilia: Saurischia) from near the Trias-Jurassic boundary. Arnoldia (Rhodesia), 7:1-7.

Rauhut, O.W.M., Remes, K., Fechner, R., Cladera, G., and Puerta, P. 2005. Discovery of a short-necked sauropod dinosaur from the Late Jurassic period of Patagonia. Nature, 435:670-672.

Reisdorf, A.G. and Wuttke, M. 2012. Re-evaluating Moodie's opisthotonic-posture hypothesis in fossil vertebrates part I: Reptiles-the taphonomy of the bipedal dinosaurs Compsognathus longipes and Juravenator starki from the Solnhofen Archipelago (Jurassic, Germany). Palaeobiodiversity and Palaeoenvironments, 92:119-168. doi:10.1007/s12549-0110068-y

Remes, K. 2008. Evolution of the pectoral girdle and forelimb in Sauropodomorpha (Dinosauria, Saurischia). Unpublished PhD Thesis, Fakultät für Geowissenschaften, LMU München, München.

Riggs, E.S. 1901. The fore leg and pectoral girdle of Morosaurus: with a note on the genus Camarosaurus. Field Columbian Museum, Geological Series, 2:275-281.

Romer, A. 1956. Osteology of the Reptiles. University of Chicago Press, Chicago.

Royo-Torres, R., Alcalá, L., and Cobos, A. 2012. A new specimen of the Cretaceous sauropod Tastavinsaurus sanzi from El Castellar (Teruel, Spain), and a phylogenetic analysis of the Laurasiformes. Cretaceous Research, 34:61-83. doi:10.1016/j.cretres.2011.10.005

Royo-Torres, R., Upchurch, P., Mannion, P.D., Mas, R., Cobos, A., Gascó, F., Alcalá, L., and Sanz, J.L. 2014. The anatomy, phylogenetic relationships, and stratigraphic position of the Tithonian-Berriasian Spanish sauropod dinosaur Aragosaurus ischiaticus. Zoological Journal of the Linnean Society, 171:623-655. doi:10.1111/zoj.12144

Salgado, L., Coria, R.A., and Calvo, J.O. 1997. Evolution of titanosaurid sauropods: Phylogenetic analysis based on the postcranial evidence. Ameghiniana, 34:3-32.

Santos, V.F., Moratalla, J.J., and Royo-Torres, R. 2009. New sauropod trackways from the Middle Jurassic of Portugal. Acta Palaeontologica Polonica, 54:409422. doi:10.4202/app.2008.0049

Schwarz, D., Ikejiri, T., Breithaupt, B.H., Sander, P.M., and Klein, N. 2007a. A nearly complete skeleton of an early juvenile diplodocid (Dinosauria: Sauropoda) from the Lower Morrison Formation (Late Jurassic) of north central Wyoming and its implications for early ontogeny and pneumaticity in sauropods. Historical Biology, 19:225-253.

Schwarz, D., Wings, O., and Meyer, C.A. 2007b. Super sizing the giants: first cartilage preservation at a sauropod dinosaur limb joint. Journal of the Geological Society, 164:61.

Senter, P. 2010. Evidence for a sauropod-like metacarpal configuration in stegosaurian dinosaurs. Acta Palaeontologica Polonica, 55:427-432. doi:10.4202/ app.2009.1105

Senter, P. 2011. Evidence for a sauropod-like metacarpal configuration in ankylosaurian dinosaurs. Acta Palaeontologica Polonica, 56:221-224. doi:10.4202/ app.2010.0041

Sertich, J.J.W. and Loewen, M.A. 2010. A new basal sauropodomorph dinosaur from the Lower Jurassic Navajo Sandstone of southern Utah. PLoS ONE, 5:e9789. doi:10.1371/journal.pone.0009789

Shaw, H.M. and Benjamin, M. 2007. Structure-function relationships of entheses in relation to mechanical load and exercise. Scandinavian Journal of Medicine \& Science in Sports, 17:303-315. doi:10.1111/j.16000838.2007.00689.x

Sikes, S.K. 1971. The Natural History of the African Elephant. Weidenfeld \& Nicholson, London, UK.

Sternberg, C.M. 1925. Integument of Chasmosaurus belli. Canadian Field Naturalist, 39:108-110.

Thulborn, R.A. 1989. The gaits of dinosaurs, p. 39-50. In Gillette, D.D. and Lockley, M.G. (eds.), Dinosaur Tracks and Traces. Cambridge University Press, Cambridge, UK.

Thulborn, T. 1990. Dinosaur Tracks (first edition). Chapman and Hall, London; New York.

Trujillo, K.C. 2006. Clay mineralogy of the Morrison Formation (Upper Jurassic-? Lower Cretaceous), and its use in long distance correlation and paleoenvironmental analysis. New Mexico Museum of Natural History and Science Bulletin, 36:17-23.

Tschopp, E., Mateus, O., and Benson, R.B.J. 2015. A specimen-level phylogenetic analysis and taxonomic revision of Diplodocidae (Dinosauria, Sauropoda). PeerJ, 3:e857. doi:10.7717/peerj.857

Tschopp, E., Wings, O., Frauenfelder, T., and Rothschild, B.M. in press. Pathological phalanges in a camarasaurid sauropod dinosaur and implications on behaviour. Acta Palaeontologica Polonica. doi:10.4202/app.00119.2014.

Turner, C.E. and Peterson, F. 1999. Biostratigraphy of dinosaurs in the Upper Jurassic Morrison Formation of the Western Interior, USA, p. 77-114. In Gillette, D.D. (ed.), Vertebrate Paleontology in Utah. Utah Geological Survey Miscellaneous Publication. Salt Lake City.

Turner, C.E., Peterson, F., and Dunagan, S.P. (eds.) 2004. Reconstruction of the extinct ecosystem of the Upper Jurassic Morrison Formation. Sedimentary Geology, 167:111-355.

Upchurch, P. 1994. Manus claw function in sauropod dinosaurs. Gaia,10:161-171. 
Upchurch, P. 1995. The evolutionary history of sauropod dinosaurs. Philosophical Transactions of the Royal Society of London. Series B: Biological Sciences, 349:365-390.

Upchurch, P. 1998. The phylogenetic relationships of sauropod dinosaurs. Zoological Journal of the Linnean Society, 124:43-103.

Upchurch, P., Barrett, P.M., and Dodson, P. 2004a. Sauropoda, p. 259-322. In Weishampel, D.B., Dodson, P., and Osmólska, H. (eds.), The Dinosauria (second edition). University of California Press, Berkeley, CA.

Upchurch, P., Barrett, P.M., and Galton, P.M. 2007. A phylogenetic analysis of basal sauropodomorph relationships: Implications for the origin of sauropod dinosaurs. Barrett, P.M. and Batten, D.J. (eds), Special Papers in Palaeontology, 77:57-90.

Upchurch, P., Tomida, Y., and Barrett, P.M. 2004b. A new specimen of Apatosaurus ajax (Sauropoda: Diplodocidae) from the Morrison Formation (Upper Jurassic) of Wyoming, USA. National Science Museum Monographs, 26:1-118.

Waskow, K. and Sander, P.M. 2014. Growth record and histological variation in the dorsal ribs of Camarasaurus sp. (Sauropoda). Journal of Vertebrate Paleontology, 34:852-869. doi:10.1080/ 02724634.2014 .840645

Whitlock, J.A. 2011. A phylogenetic analysis of Diplodocoidea (Saurischia: Sauropoda). Zoological Journal of the Linnean Society, 161:872-915. doi:10.1111/ j.1096-3642.2010.00665.x

Wilhite, D.R. 2003. Biomechanical reconstruction of the appendicular skeleton in three North American Jurassic sauropods. Unpublished PhD Thesis, Graduate Faculty of the Louisiana State University and Agricultural and Mechanical College, Louisiana, USA.

Wilson, J.A. 2002. Sauropod dinosaur phylogeny: critique and cladistic analysis. Zoological Journal of the Linnean Society, 136:215-275.
Wilson, J.A. 2005a. Overview of sauropod phylogeny and evolution, p. 15-49. In Curry Rogers, K.A. and Wilson, J.A. (eds,), The Sauropods: Evolution and Paleobiology. University of California Press, Berkeley, California.

Wilson, J.A. 2005b. Integrating ichnofossil and body fossil records to estimate locomotor posture and spatiotemporal distribution of early sauropod dinosaurs: a stratocladistic approach. Paleobiology, 31:400-423. doi:10.1666/00948373(2005)031[0400:IIABFR]2.0.CO;2

Wilson, J.A. and Sereno, P.C. 1998. Early evolution and higher-level phylogeny of sauropod dinosaurs. Journal of Vertebrate Paleontology, 18:1-79.

Wilson, J.A. and Upchurch, P. 2009. Redescription and reassessment of the phylogenetic affinities of Euhelopus zdanskyi (Dinosauria: Sauropoda) from the Early Cretaceous of China. Journal of Systematic Palaeontology, 7:199-239. doi:10.1017/ S1477201908002691

Witzel, U. 2007. A case study of Camarasaurus as an illustrative example for a new method for virtual synthesis of skulls in vertebrates. Hallesches Jahrbuch der Geowissenschaften, 23:73-78.

Wright, J.L. 2005. Steps in understanding sauropod biology, p. 252-285. In Curry Rogers, K.A. and Wilson, J.A. (eds,), The Sauropods: Evolution and Paleobiology. University of California Press, Berkeley, California.

Yates, A.M. and Kitching, J.W. 2003. The earliest known sauropod dinosaur and the first steps towards sauropod locomotion. Proceedings of the Royal Society of London. Series B: Biological Sciences, 270:17531758.

Zhang, Y. 1988. The Middle Jurassic Dinosaur Fauna From Dashanpu, Zigong, Sichuan, Vol. 1: Sauropod Dinosaur (I): Shunosaurus. Sichuan Publishing House of Science and Technology, Chengdu, China. 


\section{APPENDIX 1.}

Digital 3D model of the articulated left manus. Produced based on CT scans. Copyright SMA, provided under the Creative Commons license CC-BY-NC-SA. Electronic file available at palaeo-electronica.org/ content/2015/1284-manus-and-pes-of-camarasaurus.

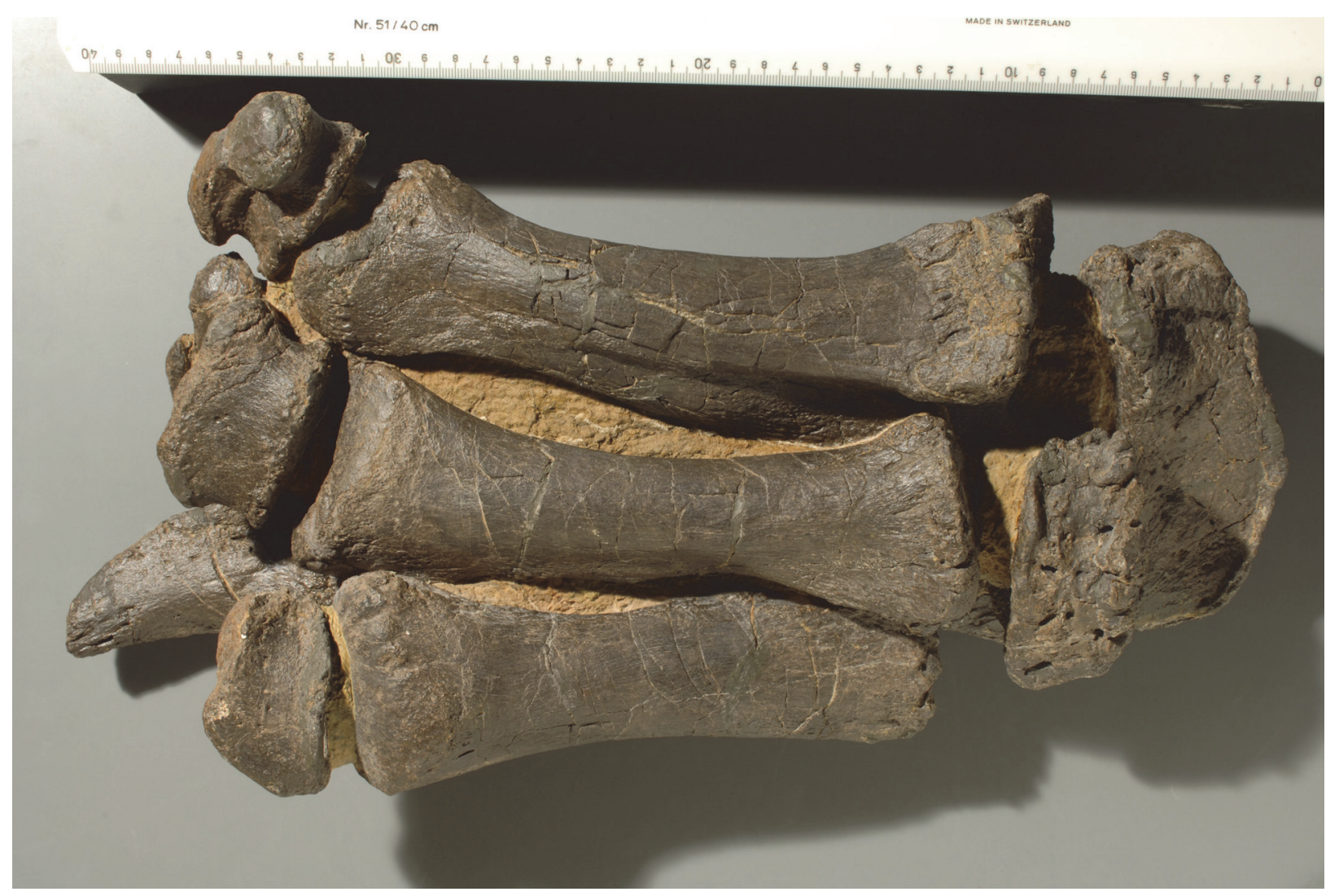




\section{APPENDIX 2.}

Textured 3D model of the mounted right manus. Produced with photogrammetry. Copyright SMA, provided under the Creative Commons license CC-BY-NC-SA. Electronic file available at palaeo-electronica.org/ content/2015/1284-manus-and-pes-of-camarasaurus.

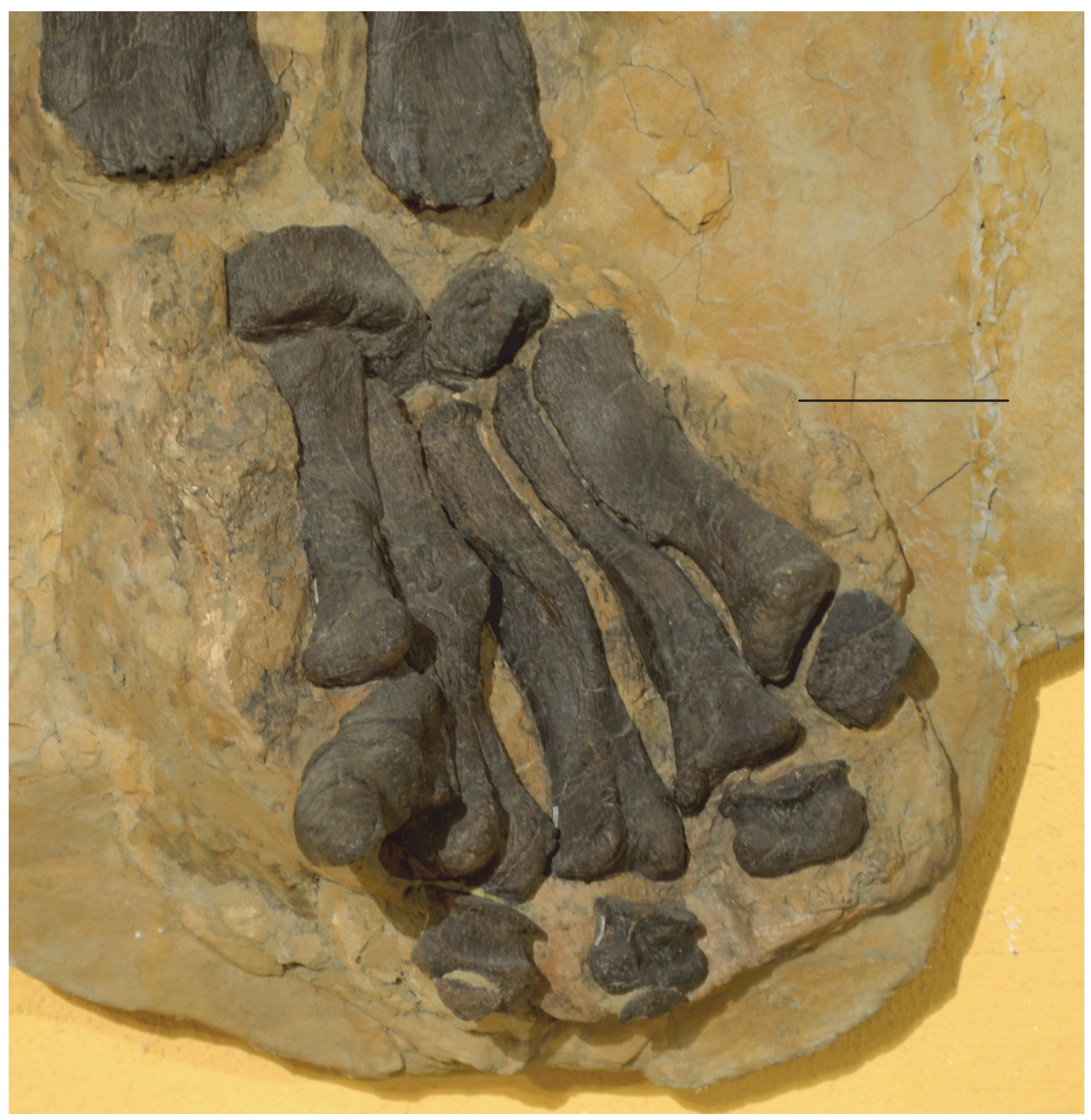




\section{APPENDIX 3.}

Textured 3D model of the mounted left pes. Produced with photogrammetry. Copyright SMA, provided under the Creative Commons license CC-BY-NC-SA. Electronic file available at palaeo-electronica.org/ content/2015/1284-manus-and-pes-of-camarasaurus.

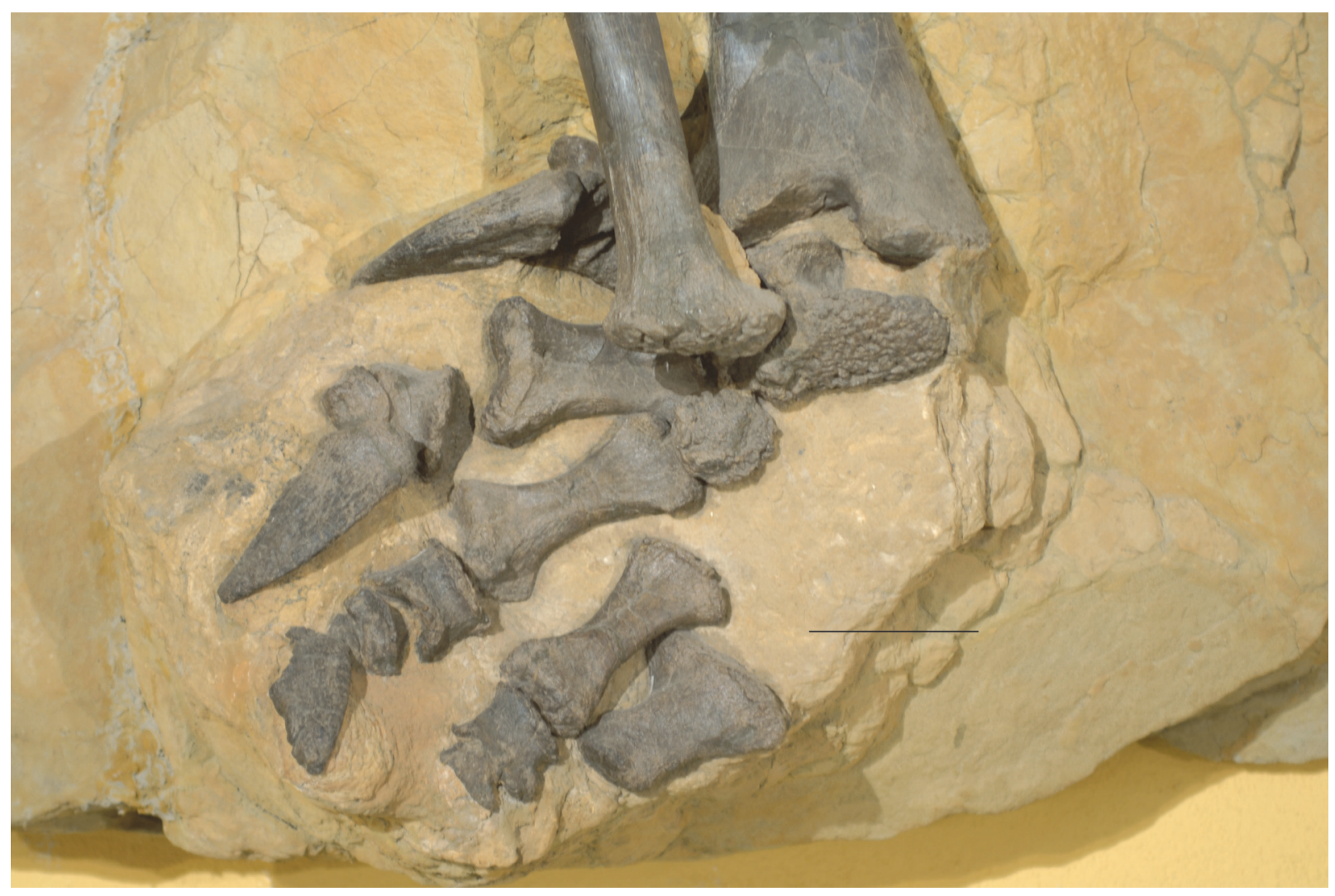

